\title{
SERVING EACH OTHER: SHARING ECONOMIES AND AFFECTIVE LABOUR IN MONTRÉAL'S KIKI SCENE
}

\author{
by \\ Jess D. Lundy
}

A thesis submitted to the Faculty of Graduate and Postdoctoral Affairs in partial fulfillment of the requirements for the degree of

Master of Arts

In

Women's and Gender Studies

Carleton University

Ottawa, Ontario

(C) 2019, Jess D. Lundy 


\begin{abstract}
Against a tense socio-political backdrop of white supremacy, intensifying pressures of neoliberal fiscal austerity, and queer necropolitics, this thesis addresses performance-based activist forms of place-making for urban-based queer, trans, and gender nonconforming communities of colour. Using participant observation and qualitative interviews with pioneering members of Montréal's Kiki scene and Ottawa's emerging Waacking community and interpreting my findings through the theoretical lens of queer of colour theory, critical whiteness studies, queer Latinx performance studies and Chicana feminism, I argue that Kiki subculture, which is maintained by pedagogical processes of 'each one, teach one', is instrumental in facilitating i) life-affirming queer kinship bonds, (ii) alternative ways to simultaneously embody and celebrate nonnormative gender expression with Black, Asian, and Latinx identity, iii) non-capitalist economies of sharing, and iv) hopeful strategies of everyday community activism and resilience to appropriative processes during economic insecurity and necropolitical turmoil.
\end{abstract}




\section{Acknowledgements}

First and foremost, I would like to acknowledge the members of Montréal's Kiki scene and Ottawa's Waacking founder for their willingness to participate in this study despite the understandable reflex to safe-guard their own. Secondly, I extend my sincerest gratitude to my thesis supervisor Dr. Dan Irving. Apart from disproving that you should never meet your heroes, Dr. Irving has provided me with unyielding guidance and fierce support throughout every step of the sometimes-dizzying research process. 'Thank-you' does not seem adequate and I am so fortunate to have you in my corner, Dr. Irving. Similarly, many thanks go to my second reader Dr. Grace Adeniyi-Ogunyankin. Your tutelage in theory and methods and (hilarious) story-telling teaching-style has expanded my thinking in ways I am forever grateful for. I would also like to thank Dr. Megan Rivers-Moore for allowing me to witness your teaching process - you are a scholar/activist who 'walks the talk' and I endeavor to emulate that. To Lana Keon and family: thank you, so very much, for taking me in and showing me familial love. I will never forget the kindness y'all have shown me and the department is lucky to have you, Lana. Furthermore, thank you to my committee members for your time and earnest efforts during the research review process.

Lastly, I would like to acknowledge the queer kin who have loved and supported me throughout the years - please know you are the reason for this research. A special shout-out to my Ottawa brother and sister Leon and Nic for your love, support, and undying encouragement. And to my (bio) sister Brit: I was beyond lucky to have you, Mark, Jordy, and Juney in my life throughout the duration of this research. 


\section{Table of Contents}

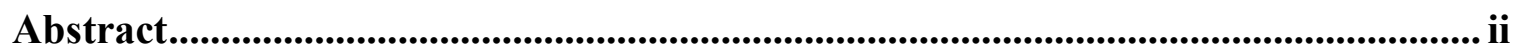

Acknowledgements ......................................................................................................ii

Table of Contents .............................................................................................................. iv

List of Table(s)

List of Appendices............................................................................................................... vii

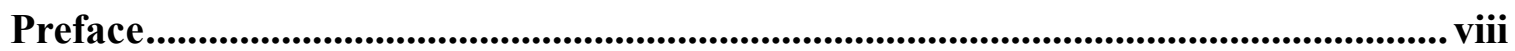

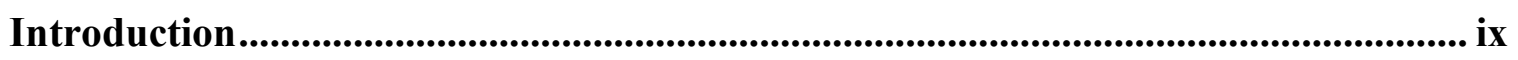

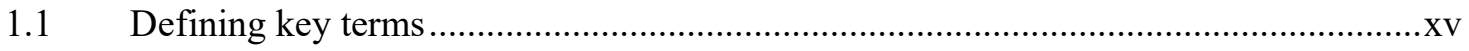

$1.2 \quad$ Chapter organization \& arguments expanded …………...................................... xviii

Chapter 1: Literature review \& Qualitative Research Design ............................................ 1

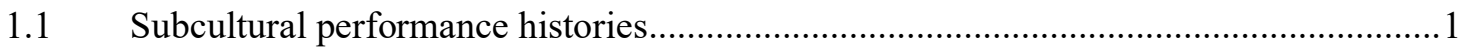

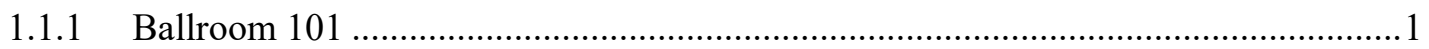

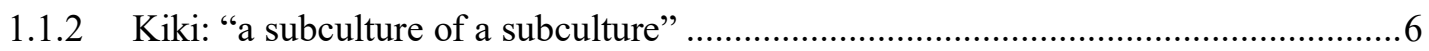

1.1.3 From Punking \& Whackin' roots to contemporary Waacking subculture .................9

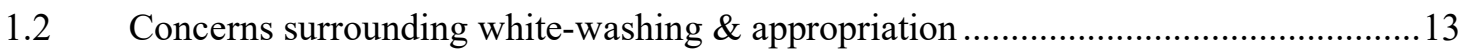

1.2.1 The cis-and-white washing of Waacking/Punking ................................................ 13

1.2.2 Ballroom \& Kiki anxieties surrounding appropriative processes ............................ 14

1.3 Research problem: White supremacy \& Exclusionary pride politics .......................... 17

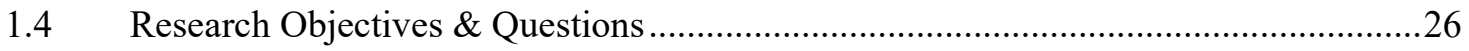

Chapter 2: Methods/methodologies, theoretical frameworks, \& key arguments ...... 29

2.1.1 Methodological approach: Participant observation ….............................................30

2.1.2 Methodological approach: Semi-structured qualitative interviews .........................32

2.2 Queer of colour methodologies with an affective engagement..................................33

2.3 Participant demographics \& affective considerations .................................................. 


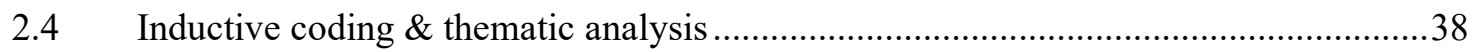

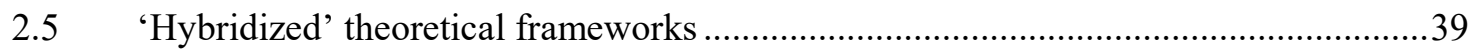

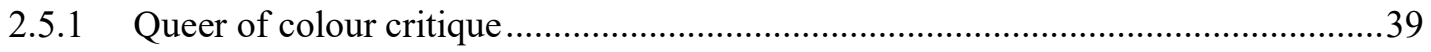

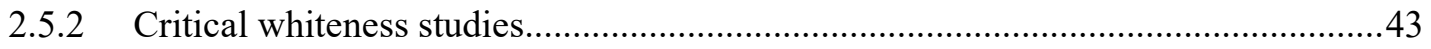

2.5.3 Whiteness as property: The project of queer of colour place-making ......................44

2.5.4 Hybridized theory: Queer Latinx performance studies \& queer worlds with an

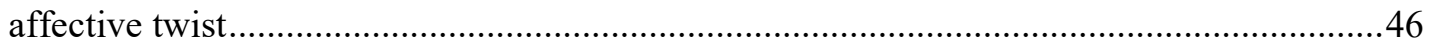

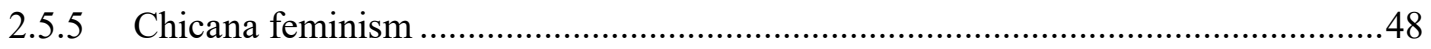

2.6 Contributions to sexuality studies \& Key arguments..............................................48

Chapter 3: Kiki kinship, Gender, \& Embodied intergenerational praxis................... 52

3.1 Queer kinship in Ballroom and Kiki subculture .........................................................52

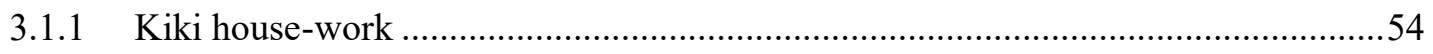

3.1.2 Kiki mothering: "More like a cool gay aunt" ........................................................

3.1.3 Intergenerational [grand]fathering across scenes ..............................................6 60

3.2 Situating Gender in Ballroom \& Kiki House culture................................................63

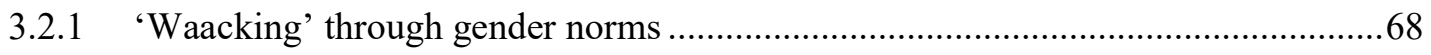

Embodied intergenerational praxis...................................................................... 70

3.3.1 Pedagogical tactics: Whacking subculture in Ottawa............................................. 72

\section{Chapter 4: Space \& Place-making, Sharing Economies \& Affective labour, \&}

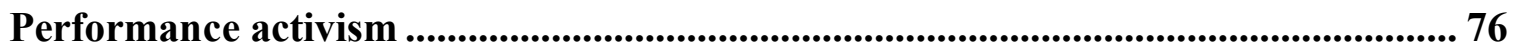

4.1 Queer of colour place-making \& world-making .................................................. 76

4.2 Creating 'queer of colour worlds' despite the odds ................................................ 79

4.2.1 'Queering' city hall through improvisational Waacking ........................................ 82

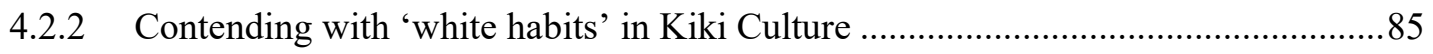

4.2.3 De-centering whiteness: "Thick Black girls to the front!" "......................................89

4.3 Serving each other: Sharing economies \& Affective labour....................................90 
4.3.1 Defining 'sharing economies' in the context of this research

4.3.2 Kikiers' - neoliberalism's party poopers! ............................................................ 93

4.4 Sharing economies in the Black Radical Tradition..............................................96

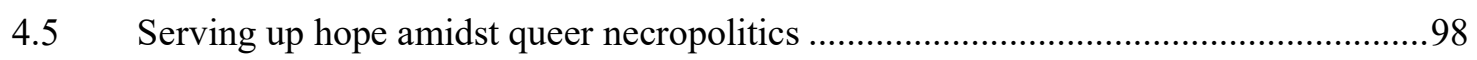

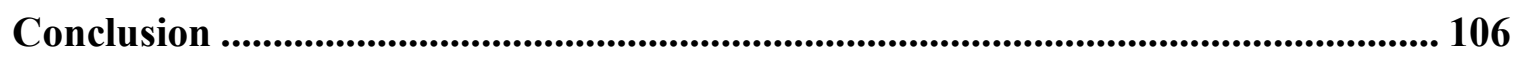

1.1 A note on affect: The maddening impossibility of ignoring 'feelings' ......................106

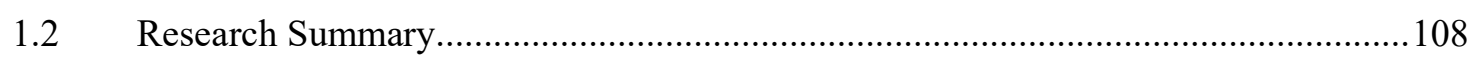

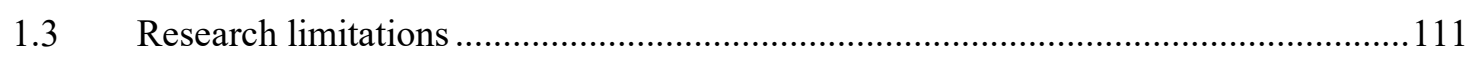

1.4 Knowledge gap regarding Waacking subculture …............................................. 112

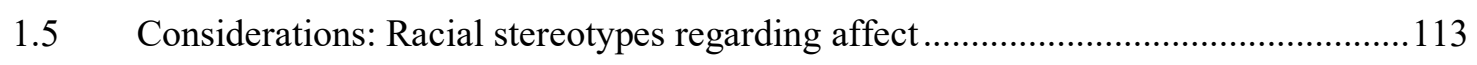

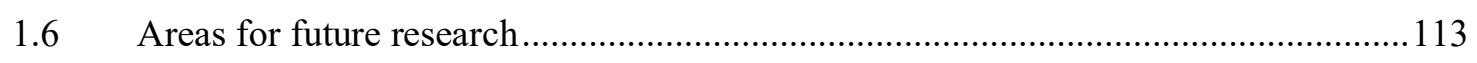

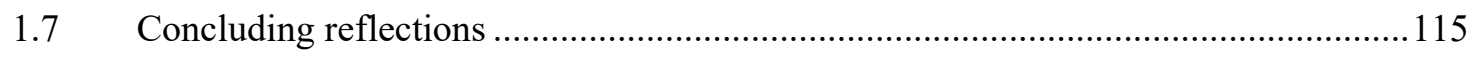

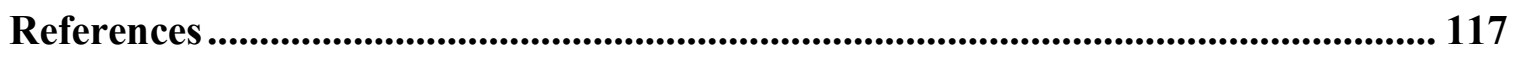

Appendix A: Informed consent form ......................................................................... 139

Appendix B: Interview guide \& Demographic form ................................................... 142

Appendix C: Recruitment Posters (original \& revised version)................................. 143 


\section{List of Table(s)}

Table A1: Participant demographics (see page 36).

\section{List of Appendices}

Appendix A: Informed consent form (see page 139).

Appendix B: Interview guide \& demographic form (see page 142).

Appendix C: Recruitment Posters (original \& revised version see page 143-44). 


\section{Preface}

With the clarity of hindsight I can confidently say that my queer chosen family has saved my life in many ways. Apart from providing me with material resources in my early 20 s like temporary places to live, hand-me-down clothes, and food to eat, more than anything my queer alternative kinship network gave me hope - hope that I could hold down a job, afford to rent an apartment, eventually go to university, and generally thrive when my biological family failed to provide adequate support. Years before I learned about Warner and Berlant's (1998) theoretical concept of 'queer worlds' in the classroom, I was living in one. A queer world created by the loving and resourceful older queer and trans people I was lucky enough to have in my life. Despite living off of humble means, some with the post-traumatic stress of surviving the HIV/AIDS epidemic in conservative Alberta, queer and trans people, often people of colour, immigrants, and Indigenous folks, did for me what their chosen parents did for them and extended a helping hand expecting only the reciprocity of family in return.1 I shudder when I think about what would have happened to me without the love of my queer chosen family. In fact, my social media platforms unfortunately produce ghosts from my past that remind me of the deadly consequences of a lack of support. Therefore, in more ways than one, this research is indebted to my own chosen family and to the people of colour in this study providing invaluable and immeasurable affective and material support to their loved chosen children.

1 What I mean by this is that my relationship to my elders was not parasitic in that I offered the humble reciprocity of what little I did have - from volunteering at fundraisers, subtly encouraging new visitors to the gay bar to tip my performing drag mommas, helping format and edit resumes, to even just giving out cigarettes when I had them. I make this distinction due to the forced physical and emotional labour put onto people of colour by white people. 


\section{Introduction}

I climb the stone steps of the old church in my rain-soaked second-hand high tops. After navigating an unfamiliar city on-foot from Montréal's greyhound terminal I was eager to get out of the rain, but simultaneously weary about occupying space meant for the safety and celebration of queer and trans people of colour. Albeit not my first exposure to grassroots HIV/AIDS activism, this was my first HIV/AIDS prevention Kiki ball and participant observation session. Aptly titled 'Let's talk about sex', I was granted permission to attend the ball by the pioneer of Montréal's Kiki scene - self-described gay Latinx2 gender-queer, Gerard X Reyes (aka Bronzé 007). I try to make myself as unobtrusive as possible as I toss my last five dollars into the entry fee bowl. A queer gender non-binary white person in banal street clothes, I occupy the somewhat awkward liminal space of the outsider-quasi-insider researcher conducting observational field work (but trying desperately to make it look like I was not).

As the crowd grows, the emcee kicks things off by acknowledging the local and visiting 'legends, statements, and stars' (LSS) of the Kiki and Ballroom scene. The most prestigious member of the LSS in attendance was New York's legendary grandfather Archie Ninja. As the emcee calls out "Ar-chie, Ar-chie" to the beat, Ninja jumps on top of the judges table and begins voguing as the crowd closes in to get a rare glimpse of legendary vogue in the 'old way' style.3 The line between judge, competitor, and

2 Following Johnston-Guerrero (2016) and Monzo (2016), I use the term Latinx rather than the gendered term 'Latino/a' to be gender inclusive of all peoples of Latin American descent. The only exception to this is if a person mentioned in this thesis identities as 'Latino' or 'Latina'.

3 Vogue in the 'old way' (as opposed to 'new way') has roots in early ballroom competitions of the 196080s (Bailey, 2013; Susman, 2000) and will be examined for its unique impact on queer and trans people of colour in the Ballroom background section. 
audience member has been blurred and the excitement of those around me is contagious. After the well-received improvisational performance, Bronzé 007 proudly hands the mic over to his chosen father, Ninja, who instructs the DJ to "cut the beat" and addresses the now hushed room. I listen carefully to the legendary grandfather's advice:

In my lifetime it's nice to see what has happened with just a little bit of community. That 'each one teach one'...you understand? When you have functions together - in the social - it makes sure that everybody is connected. Whether it is race, creed, colour... are you with that? Now, you may hear people who say that Ballroom is not for you. Here's the thing... Everyone has a struggle. It doesn't matter where the struggle is and you cannot compare one struggle to another because it is real. You get that? So. When people come at you for the statement that this is not for you...? Well, you never know what's in another mother fucker's shoes... you understand that? We are celebrating living your life being comfortable in your own skin no matter where you walk [gestures to runway], no matter where you are ("Let's talk...", 2019).

At the time it was clear Ninja's words were impactful for the cheering crowd, whose visible demographics varied significantly, but his impromptu commentary also made a lasting impact on me and became significant for the larger context of my research.

In opposition to Ninja's New York scene and the Ballroom scene in Toronto, the Montréal crowd that evening was nearly half white appearing/passing. Even if not explicitly stated, Ninja was addressing the large (white) elephant in the room: the question or quandary regarding white involvement in a performance tradition created byand-for queer and trans people of colour.4 Reminiscent of intersectional Black feminists such as Patricia Hill Collins $(1990,1997)$ who argue against oppression hierarchies or “oppression olympics" (Hancock, 2011), Ninja's message was unifying in that it covertly acknowledged different forms of oppression and the importance of carrying on

4 As explored in my literature review, ballroom members have been exploited for their performance form and this has led to the commercialisation and appropriation of ballroom traditions. 
pedagogical traditions outside of dominant, oppressive forms of white culture. This antioppressive pedagogical approach harkens to 1970s transgender activism militantly led by trans-foremothers of colour such as Sylvia Rivera and Miss Major Griffin-Gracy, who unapologetically urge trans women of colour to shout "we're still fucking here!" ("Major!," 2016). Queer and trans people of colour in the Kiki scene take up this brave 'Majorian' proclamation to living unapologetically in a city that makes life precarious for them. This coming together "in the social" (as Ninja puts it), further proves the resilience of Kiki House members as they continually fight to claim physical space in the city and create queer alternative worlds despite living under the conditions of white supremacy. In addition to having a noticeable impact on the Kiki ball spectators that evening, Ninja's advice spoke to me on a personal level. As an able-bodied white person I often feel an odd sense of guilt and shame for seeking out various social services. For instance, in the space of a foodbank my presence gestures towards a failure of my own white privilege. Friendly white Christian volunteers at the Calgary food bank do a double take when they see me; they speak to me in a respectful and dignified way. I am assumed to be acquiring services due to an extreme situation. Meanwhile, the woman of colour standing in line next to me with a crying baby in her arms and kids playing at her feet is getting jeered at from those same nice white Christian volunteers. I could feel their judgement of her. On a different occasion, another well-meaning white volunteer gave me a big smile and winked as she stepped closer to me and whispered "you don't belong here, sweetie! I don't want to see you here again!' I doubt 'racialized' service recipients 
are offered this reassuring restoration of dignity as they leave any social service provider.5

Ninja's commentary stays in my mind as I walk back to the greyhound station to catch the midnight bus back to Ottawa after my first Kiki ball. While I consider Ninja's unifying message, I remember an important warning from self-described Black, queer, femme artist, educator, and voguer, Benji Hart (aka Radical Faggot) (2015), who insists that "voguing belongs to queer people of color-specifically trans, poor, working, sexworking, homeless and young queer people of color. We created it, we need to be the ones dancing it, and we need to be the ones protecting it" (para. 11). Voguers like Hart highlight the dangers of white consumption of Ballroom culture. Indeed, vogue, a category and major tenant of ball(room) culture, is not for me. In fact, the subcultural practice of this life-asserting performance form, which dates back to the Harlem Renaissance (Dickson-Gomez et. al, 2014), is not for any white people - gender nonconformity and queerness aside.

These voices from Ballroom community experts on North America's east coast raise significant questions regarding critical race, whiteness, and sexuality studies scholarship and contemporary activism. These questions have particular resonance for me as a gender non-binary identified queer graduate student still parsing out how to conduct anti-oppressive, socially responsible research. If I am truly in accord with Hart's staunch commitment to keeping ball culture within communities of colour, how can I - a white

5 See Robyn Maynard's (2013) "Misogynoir in Canada" (subsection on 'Welfare fraud, misogynoir, and the criminalization of poverty' p.131) in Policing Black Lives for a fuller understanding of the ways working-class racialized women are doubly oppressed and criminalized through the process of seeking (poorly funded) social services. 
researcher external to Kiki ball culture- ethically conduct this research at all? Wanting to avoid feeding what artist and activist Juliana Huxtable calls the "consumption of [racialized, trans] marginality" for personal gains (2018), not to mention the replication of tenuous white-washed and reified portrayals of Ballroom culture à la Madonna and Jennie Livingston, a large component of the research that follows involves interrogating whiteness within these scenes and grappling with this very question.6

I have been buoyed by the support of my queer chosen family when biological parental support deteriorated in my youth and young adulthood. As a result, as a researcher I strive to understand the nuances and revolutionary potential of queer and trans kinship networks. On a personal level I have witnessed the reproduction of hegemonic, cis-patriarchal, homonormative, colonial logics in what I will refer to as 'commercial drag', such as in the case of the 2009 - present reality television show RuPaul's Drag Race. Well before this, however, performance theorist and queer of colour scholar José Estaban Muñoz (1999) notes that "corporate-sponsored drag has to some degree becomes incorporated within the dominant culture.” (p. 99).

Moreover, my alienation from the competitive contemporary dance world has been a flashpoint in my youth that ultimately became another starting point for this project. When puberty exacerbated what I will reluctantly call my gender dysphoria, I

6 Since the documentary film's release in 1990, Jennie Livingstone's Paris is Burning has garnered much critical attention. For example, scholars such as Haritaworn (2008) and Reddy (1997) critique the way the film represents ballroom house familial structures for people of colour. While some scholars have critiqued the film as an ethnographic document (Butler, 1993), Prosser (1998) and hooks (1992) argue that the film's director's whiteness and outsider status preclude the film for being critiqued as an authentic ethnographic piece. That being said, some members of the ballroom community, including 2 of 5 of my participants, view the film as an accessible piece of documented history and teaching tool (one can watch the full documentary on YouTube) about their tradition and fondly associate the film with 'old way' vogue in particular. 
quit ballet and contemporary dance altogether. Around that time I rented (and re-rented) VHS dance tapes like Beat Street (1984), Breakin', Breakin' 2: Electric Boogaloo (1984), and Fast Forward (1985) to satiate my thirst for dance, albeit in a completely new form.7 Although at the time I was admittedly naïve to the social and political significance of these dance forms for people of colour, I marveled at how the dancers could remain fierce competitors while also forming a collective - a family. Having opted out of competitive dance I remain a devotee to performance in varying forms. Even though I no longer practice, I understand the edifying power of dance for those living in the margins. My white privilege is just one of the reasons that I do not compare my life events or intersecting identities to those of Ballroom, Kiki, or Punking/Waacking members. Rather, I preface this research with my lived experiences as they relate to performance and queer families of colour in order to create a rhetorical space to inquire about the transformative potential of Kiki and Punking/Waacking subcultures as they exist in increasingly precarious times.

7 Unbeknownst to me at the time, Viktor Manoel danced in Breakin' 2: Electric Boogaloo (a movie I must have rented a dozen times); Viktor informs a large part of the background research on Waacking/Punking subculture. 


\subsection{Defining key terms}

Prior to articulating my research questions, I will briefly define the terms 'Ballroom, Kiki, and Waacking/Punking' to frame the arguments that follow. Established around 1967 in response to white supremacy within New York's drag ball pageant circuit (Jones \& Ellis, 2017), Ballroom (or ball) culture consists of two main features: "anchoring family like structures called houses, and the flamboyant competitive balls [or runway competitions] that they produce" (Arnold and Bailey, 2009, p. 174). Conceived of around 2002-2003, the Kiki scene is a less-competitive subset of the Ballroom scene created by and for trans youth of colour, sometimes with the help of community-based organizations serving LGBTQ2S populations (Jones \& Ellis, 2017).8 An onomatopoeia for having a laugh between friends, Kiki can be likened to a less competitive, more racially and gender diverse performance form with more flexible rules than the mainstream Ballroom scene (Raeanne, 2011; Eff, 2017). To the majority Black and Latinx youth and young adults within the scene, this subculture offers "access to HIV/AIDS prevention and treatment information and services, personal and professional development assistance and a sense of peer-led community support” (Jones \& Ellis, p. 42).

Turning to the west coast of the United States, the improvisation-based dance form Waacking/Punking was created by gay Black, Latinx, and Asian cis-gender male dancers' parody of movie stars and cultural icons during the Soul Train and Disco era.

8 Predominantly white queer spaces and LGBTQ2S service organizations "may not have the same investment in, capacity for, and approach to the culturally responsive pedagogical work found" within service organizations specifically designed for LGBTQ2S people of colour; Ballroom and Kiki communities involving youth often fill in these service provider gaps (Brockenbrough, 2016, p. 188) 
Characterized by "fast, rhythmic arm whipping [that] ... incorporates elements of large locomotion, dramatic gesture and facial expression, and narrative," Waacking/Punking developed in underground gay clubs and slowly entered mainstream culture through television and music videos (Bragin, 2014, p. 63-64).9 Similar to the Ballroom scene, Waacking/Punking was a subculture where "dancers staged their rejection of whiteness and Black heteronormativity through affective-kinesthetic practice" (Bragin, p. 70). This performance tradition was lesser known than Ballroom culture but experienced a resurgence in the 2000s as majority heterosexual break dancers (often called b-boys/bgirls) turned to the style for inspiration.

With these working definitions in mind, I will briefly describe the timely significance of this project. Physically gathering together 'in the social' has become rarer with the thrust of neoliberal individualism and the ubiquity of hand-held technology that allows for immediate 'social connection' and communication across multiple platforms. My research is significant as it acknowledges the radical potential of 'coming together in the social' in a white supremacist, queer exceptionalist, neoliberal-hyper-capitalist, digital age - especially for working class queer and trans people of colour. With the rise of commercial drag such as RuPaul's Drag Race, which references Ballroom lexicon and vogue performance while simultaneously privileging able-bodiedness, whiteness, and what Cedric J. Robinson (1983) calls 'racial capitalism' without much consideration for Ballroom history, this research is timely as I agree with Nishant Upadhyay (2019) that forms of drag in North America are "not beyond the logics of hegemony and

9 'Whack', like Kiki, is an onomatopoeia that was inspired by comics books such as Batman. 'Punking' is derived from the derogatory slang for a gay person or 'punk' (Bragin, 2014.) 
normativity" (p. 480). Indeed, Upadhyay (2019) makes clear that "queerness does not inherently transcend gender, sexual, and racial hierarchies. Thus, drag as a genderfucking creative praxis can be co-opted within multiple colonial processes" (p. 481). This process of co-opting has damaging effects on the rich traditions of Ballroom and Kiki culture and there is a necessity to make an "epistemological shift from romanticizing marginalized politics and praxis to understanding them within a spectrum of resisting and reproducing normative and dominant power structures" (Upadhyay, 2019). Part of this understanding involves keenly listening to elders in these scenes who have invaluable knowledge that is in threat of disappearance if these histories are not attended to and cherished.

Furthermore, my project is vital as it reveals hopeful activist strategies à la social improvisational performance subcultures that creatively employ the traditions of Black Radical Activism.

This research is guided by the questions: how do Kiki and Waacking/Punking subcultures resist and transform hegemonic productions of racialized gender and sexuality, and what radical activist tactics are being deployed in these nuanced scenes? I argue that Kiki and Waacking/Punking subcultures in Montréal are instrumental in facilitating queer kinship bonds, alternative ways to simultaneously embody and celebrate non-normative gender expression, non-capitalist economies of sharing (both material and affective), and hopeful strategies of resilience and resistant during economic insecurity and necropolitical turmoil. This research adds to broader debates in sexuality studies surrounding creatives modes of queer of colour empowerment, place-making, and the hopeful effects generated by having queer alternative kinship networks for those marginalized by ethnicity, race, class, gender, and sexuality. 


\subsection{Chapter organization \& arguments expanded}

To present my analysis of Kiki culture, and to a lesser extent, Waacking subculture, I have structed my thesis into four chapters with an introduction and conclusion. Chapter one describes the research background of Ballroom, Kiki, and Waacking/Punking histories using scholarly literature and secondary sources authored by key members of each performance scene. With these detailed histories in mind, I then reinforce the timely necessity of this research using an example of white supremacy within Kiki subculture wherein a white ball walker publicly spat a mouthful of water at a table of judges (which hit a trans woman of colour in the face). The first chapter continues with a thorough examination of my qualitative research design.

My second chapter articulates my recruitment and data collection methods, queer of colour methodologies, and triangulated (and 'hybridized') theoretical frameworks. This chapter concludes by relaying how this research contributes to sexuality studies and reveals all of my essential arguments.

The third chapter starts by expounding upon the unique gender and familial systems within Kiki and Waacking House culture in Montréal and Ottawa, which provides its members with alternative ways to simultaneously embody Blackness, Latinx, and Asian identity in harmony with ones' preferred gender expression. Secondly, this chapter will explain how these performance subcultures have changed throughout the decades through the radical pedagogical intervention of 'each one-teach' (which I refer to as 'embodied intergenerational praxis').

Chapter four will begin by delving into the significance of queer of colour placemaking (and queer world-making) in urban spaces - which are becoming increasingly 
gentrified and hostile for working-class queer and trans people of colour. Next, chapter four describes the material and immaterial economies of sharing between members of these underground subcultures. This last chapter continues by exploring strategies of everyday community activism and the shared culture of hope within these subcultures in the midst of necropolitical forces that would have their members 'disappeared' in the nation state of Canada. I will conclude the fourth chapter by demonstrating how House culture could be instrumental in upending queer exceptionalism and homonationalism that supports the normative, culturally contingent 'super structures' that make it hard for queer and trans people of colour to simply eke out an existence.

In many ways, this thesis will conclude where it began: by asking questions about the hopeful potential and future of Ballroom, Kiki, and Waacking/Punking subcultures in a Canadian context. After summarizing my key arguments, I will explain the limitations and knowledge gaps of this project and suggest anti-oppressive methodologies that may be useful if deployed in future research of this kind. I will conclude by offering affective considerations and areas for future research. 


\section{Chapter 1: Literature review \& Qualitative Research Design}

\subsection{Subcultural performance histories}

\subsubsection{Ballroom 101}

Ninja's spontaneous performance of Old Way Vogue at the Montréal Kiki ball described in the introduction incites a popular dance whilst gesturing to a lesser-known history. Comprised primarily of Black and Latinx queer and trans working-class people, the Ballroom community in the North Eastern United states has complex systems of 'Houses' or informal familial structures that participate in competitive balls (originally called pageants) in drag and various costumed categories. 'Old way' vogue is just one component of an underground performance subculture that was founded out of necessity in 1920s Harlem, Rockland Palace (Chauncey, 1994; La Fountain-Stokes, 2009).

A history of Ballroom culture requires an exploration of the urban landscape, which is mediated by class and racial divisions. According to George Chauncey (1994), during the 1920s New York was said to be a "peculiar social territory in which the normal social constraints on behaviour seemed to have been suspended. . . and where men and women built unconventional lives outside the family nexus"10 (p. 244). While Greenwich Village was a haven for middle-class white gays and lesbians 11 during the early 1910-30s, Black gays, lesbians, cross-dressers, and female impersonators were not afforded access to the vibrant neighborhood. During prohibition-era World War I, Greenwich Village was a hotbed for underground drag pageant balls, which were whiteorganized and often held in tea rooms and low-end restaurants that were 'whites only'.

10 See George Chauncey (1994) for the history of predominantly white-attended drag balls as they emerged (both legally and illegally) in New York from 1800s-1900s

11 Often referred to as 'bohemians', 'artists', or 'fairies' rather than gay or lesbian. 
The city of Harlem was the only place for gay people of colour in the area to gather in commercial establishments (Chauncey, 1994). Harlem's real estate crash around 1904 made the area affordable for people of colour and the city became known for its major Black churches and organizations during the Harlem Renaissance. The first recorded majority Black drag ball occurred in 1869 at Harlem's Hamilton Lodge Ball, and by the 1930s places like Savoy Ballroom and Small's Paradise were meccas for people of colour to gender transgress, drink, and let loose (Chauncey, 1994; Wilson, 2010). As this research suggests, people of colour have continually fought to obtain space in urban environments to simply exist. Finding space to occupy a 'racialized' body and simultaneously express gender-non-normativity (and homosexuality) was and remains to be decidedly onerous.

As the majority white underground balls and pageants continued, a shift occurred during the 1960s and queens of colour rose up to demand more space in the ball scene (Monforte, 2010). Into the late 1960s, a pivotal subcultural moment captured in the documentary film The Queen (1968) spawned this shift to House Ballroom culture for queens of colour in the drag pageant circuit12. During the award ceremony of the 'Miss All American Camp Beauty Pageant', third runner up Crystal LaBeija walked off stage in protest of the white drag queens perpetually winning over their competitors of colour (Lewis, Litvinoff, \& Maxtone-Graham, 1968). States LaBeija on white drag queen Jean Harlow's win: "I have a right to show my colour, darling. I am beautiful!" (Lewis, Litvinoff, \& Maxtone-Graham, n.p). It is the emphasis on 'showing colour' that united 
the legendary House of LaBeija - the first of its kind alongside The Brooklyn Ladies (now known as The House of Dupree) and The House of La Wong (Jones \& Ellis, 2017).

Into the 1970s and 1980s, Old Way Vogue was particularly popular among competitive Ballroom members. According to Marlon Bailey (2013), both Old Way and New Way Vogue are performed primarily by butch queens (or cis-gender men typically identified as gay or bisexual) "who aim to represent the shifting interplay between masculinity and femininity" (p. 175). The foundation of Old Way is "beat-knowledge," which requires an adherence to the music's rhythm, or repetitive 'counts' in the song, and hitting each beat with an intentional freeze-framed pose (Bailey, 2013, p. 174). This style requires dancers to have "clean and precise lines," which means they pay close attention to where each limb is placed in every movement (p. 174). Often associated with the film Paris is Burning, Old Way Vogue was developed by New York city icons such as Paris Dupree, Willie Ninja, and Kevin Ultra Omni. Influenced by House and Disco music, "Old Way incorporates many of the dance and movement forms of the African Diaspora. .. such as break dancing, martial arts, and capoeira" (p. 173). This complex form of movement breaks down further into two separate categories - "smooth fluid style and a pop and rock" (p. 174).13 Using stylized poses, Ballroom elder Father Aaron Enigma contends that old way vogue "captures the power of performance in Ballroom culture and the ways in which this artistic labour affirms the values and practices created by and within the community" (p. 179).

Both Old and New Way Vogue harken to African diasporic traditions, which come from “African-diasporic community-defining practices" (Browning, 1998).

13 Pop and rock style is exemplified by the vogue icon Willie Ninja (Bailey, 2013, p.174). 
Typically performed to live music accompanied by a commentator who provides the dancers with direction, vogue involves five elements: duckwalks, catwalks, spins, dips, and hand performances. Bailey (2013) maintains there are "three primary aesthetic criteria" by which the dancers are judged: 1) they must include all five elements of vogue, 2) each element must be performed on-beat to the music and the commentator's chant, and 3) performers must demonstrate uniqueness or "add a special touch that reflects the performers personality" (Bailey, p. 175-176).

Houses are alternative familial structures that encourage patience when grappling with life's circumstances, safer sex and HIV/AIDS prevention strategies, and fostering fierce creative competition (Arnold \& Bailey, 2009). Bailey (2013) attests that "three inextricable dimensions constitute the social world of Ballroom culture: the gender system, the kinship structure (houses), and the ball events (where ritualized performances are enacted)" (p. 4). 'Children' or less-experienced ball participants are led by more experienced house mothers or fathers, who "recruit, socialize, and prepare their proteges to compete successfully in categories based on the deployment of performative gender and sexual identities" (Bailey, p. 5).14 Often named after Haute Couture brand names or mottos, although Houses can be physical spaces where chosen family members meet, houses more commonly represent family units comprised of complex "gender systems and kin labour [that] create a close-knit community" (p. 5). Rather than independently partake in white pageants where the chances of taking home a trophy were slim, gay Black and Latinx cisgender men and transgender women continued to gather together and

14 Although house children tend to be younger than their house parents, chronological age is nearly irrelevant in House familial systems (Bailey, 2013). 
hold their own balls in Black-majority cities in North-Eastern United States (Bailey, 2013; Riggs, 1989).

The shift from white-organized, white-dominated drag pageants towards House culture was significant to queer and trans communities of colour in a myriad of ways. In opposition to middle-class white queers, racialized Ballroom members have a longstanding history of facing racism-fueled violence, homophobia, transphobia, un(der) employment, and "general sociocultural dispossession" (Bailey, 2013, p. 7). House culture "becomes a necessary refuge and a space in which to share and acquire skills that help Black and Latinx LGBT individuals survive the urban world" (Bailey, p.7). In cases where so-called traditional, nuclear familial support is lacking and/or inadequate for those in the Ballroom scene, house culture is an alternative model for building a supportive chosen family. According to Bailey (2009), the ball scene is "a minoritarian social sphere where performance, queer genders and sexualities, and kinship coalesce to create an alternative world" (p. 254).

These alternative queer worlds not only facilitate queer kinship for ball members of colour, but they offer an investment in the sexual health and general well-being of its members. When learning about Ballroom's history of HIV/AIDS activism, Bailey (2009) identifies "gaps in public health intervention" for people navigating HIV positive diagnoses (Bailey, p. 173). Additionally, based on his professional experiences working in public health organizations, Bailey noted that HIV/AIDS related social services were often hostile work environments for femme-identifying queers and Black heterosexual women, partly because of "the absence of transgender women and men" as volunteers or service providers (Bailey, p. 197). Moreover, Bailey contends that for queer and trans 
people of colour, "nonnormative genders or sexualities, socioeconomic marginalization, and disease equate to social exclusion from national, cultural, and communal forms of belonging" (Bailey, 2013, p. 185).

In a Canadian context, Marty Fink (2015) points out that "telling queer and trans youth to use condoms and practice safer sex remains a hollow message if such materials fail to represent and affirm the identities of those dually excluded from queer and national movements," i.e. those impacted by poverty, racism, colonization, and cissexism. (p. 152). For racialized Ballroom members living at the intersections of these identities, HIV/AIDS education and prevention efforts are made more effective when they "include the production of culture (e.g., photography, poetry, fiction, public art)," (p. 153) and as this thesis suggests - through Ball and Kiki House culture. Ballroom members, according to Bailey, "use ritualized performance as a form of cultural labor to create an alternative, more egalitarian, social existence" (p.184). House culture and the labour it requires, therefore, acts as a mediating intervention into socio-cultural exclusion, as well as the state-sanctioned neglect of queer and trans people of colour's health, wellness, and overall "life chances" (Spade, 2011). This is significant given the on-going history of anti-Black racism and homophobia in North America that makes the already queered Black queer subject what OmiSoore Dryden (2015) deems 'a queer too far': subjects whose "bodies are already out of place... and thus outer-national" (p. 118).15

\subsubsection{Kiki: "a subculture of a subculture"}

${ }_{15}$ OmiSoore Dryden examines 'blood narratives', or the racial, gendered, and sexual discursive tools found within the Canadian Blood Services' donor questionnaires. Dryden's essential argument is that 'gay Black blood' is marked as a contaminant and social threat to whiteness, health, and 'nation'. See "A Queer Too Far": Blackness, Gay Blood and Transgressive Possibilities" in Disrupting Queer Inclusion: Canadian Homonationalisms and the Politics of Belonging. 
Reflective of all things queer, Ballroom House culture resists containment. As described by Bailey (2013), the ball scene is "inclusive, egalitarian, and fluid in some ways but exclusionary and hierarchical in other" (p. 27). The "Women, Butches, and Transgender" (WBT) scene was created to address some of the hierarchical exclusions of cis-gender lesbians, gender non-binary people, and trans men in the main ball scene. During this emergence of WBT walking categories and House collectives, masculinepresenting lesbian women were said to stigmatize high-femme cis-women and femme queens (trans women) within the scene. Founder of the first WBT House (The House Of Iman) was woman-identified lesbian Aisha Prodigy Iman, who noted that despite best intentions, this micro-scene "replicates the forms of oppression that exists in the main scene" (Bailey, p.225). Along with various WBT queer and trans people of colour, Iman created the micro-scene of 'Kiki' house culture around 2000-2003 (Bailey, 2013; Eff, 2017). Although the informal familial structures associated with Kiki house culture are open to all races, ethnicities, genders and sexualities, racial minorities and trans individuals have comprised the majority of the American Kiki scene since the early 2000s (Keo-Meier \& Hicks, 2014). Like Ballroom houses, Kiki houses are commonly named after haute couture designers such as Ford, Bvlgari, Chanel, etc. (p. 91). This micro-scene "unabashedly transgress[es] the official protocol established in the main scene" (Bailey, 2013, p. 225). In an interview with Bailey (2013), Iman states "I conceived of the Kiki scene as a youth and young adult alternative - junior varsity - to the main scene, which many young people viewed as too competitive and intense" (p. 225). According to Bailey, many of his interlocuters contend that the scene "was conceived as a fun and less serious and competitive site for the younger LGBT people 
who aspire to compete in the main scene" (p. 27). As my participants will prove, although Kiki is often discussed as a gateway to the more competitive Ballroom scene, one participant described the scene in Montréal as more of an "innovative meritocracy" where members develop according to their skills and bend the rules about gendered Ballroom walking categories. States mother TKO from the House of Monroe, "the Kiki scene is a subculture of a subculture. . . [it] is a more low-stakes environment where newcomers to the scene can get their feet wet and socialize across house lines" (Walker, 2016, para. 2).

The micro-scene of Kiki fosters creative, Do-it-Yourself (DIY) focused interventions into institutionalized racism and the poverty it often forces upon racialized minoritarian subjects. According to an interview with Kiki pioneer and mother of the Opulent Haus of PUCCI Twiggy Pucci Garçon, writer Kieran Yates (2016) explains: "whereas mainstream voguing embraces competition and high-fashion, Kiki also focuses on DIY attitude and social activism" (para. 21). This activism-infused performance subculture was captured on film over the span of four years by Garçon and Swedish filmmaker Sara Jordenö in Kiki (2016).16 As indicated in the documentary, the scene "offer performers a safe and empowered space to enact various modes of gender expression, including a stylized femininity that, if executed in the communities in which they grew up in, could provoke ridicule and violence" ("Kiki the movie", n.d., para. 3). According to the documentary's website, the subculture "has evolved into an important (and ever-growing) organization with governing rules, leaders and teams, now numbering hundreds of members in New York and across the U.S and Canada" (para. 3). Pioneered

16 "Made with extensive support and trust from the [Kiki] community in NY," Kiki captures the lives of seven gender diverse American Kiki participants of colour in New York city over the span of four years ("Kiki the movie," n.d., para. 4). 
primarily by trans youth and young adults of colour, the New York scene "draws strategies from the Civil Rights, Gay Rights and Black Power movements" (para. 4). This powerful performance scene gestures towards the same type of Ballroom 'artistic labour' previously mentioned by Bailey (2013).

Like their Ballroom predecessors in the 1920s, 1960s, 1980s, and early-mid 2000s, subsequent generations of Kiki members have continued to invest efforts into informal activism surrounding safer sex and HIV/AIDS prevention strategies. Social networking was and remains a common method used to plan and organize Kiki balls and invite new members into the scene (Bailey, p. 225). That being said, in urban areas where "the culture's social networks and gatherings tend to be concentrated," Black and Latinx youth continue to laboriously organize in-person around HIV/AIDS prevention and educational strategies through the informal methodology of House culture (Brockenbrough, 2016, p. 183). According to Bailey (2013),

the Kiki scene has emerged as an essential means through which to target primarily young Black LGBT people for HIV prevention and as another refuge to which these young people can turn when they have been ostracized from or oppressed within their biological kin households or their communities of origin (p. 226).

As will be explored in chapter four, community-based organizations (CBOs) will often partner with key pioneers of the scene to obtain spaces to hold balls centered on HIV/AIDS prevention.

\subsubsection{From Punking \& Whackin' roots to contemporary Waacking subculture}

Analogous to how the Ballroom scene grew out of a response to white supremacy both within the white gay drag communities and dominant institutions in power, the 
Waacking/Punking scene was created in response to the ridicule and 'shade' thrown by straight disco club goers who attempted to push working-class people of colour out of mainstream disco clubs during the 1970s (Bragin, 2014).17 According to Naomi Bragin (2014), Waacking "might best be styled as radical Black feminist practice; working to move beyond misogyny, homophobia, and hetero-patriarchy" (p. 74). Comparable to Ballroom and Kiki performance subcultures, Waacking subculture creates sanctuary communities for its members, albeit in distinctly nuanced ways.

The signifiers used to describe Waacking/Punking as a performance form connote culturally contingent societal norms surrounding sexuality and gender expression. According to contemporary waacking choreographer Kumari Suraj (2016), 'punking' is the action and 'whacking' is the reaction. Suraj maintains that DJ Michelangelo of 1960s disco club Gino's named the dance movement 'Punking' as an inside joke amongst the working-class gay club goers performing the style (Suraj, 2016). 'Punk' was a derogatory term for gay men on the west coast, so the subculture re-claimed the homophobic insult and Punking culture was born. Similarly, 'whacking' connotes both male masturbation and a defensive move to use against a homophobic and/or racist attacker. Heterosexual 'Whackers' later sought to disassociate themselves from the 'gay' and violent connotations of the term 'punk' and 'whack'. In an interview with podcaster Ashani Mfuko of the podcast The Kiner Hour - Let's Talk Dance, contemporary Waacker/Punker Tyrone 'the bone' Proctor contends that Waacking with 'aa' was first used by the dancer Shabba-doo to disassociate from the negative sexual and violent connotations of attempt to undermine a person without being overt; it can also be an indirect critique of someone" (p. 253). 
whacking with an 'h' (Mfuko, 2011).18 Suraj confirms that as heterosexual dancers became increasingly interested in the unique dance form, they further disassociated with the homosexual term of punk or punking and "they called it waackin, the Cagney (after early Hollywood contemporary dancer James Cagney), or the Shabba-doo (the first known straight male waacker)" (Suraj, n.p). Explaining the political tensions in labeling the dance style, Soul Train's Ana Sanchez claims that gay men dancing the form in the so-called 'straight world' of dance “. . . did not want to be called fags so Waacking came about ... in their own world it was Punkin'... Punkin' was how they lived, how they expressed who they were" (Sanchez, 2011, n.p).

Stylistically, Waacking is known for fast whipping arm movements, while Punking "indicates a stylized movement behavior that expands beyond set vocabulary, incorporating elements of large locomotion, dramatic gesture and facial expression, and narrative" (Bragin, 2014, p. 63-64). To gain an understanding of the hard-to-describe style, in a video interview with Dance Mogul Magazine Punking pioneer19 Viktor Manoel explains the dance as "behavior movement," or dancing that is intended to mimic professional dancers and Hollywood actors such as Fred Astaire, Jean Kelly ("Dance Mogul Magazine,” 2012, n.p). Adds Suraj (2016), “the golden era of Hollywood was a major influence on the original punks. [From] Silent films, musicals, features [films], .. .

\footnotetext{
${ }_{18}$ Proctor adds that Jeffery Daniels from the dance troop Shalamar added the ' $\mathrm{g}$ ' on the end to form the contemporary form of 'waacking' (Mfuko, 2011).

19 According to Bragin (2014), alongside the last remaining Punker Viktor Manoel, original Punkin' dancers include Tinker, Arthur Huff, Andrew Frank, Michael Angelo Harris, Billy Star, Lonnie Carbajal, China Doll, and Tommy. Moreover, key contributors to contemporary Waacking/Punkin' include Tyrone Proctor, Jodi Watley, Jeffrey Daniel, Adolfo "Shabba Doo" Quiñones, Toni Basil, Ana Sanchez, Archie Burnett, Dallace Ziegler, Angel Ceja, and Brian Green” (p. 76)
} 
to Looney Tunes, Bugs Bunny. . . Batman and Robin .. all of these things influenced the movement" (n.p). Comments Manoel,

... [I]t was such an escape from everything I was going through. It was a safe haven - $\quad$ something I could control. I grew up in projects and you know there is gangs and you know everybody's calling you 'puto', 'fag', all of that. And going into a dance class was the only place where I had control. If I wanted to plie .. anything I wanted to do technically.. to give me facility for my body to do what I wanted to do, which was expression, I did it.. and I started working" (n.p).20

Subsequently gaining notoriety within the once underground dance scene, Manoel was hired as a dancer in movies such as Staying Alive (1983), Breakin' 2: Electric Boogaloo (1984), and David Bowie's Glass Spider (1988) ("Viktor Manoel Bio" n.d.).21 Before his debut on stage and screen, Manoel danced semi-professionally and was rarely financially compensated except for food per diems while traveling. States Manoel on the professional dance culture of early Punking: "sometimes dancers were hired for $\$ 50$ a day, [but] because kids wanted to be seen ... As long as you got featured, you didn't get paid" ("Dance Mogul Magazine," 2012). Most dancers in the scene attempting to perform the style professionally were un-unionized, under-paid (if paid at all), and typically took the work where they could find it.22

The aforementioned Tyrone Proctor was a founding member of the subculture and formed the 'Outrageous Waack Dancers' with Jeffrey Daniel, Jody Watley, Sharon Hill, Cleveland Moses Jr, and Kirt Washington (Mfuko, 2011; “Outrageous Waack," 1978).23

20 When used as a masculine noun 'puto' is a derogatory Spanish term for male sex worker ("puto," n.d.). 21 Manoel was also hired as a background dancer alongside fellow punker' Danny Lugo in a live concert disco version of Grace Jones' single "Do or Die" at The Roseland Ballroom in NYC in 1978 (“AlyssaChloeNYC," 2012, n.p).

22 The difficulties of finding paid dance jobs and the under-recognition of the performance form will be explored in chapter 2 .

23 Proctor famously (and successfully) rode in the trunk of a car to sneak into the Soul Train filming studio to have the chance to get airtime as an amateur dancer (Mfuko, 2011). This points to the un(der) employment of LGB and trans punkers and dancers of colour in the mainstream contemporary dance world. 
According to Proctor, Soul Train had a major influence on working-class amateur Punkers of colour during the 1960s (Mfuko). Echoing this, Bragin (2014) posits that "Soul Train brought gay Black dance styles to international exposure, at a time when 'Black' and 'gay' were (and still widely are) imagined to be completely separate" (p. 63). In the 1980s, Proctor moved from the west coast of the United states to New York City. It was in NYC that Proctor formed a dance troop with Benjamin Harris, Javier Izquierdo, and famous voguer Willie Ninja, called 'Breed of Motion'. According to Proctor, the influence of Breed of Motion is why Waacking and Vogueing resemble one another to an extent, although Waacking has not been embraced internationally as much as Vogue (Mfuko, 2011). While Waacking culture continued to develop underground, during the late 1980s and 90s the style faded from the public eye (Suraj, 2016).

Waacking/Punking "was virtually unknown by the 1990s with the disappearance of most [male] progenitors during the early AIDS crisis" (Bragin, 2014, p. 64). Some exceptions included female-identified Waackers' of colour who were featured in the 1990-1994 TV series In Living Colour (Suraj, 2016). Since then, the scene grew transnationally and across genres with the b-boy and b-girl movement in the year 2000s (Bragin, 2014). As Bragin attests, "contemporary Waacking is most widely practiced by non-Black, cisgender females in transnational hip-hop/street-dance communities” (p. 63).

\subsection{Concerns surrounding white-washing $\&$ appropriation}

\subsubsection{The cis-and-white washing of Waacking/Punking}

This is also an example of the resiliency and tenacity of the early working-class punkers of colour who are passionate about their artform. 
According to Bragin (2014), the resurgence of Waacking "into mass-media culture is part of an appropriative process by which hegemonic power reconfigures cultural identity wrapping transgressive relationality and queer practice in hegemonic heteronormativity" (p. 65). The exhibition of Waacking on the Fox series So You Think You Can Dance (SYTYCD) demonstrates this appropriative process. States Bragin (2014), "textual and verbal descriptions of Waacking often obscure its queer (Punk) history, or resort to vague characterizations of the style as "feminine," perpetuating the most common slippage of assumptions about gender and sexuality" (p. 64). Onscreen and in Fox's online 'Dance Dictionary' the subculture is reductively described as a type of "street dance that originated in Los Angeles in the early ' $70 \mathrm{~s}$. It takes a lot of skill, precision and control. It is typically choreographed to Disco music as the driving rhythms and defined beats compliment the quick hand and body gestures" (Bragin, 2014, p. 65). This description neglects to mention the gay and trans Black and Latinx pioneers of the scene, nor the tenuous social conditions they endured while creating the dance style. The cisgender man and woman dance duo on SYTYCD demonstrated a white-washed marketable version of Waacking. By erasing its complex and rich tradition of gay sexuality, gender-non-conformity, and celebratory Blackness, the popular TV series effectively staged a Waacking "performance of properly dressed gender relations [which] sells a narrow vision of cisgender straightness" (Bragin, 2014, p. 66). For Bragin, alongside the "compulsory cisgendering of movement," these appropriative processes pose questions about the "heightened stakes of performing social inclusion under terms of a white patriarchal order that suture Blackness-to-pathology-to-violence" (p. 65).

\subsubsection{Ballroom \& Kiki anxieties surrounding appropriative processes}


Since the days of its inception, house and Ballroom culture has exploded internationally - from Paris to Tokyo (Yates, 2016). According to Bailey (2013) and his New York Ballroom interlocutors, straight-identified cis-gender Japanese woman Ms. Koppi Mizrahi learned to vogue from YouTube videos and "impressed legendary voguers" in the NY scene before taking the scene to Japan (p. 223). Similarly, Kiddy Smile of Paris's House of Mizrahi tells BBC culture journalist Arwa Haider (2018) that “. . places that have had colonies are going to have a Ballroom scene. In London. .., Amsterdam, Berlin, Madrid... Paris is. . . a place where LGBT people of colour could unite" (para. 13).24

Because of this expansion, varying walking categories, unique ball themes, and nuanced house familial structures have resulted. So much so that choreographer and house father Rashaad Newsome deems the culture "open source" (Balzer, 2015, para. 13). But as Tav Nyong'o (2015) points out, the popularity and "open source basis of culture should also not be license to pillage, to take work without credit or compensation, or to only focus on minority culture when it is in the white glare of media hype" (para. 12). This has been a concern in contemporary consumerist society where Ballroom culture -vogue in particular - is "blowing up in new ways in European dance studios [and] in suburban recreational centers" (Hart, 2015). Contemporary voguers like the previously mentioned Benji Hart (2015) contend that the mainstream expansion of Ballroom culture does nothing to serve the impoverished, queer communities of colour that created it.

24 Steffie Mizrahi, a pioneer of Paris's ballroom scene, founded the House of Mizrahi (Hahn, 2019). 
Hart's insistence on guarding this artform is understandable considering the prevalence and availability of binge-worthy reality television series' like Rupaul's Drag Race (RPDR) in contemporary mainstream pop-culture. According to recent scholarship (Goldmark, 2015; Hall-Araujo, 2016; Upadhyay, 2019) on the cultural phenomenon that is $R P D R$ suggests that properties of ball culture such as voguing and ball vernacular have been appropriated, infused with US nationalism, whitewashed, and packaged for consumption by mainstream white popular culture via Netflix.

In explaining their drag performance aesthetic, Lou Henry Hoover (2017) articulates the importance of "remembering that delivering realness was once political," especially when droves of viewers "are safely consuming images of drag performance on their TVs in their living rooms without having to set foot in a gay bar or actually engage with a queer person" (p. 38). Furthering this, Nyong'o (2015) indicates that some advocates for Ballroom house culture contend that any performance "beyond the ball scene... [constitutes] cultural appropriation" (para. 9).

In this present time of relatively affordable and readily available streaming entertainment and new media, selective 'gay' content is being consumed by most anyone with an Internet connection. Well-known performance artist Rashaad Newsome states that "vogue was co-opted very early in its creation, like so many other things in Black cultural history. But we can still push our art further, out of Ballrooms and into galleries and art spaces." (Yates, 2016). Rather than binarily reduce Newsome's sentiment to either a statement on the marketable conditions of the performance form or solely the words of an established performance artist already making a living from his craft, I intend to put forward alternative ways of imagining the subculture in the sections to follow. 


\subsection{Research problem: White supremacy \& Exclusionary pride politics}

Although people of colour within the scene are successfully maintaining and growing the subculture, acts of white supremacy do impact these scenes. In the late-night hours of December $31_{\text {st }} 2018$, rather than serve up tapas and flamenco in their typical fashion, the Spanish restaurant and community performance space La Sala Rossa in Montréal hosted the Y2K19 Vogue Ball: TNT!. Set against the thematic backdrop of “cyberpunk dystopian post-apocalyptic hyper-technological warfare," the mid-sized Canadian ball featured over-the-top categories like Runway: futuristic military, Realness: New World Order, and Body: Artificial Intelligence. Montréal's most active Kikiers' and competitors from Toronto's larger Ballroom scene were gathered on New Year's Eve to 'get their tens', snatch those trophies, and earn $\$ 200.00$ per category. The colloquial phrase 'get your tens' refers to scoring 10/10 (100\%) from all judges adjudicating the performance. To 'snatch a trophy' is to win first prize in your category (Bailey, 2013). As Toronto-based DJ's Chivengi and Tati au Miel provided the beats, Canadian Ballroom

pioneer Twysted Miyake-Mugler commentates for the mixed gender, mixed race crowd that has formed around the raised T-shaped runway and judges table. Competition was fierce as grand prize in the 'bizarre' category went to a competitor waddling down the runway in a large bulbous neon-green sumo-suit with smoke emulating from their homemade robot arms.

Despite not being in attendance and only watching from a live-stream on Facebook, the intensely jovial reaction from the commentator and crowd had me cheering into my screen. My remote physical reactions only intensified for the category that followed. A white, masculine-presenting person with a strip of Black face-paint 
concealing their eyes sauntered onto the stage unceremoniously donning a Black winter coat, Black pants and white sneakers. Seemingly undecided on how to interpret the look at first, the audience hesitantly encouraged the individual by wagging snaps high into the air.25 Being that it was the Face category, it was unsurprising that the competitor leaned in closely to present to the judges. What was drastically surprising, however, was when the individual brazenly spat a mouthful of water directly into the judges' faces: most of which was said to hit a self-identified Black femme, trans woman and Kiki icon in the scene. The competitors to the side of the stage looked horrified and one looked scared as they clasped their hands to their face in stunned silence.

Upon viewing the footage numerous times, a perk of the otherwise inadequate way to view a ball, I observed mainly stunned looks from the audience. That being said, when I paused the footage something is clear. Some feminine, cis-presenting white people in the front continued to stage stomp (a celebratory reaction) and a few even clapped directly after the incident. The majority of these audience members either looked unsure of how to respond or they are smiling and clapping as though it was just a stunt comparable to any other bizarre moment created on the runway that evening. Across the runway, the majority Black, mixed gender audience members looked shocked and disgusted. It was not until the white-presenting crowd seemed to make eye contact with those displaying distaste and heard the MC state, "okay stop... cut the beat...", did they respond with solemn faces and cease their quiet cheering.

While it is hard to make out what the MC was saying, I believe I hear "honestly. .

25 Wagging finger snaps are similar to clapping or expressing praise to a competitor walking in a ball competition. 
. I want to attack you... (unintelligible), but I completely refuse" (00:31:12). The offending individual threw their head back laughing and did an uncomfortable shuffle near the judges table. Someone yelled from the audience "get off the stage" as the MC walked out from behind the judges table to address the matter head-on. The 'spitter' steps back. Twysted stated, “I don't give a fuck. No. There are certain things that are not cute. I will not stand for it. You will never spit on my girls!" An audience member echoes, “never!," as Twisted continued: “playfully, lovingly, angrily, I don't give a fuck - you do not spit on my girls... That is just it. That's just it.. [unintelligible]... oh my lord Jesus." As the offender was directed off the stage and disappeared into the crowd, another judge rose from the table, walked across the runway, and spoke with security off-camera. With frustration in his voice the MC asked "anybody else walking fucking face [the category]? Pump the beat.. Just pump the beat." The next competitor walked across the stage seemingly unseen as the observers turned to one another animated and still in shock. After the winner for the category was announced, the MC stated that "every experience is a learning experience" and struck a pose to ease the tension in true Kiki ball fashion.

It is impossible to know what the audience saw from their point of view as the spitting individual's back was turned to them. What was clear, however, was the general outrage expressed from members of the Ballroom and Kiki community commenting offsite but in real time via the mode of live streaming. Comments such as "wft; I'm disgusted!; what was he thinking?!... [and] I'm so gagged"' littered the discussion panel to the left. As the commentators peppered the feed with angry and sad emoticons, one person generated the hashtag \#Justice4[name redacted]. Reflecting on the ordeal the next day via the Facebook group 'Vogue Montréal and Ballroom Community', prominent 
Ballroom member Amazon Wayne wrote:

I am still in shock at what happened at the NYE Ball. I have never seen such disrespect at a ball EVER and this behavior will not be tolerated. If you come in the Ballroom scene, be mindful of who this scene was built by, and for, and behave accordingly. I have never seen this individual before but I am horrified and embarrassed that this happened. To spit on ANYONE at a function, and of all people a Black woman of trans experience, not to mention a judge, a pioneer of the scene and a wonderful person who welcomed you in their space. Montréal, we have to do better.

In a comment made on this post, someone wrote "I noticed that there was a significant increase in the amount of drunk white people at the last ball. . If security is becoming an issue, I volunteer as tribute (sic).”

The presence of 'drunk white people' causing issues or drawing focus away from the ball itself does not go unnoticed. This commenter volunteered their time to 'deescalate' and 'remove' drunk white people causing trouble, which received 15 'likes' and 4 'hearts'. Shot from his hotel room after the ball, MC Twysted recalled the moment in a Facebook live video viewed 682 times: "we let this white person spit on this Black trans woman in front of us... This is a Black trans woman at her event! It was one of those things, like I can't believe this happened in Canada! Like... Canada... oh my god!” Twysted paused and put his head in his hands.

Chivengi's earlier statement "y'all getting too bold" and the important cultural commentary that it elicited reveal much about the social climate in which Kiki and ball culture in Canada have emerged. As Eng \& Han (2018) aptly call it, our "putatively colourblind age" presents contradictions of "celebratory discourses of multiculturalism and diversity in the face of intensifying racial discord and violence" ("Preface," p. vii). Continuing this line of inquiry, queer of colour theorist Roderick Ferguson (2003) claims that by complying with national citizenship and the supposed rights it offers, "white gays 
and lesbians" gain privileges at the detriment of "racialized, classed, and gendered" queer others (p. 53). Demonstrating this, the 2018 anthology Marvelous Grounds offers an invaluable counter-archive narrated by artists, activists, and scholars of colour that decenter white-normative, hegemonic 'queer history' that remains stamped on the white imaginary 26 in the effort "to challenge colonial logics of time and place, and to re-engage with the past in order to denaturalize the present" (p. 5).

Similar to other Western democratic countries, LGBTQ2S communities in Canada have undergone a significant mainstreaming in their bid to win gay rights and recognition.27 This mainstreaming of LGBTQ2S movements constitutes what Lisa Duggan (2003) calls the emergence of the "new homonormative [-] a depoliticised gay culture anchored in domesticity and consumption" (Duggan, 2002, p. 179). For example, according to Tom Warner's (2002) extensive research on early gay and lesbian organizing in Canada, the success of human rights campaigns during the 1970s "were bittersweet for liberationists. . . [as] they accentuated the inherent conflict always present in the human rights strategy and. . . actually strengthened the equality-seeking assimilation they so fundamentally opposed - at the expense of liberation advocacy" ( $p$. 215-216).28 Further exploring the contradictions in legal rights recognition, Gary

26 By 'stamped on the white imaginary' I refer to the ways in which a white-washed writing of 'queer history' perpetuates a white-supremacist configuration of queerness and gender-non-conformity as separate from racism, classism and white nationalism. From personal experience, these histories not only misinform white queer and trans people, but they re-victimize and silence QTBIPOC people.

27 See Kinsman, G. (1996). The regulation of desire: Homo and hetero sexualities (2nd, rev. ed.). Montréal: Black Rose Books; and Warner, T. (2002). Never going back: A history of queer activism in Canada. Toronto, Ont: University of Toronto Press; and FitzGerald, M., Rayter, S. (2012). Queerly Canadian: An introductory reader in sexuality studies. Toronto, Ontario: Canadian Scholars' Press. 28 As Warner (2002) reminds us, "Liberationists differ from assimilationists [in that] legislative amendments alone would not significantly change the everyday lives of gays and lesbians nor remove the homophobia and heterosexism that oppresses them" (p. 215). 
Kinsman and Patrizia Gentile (2010) state that "on the one hand, our individual formal and abstract human rights are now increasingly recognized, on the other hand, our relationships often remain stigmatized and our sexualities and our desires are still censored, criminalized, and hated" (p. 394). A fundamental issue with a rights-based activist perspective is that "it accepts existing social forms and argues simply for the inclusion of queers" (Kinsman \& Gentile, 2010, p. 394). In the same manner, Bassichis, Lee, and Spade (2011) contend that "well-resourced" 'official solutions' to queer and trans oppression such as passing hate crime legislation and legalizing same-sex marriage ought to be expanded to more radical, "transformative approaches" such as prison abolishment, immigration reform, and universal healthcare (p. 17). The key to these transformative approaches is to confront the whiteness inherent in rights and recognition discourses.

Twysted's disbelief that the transphobic and racist staged spitting act happened in Canada demonstrates just how entrenched anti-Black racism is in the nation state. This homonationalist sentiment is used to construct Canadian exceptionalism in particular as a safe haven for LGBTQ2S immigrants, migrants, and refugees. Rinaldo Walcott (2003) debunks the myth that Canada is a place of safety and security for racialized immigrants by explaining that "Jamaicans have been marked as the most violent and criminal among Black immigrants in Canada, and a reverse migration (deportation) back home. . . has been inaugurated" (p. 102). Robyn Maynard (2017) articulates homonationalist white supremacy as a type of "social amnesia about slavery" in a country that is lesser known for its sordid history of anti-Black racism (p.19). Similarly, David Murray (2015) further characterizes the ways in which LGBTQ asylum seekers and refugee applicants are 
forced to represent themselves as respectable victims and "reproduce a homonationalist narrative of Canada as a nation of freedom to which the refugee 'victim' must be eternally grateful." (p. 80). This point-of-view results from the collision of normative, compulsory homosexuality and discourses of nationalism (Puar, 2007). To Jasbir Puar (2013), homonationalism is neither a political position, nor an identity, rather, an "analytics of power" and "a facet of modernity... marked by the entrance of (some) homosexual bodies as worthy of protection. . ., a constitutive and fundamental reorientation of the relationship between the state, capitalism, and sexuality" (p. 337).

Radical grassroot movements like Black Lives Matter - Canada (BLM) have continued to challenge white supremacy in a multitude of ways. 29 Maynard (2017) contends that Canada is experiencing a "revitalization of Black resistance. . . spurring new forms of activism, art, [and] intellectual work" (p. 13). For instance, record numbers of uniformed military personnel, police in OPP polo shirts, and the Prime Minister of Canada himself marched in the annual Capital Pride Parade celebration of 2017 in Ottawa (Duffy, 2017). Due to the sordid histories of state-sanctioned violence against people of colour, BLM-Ottawa protesters took heed of the 2016 BLM-TO sit-in and intervened in the Ottawa Pride parade for 15 minutes of peaceful protest (Duffy, 2017). According to Miriam Smith (2018), protests such as these have successfully "highlighted the impact of violence towards Black Canadian communities" (p. 188). In a panel discussion on the current state of social justice movements Rinaldo Walcott (2018) offers

29 International ambassador for the Black Lives Matter Canada Network, janaya khan, co-founded BLM Canada and its Toronto chapter (with Yusra Ali) in October 2014 “... following the killing of Jermaine Carby, who was shot in a car by police during a routine traffic stop in Brampton, Ontario. Since then they've worked to resist anti-Black racism in the Greater Toronto Area" (see Khan, 2019, para. 2). 
that "BLM is not simply a movement responding to the immediacy of police violence and abuse. . . [for], it sits in a genealogy of Black activists' eruptions meant to transform the state as we presently know it" (Simpson, Walcott, \& Coulthard, 2018, p. 82)30 These social justice processes are instrumental in building kinship between queer and trans people of colour.

Although the media often vilifies people of colour involved in BLM and other peaceful radical activist groups, these groups continue to fight for survival and emotional justice. A growing number of studies have conducted discourse analyses of media reactions to these peaceful protests. In response to BLM-TO's 2016 sit-in, Ali Greey (2018) identifies "a narrative of terrorism, a discourse framing BLM-TO as an aggressor, and language identifying BLM-TO as an outsider to the queer community" (p. 662). Correspondingly, in an empirical study on media descriptions of police shootings of unarmed people of colour, Obasogie and Newman (2016) claim that "local journalists' inattention to race means that these fatal engagements are being articulated to the public as an instance of raceless police officers interacting with raceless victims" (p. 562). This anti-Black and 'post-racial' rhetoric in fact demonizes people of colour and Black radical activism. As Chloe Banks (2018) suggests, these mainstream media rhetorical strategies encourage "delegitimization of the very real problems concerning racial profiling and racial killings that the Black Lives Matter group protests” (p. 709). Despite being positioned as 'terrorists' and aggressors, activists are standing their ground and creating 
alternative social worlds within the larger white supremacist, hetero-patriarchal, capitalist framework.

The way BLM interventions have been reported on in the media reflect the current issue of queer exceptionalism and white supremacy within mainstream pride movement(s) in Canada and the United States. Sexual exceptionalism, or the "acceptance and precarious protection of some [white, middle-class] LGBTQ2S people" dictates whose bodies are worthy of protection and social acceptance (Trevenen \& Degagne, 2015, p. 107). According to Puar (2007), sexual exceptionalism "does not necessarily contradict or undermine heterosexual sexual exceptionalism; in actuality it may support forms of heteronormativity and the class, racial, and citizenship privileges they require" (p. 9). The underlying impulses of this exceptionalism can be traced to what Roger Foster (2016) calls the "forced freedom" or "corrosive liberation" of neoliberalism (p. 109). This deceiving 'freedom' only forces high standards of self-efficacy and competitive fiscal responsibility upon the masses. Neoliberalism has successfully encouraged the capitalist consumer to brand themselves as unique through self-serving identity labels that covertly reinforce "structured competition" (Foster, 2016, p. 101). This culture of toxic individualism has led to what Puar (2007) calls "queer exceptionalism," which favors 'individual queerness' over queer collectivity working in solidarity with working-class people of colour (p. 77). Black collective activism, therefore, becomes a perceived threat to the social (and in the case of Pride parades - sometimes the physical) mobility of the privileged 'respectable' queer. In these cases, collective grassroots movements like BLM are essential in dismantling queer essentialism in the nation-state of Canada. 


\section{$1.4 \quad$ Research Objectives \& Questions}

With the aforementioned research context in mind, the Kiki ball spitting incident not only demonstrates the timeliness and necessity of research that interrogates how whiteness mobilizes selective queer populations, but also how queer of color counterculture is 'clapping back' to offensive and abusive displays of white supremacy and queer exceptionalism. As previously mentioned, research focusing on the intersections of gender, race, ethnicity, and sexuality are under-researched in a Canadian context31. Furthermore, many white Canadians are in "pervasive denial" that racism has ever been an issue in Canada (Aylward, 1999). In a time when queer and gender non-conforming people are "gaining unprecedented representation in the mass media while remaining subject to explicit forms of prejudice and violence," research on forms of resilience within racialized and gender oppressed groups are tremendously vital (Burton, Gossett, \& Stanley, 2018). Prominent Canadian Kiki competitors Billy Eff and Twiggy Pucci Garçon have made sound arguments for Kiki's continued importance to trans and queer people of colour in urban centres across the border in Canada (Raeanne, 2011). But scholarly inquiries into the queer subculture of Kiki as it both differs and mirrors wider commercial Ballroom performance culture have been contained to the United States (Bailey, 2009, 2013; Halberstam, 2005; Becquer \& Gatti, 1991). As illustrated in Jordenö's 2016 documentary, Kiki, the New York piers have been bustling with trans youth carrying on and transforming the traditions of Ballroom culture (Rogell, Cheatle, \& Jordenö, 2016). Unbeknownst to many, just north of the border in Montréal, Quebec

31 With noteworthy exceptions such as Carol Aylward (1999), Robyn Maynard (2016; 2017), Katherine McKittrick (2006); Rinaldo Walcott (2003; 2006; 2009; 2016), and OmiSorre Dryden (2010; 2015). 
there exists a burgeoning Kiki scene and - to a lesser extent -a promising Waacking gatekeeper who is successfully educating youth about the gradually growing scene in Ottawa.

The wider objective of this research is to interrogate what Rinaldo Walcott (2016) calls "white queer culture" in a Canadian context (p. 324). I am interested in understanding the mechanisms through which Kiki subculture could be considered what Robyn Maynard (2016) deems 'self-determination' movements in the tradition of Black radical activism in Canada. To clarify, self-determinism or self-sustaining, activist-led community-based collectives are organized by the community impacted - for the community impacted.32 Another objective of this research was inspired by recent archival efforts to collect queer of colour histories in Toronto as evidenced in Marvellous Grounds (2018). I agree it is vital to avoid a white-washing of queer histories and "reengage with the past in order to denaturalize the present" in efforts to purposefully center the voices of people of colour in adding to their own invaluable counter-archives (Ware, Haritaworn, \& Moussa, 2018, p. 5). By examining the informal familial social structures, embodied performance praxis, and sharing economies within Montréal's Kiki subculture and, to a lesser extent, Ottawa's Waacking/Punking mini-scene, this research questions how Kiki and Punking/Waacking subcultures resist and transform hegemonic productions of racialized gender and sexuality? What radical activist tactics are deployed in these nuanced scenes? 
Described in the epilogue of Bailey's 2013 text as one of the "evolutions of Ballroom culture," Kiki subculture is "generative and dynamic" and never static (p. 225). Over the span of the ten years it took Bailey to conduct his ethnography and publish his results, he noted that elders in the micro-scene relayed the concern that "the Kiki scene has become a carbon copy of the main scene by maintaining all of the harsh and cutthroat forms of competition for which Ballroom is notorious" (p. 226). Despite humble beginnings in DIY subculture, young Kiki members began to "craft and stunt to acquire extravagant clothing" in order to win walking categories and gain notoriety. 33 Additionally, Bailey notes that some in the Kiki scene claimed "legendary status without having achieved the required level of accomplishment commensurate with such status in the overall scene" (p. 226). Aisha Iman described this as "an issue of great consternation" in Kiki culture and warned that "the Kiki scene is going to become its own mainstream scene" (p. 226). In the spirit of continuing this important conversation, a peripheral line of question in this research project is: what is at stake when this unique, under-ground sub-culture goes through a mainstreaming process influenced by Western consumerism; and in what ways do these subcultures resist appropriative processes?

${ }_{33}$ Crafting or stunting "signifies fraudulent activities or the acquisition of items or services through illegal means" (p. 253). According to Bailey, stunting is common within the ballroom scene but it cannot be understood outside of the pressures to adapt to a capitalist urban-lifestyle that places importance on image. Self-fashioning even by shoplifting in this sense gives ballroom members "access to a more livable life" (Bailey, 2013, p. 71). 


\section{Chapter 2: Methods/methodologies, theoretical frameworks, \& key}

\section{arguments}

I mobilized queer of colour methodologies by using non-traditional, non-scholarly secondary and tertiary sources of information written, directed, and created by key Kiki and Waacking/Punking community experts. According to Syrus Marcus Ware (2017),

The classic archive structure - primarily white trans and queer archives - is the allegedly neutral disembodied collection of objects that create and inscribe a narrative of struggle and resistance that always begins with whiteness and that is used too often in the service of homonationalism, gay imperialism, and the vilification of the less progressive other (p. 171).

Rather than relying solely on the helpful yet small body of research on my topic in peerreviewed scholarly databases, which are traditionally gatekept by dominant white institutions in power, I have taken Ware's 2017 (and 2019) insights into consideration while sourcing secondary information about these underground performance scenes. Following Ware's (2017) commitment to "starting with Black trans and queer history as a way [of reorientation] towards a radically different account of the present and what needs to change," this research consults QTBPOC documented histories from a self-determinist, anti-oppressive queer of colour perspective. In addition to attending various participant observation sessions, I viewed hundreds of hours of dance videos and interviews posted on Facebook Live and YouTube platforms.

I sourced archival magazine articles about Ballroom, Waacking/Punking and Kiki subcultures such as Ebony, Jet, Harlem World, and Vibe magazines as well as community-authored and published informational websites and online blogs from Ballroom, Kiki, and Waacking/Punking members themselves. To gain a basic working understanding of these subcultures early on in my research I screened community- 
informed documentary films and docu-series' such as The Queen (1968), Kiki (2015), and Viceland's My House (2019). This approach is not without challenges as some of the information found on blogs and videos concerning Waacking/Punking subculture has been contradictory. As a researcher I have the responsibility of parsing out what secondary data is informed by experienced members of the community before using it to shape my production of knowledge.

\subsubsection{Methodological approach: Participant observation}

Although an impressively immersive 6-year performance ethnography such as Marlon Bailey's (2013) is outside the scope of this research, I have learned from Bailey to center 'performance' as a fundamental mode of expression to understanding Kiki and Waacking/Punking subcultures. Seeing as how Kiki balls are a central means with which members congregate and find shared belonging, observation of said balls was a key data collection method in developing an understanding of the complex social dimensions of both scenes. To enrich the qualitative interview-based data obtained from my small sample size of five participants and inform my understanding of unspoken, performancebased subtexts within these subcultures, I conducted three sessions of participant observation at two mini Kiki balls in Montréal and one public dance battle involving Waacking at city hall in Ottawa.

Researching a subculture whose activities revolve around subjective bodily expressions also requires a methodological approach attune to affective responses - both that of the researched and the researcher. For Sara Ahmed (2004), "emotions show us how power shapes the very surface of bodies as well [as] worlds" (p. 12). In short, our emotions are attached to our material experiences, and in a study that centers bodies and 
performance, these emotional and affective responses are highly relevant. The relevance of affect and emotion occurred to me most prominently during my two participant observation sessions at Kiki balls in Montréal. To dance competitively without the reassurance of planned choreography in front of judges and an audience is to perform a miracle - a burst of emotional labour crammed into mere minutes of movement. Dancers must feel the music and the tenor of the room and breathe life into their body in order to tell an entire story without words, kinaesthetically, with their body and their intuition. To compete in front of your highly respected queer family members and renowned legendary judges in the scene without choreography is most unthinkable to even the most practiced dancer. Per Corrine Glesne (1999), participant-observation falls on a continuum ranging from largely participatory to primarily observational (p. 44). Because of the importance placed on performer-audience affective exchanges and the physical closeness of what I call 'cipher-style' research, my attendance at the balls could not be anything but mildly participatory. 34

Witnessing such raw, unfiltered emotive performance draws the affect out - no matter how objective and emotionally removed one attempts to be as a researcher. This included interacting with those in the cipher by responding to small talk in between categories, clapping, cheering, whistling, and even tearing up at one point - ultimately all expressions of affect. Borrowing from journalist Kieran Yates (2016), I agree that balls are “... a euphoric experience to witness" (n.p). Employing queer of colour

34 According to Sally Sommer (2001), "a cipher denotes fast-moving riffs (verbal, physical, sung, or percussive responses) that can spring up anywhere, and any time-in the street, in a car, in the subway, or at the club. The word also applies to the actual circle that forms around the action or person when something creative [like break-dancing or a vogue battle] is happening" (p. 82). 
methodologies I knew I had to be sensitive in carrying out participant observation due to the historical surveillance and criminalization of queer and trans bodies of colour by primarily white people in power (Maynard, 2017) and the Canadian criminal justice system's sordid history of surveilling LGBT folks by conducting gay bar and bathhouse raids.35 Rather than scribe notes by hand, record with an audio-recorder, or take pictures which would likely seem odd or even suspicious at a Kiki ball - I took notes on my phone's notes application. My methodological approach captures these intense affective responses as witnessed and as felt by the researcher.

\subsubsection{Methodological approach: Semi-structured qualitative interviews}

I also realized the importance of affect when I transcribed my semi-structured qualitative interviews. I found myself searching for the language to most accurately characterize a participant's emotional response to talking about a topic they were all extremely passionate about. Qualitative interviews were conducted in order to understand the motivation behind respondents active participation in their scene; to understand what role (i.e. house parent, child, or free agent) they occupied and how they related to it; and discuss the implications of their participation in the scene on their well-being and overall lived experiences.

I initially used the recruitment method of posters and site-visits to 'urban/street' dance studios such as Montréal's Espace Sans Luxe and Urban Element Zone. After nearly two months with no success I was fortunate enough to meet with my first participant, who described some understandable reluctance by people she knew in the 
scene to engage with researcher(s) looking to collect data on their subculture. The effects of my recruitment difficulties ultimately led to one of my most important arguments concerning the strength of Kiki kinship networks: this community protects its own. More senior members (house parents) in the scene approached me about the study, but I was largely unable to access young newcomers to the scene. After developing a rapport, I was able to recruit more participants using the snowballing technique (thanks to participant P1) and social media call-outs posted through Facebook and Instagram. Prior to asking my interview questions I gave all informants a demographic questionnaire which asked them to voluntarily disclose their age category (ex. 18-25), race, ethnicity, specific dance form, favorite walking category, and house affiliation (i.e. house parent, free agent, house child) (see Appendix B).

\subsection{Queer of colour methodologies with an affective engagement}

Jin Haritaworn (2008) posits that queer methodologies "could be a way of examining and redefining social relations, both in a traditional sociological sense, and in an emancipatory sense of reframing difference with a view to social change" (p. 2). Just as those in the Kiki community believe in the mantra "not about us without us," so too does this thesis employ queer methodologies that centre the first-hand experiences of its racialized queer and gender non-conforming informants.36 Furthering this, I seek to engage with the affective responses of my participants, audience members at Kiki balls, and my own affective responses to witnessing the almost indescribable excitement of a Kiki ball. I find it useful to mobilize a hybrid theorization of queer of colour

36 The mantra "not about us without us" is used in the 2016 documentary film, Kiki, which was made in collaboration with key pioneers of the Kiki scene in New York (see http://www.kikimovie.com/synopsis). 
theory/methodologies with attention given to affect. Rather than make a distinction between affect and emotion by describing them in accordance with one theory (such as a psychoanalytic one), I employ Ann Cvetkovich's (2012) characterization of 'affect' as “. . . a category that encompasses affect, emotion, and feeling, and that includes impulses, desires, and feelings that get historically constructed in a range of ways" (p. 4). Described as "point[s] of departure," Cvetkovich (2012) describes feelings as "intentionally imprecise[,]" ranging from "embodied sensations" to cognitive experiences; Feelings are "something we come to know through experience... a conception of mind and body as integrated" (p. 4).

This research continually employs the anti-racist feminist principle of positionality in order to reflect on how my own lived experiences may impact my role in the production of knowledge. For Haritaworn (2008), scholarship informed by the antiracist feminist principle of positionality encourages the researcher "to reflect on where we stand, to define our speaking positions and how they relate to others, especially those whom we claim to speak for" (p.2).37 For example, my own queerness and working knowledge about Waacking/Punking history led me to wrongly assume my Waacking informant (P5) held an identity under the LGBTQ2S umbrella. As a heterosexual ally of the queer and trans people of colour within the subculture, P5 subsequently informed me that their androgynous gender expression and sense of self as a second-generation Asian led them to learn more about b-girl culture rather than continue on with the white dominated world of competitive Ballet. P5 reports adapting the history of

37 Which Haritaworn (2008) suggests helps the researcher "avoid colonising and appropriative instances of 'queering from above"' as suggested by Jay Prosser (1998) (p. 2). 
Waacking/Punking subculture to make it more accessible and understandable to a younger generation of dancers who have little-no knowledge about LGBTQ2S performance traditions.

Before I presented my preliminary findings at a conference in July 2019, I approached one of the founders of Kiki culture in Montréal - Gerard Reyes (AKA Bronze 007) to ask if they would be interested in consulting on how I presented the results of this project. The Mother of Kiki in Montréal suggested alternative terms more reflective of the particulars of Kiki culture and thoughtfully offered comments concerning how to represent their community in a valorizing and respectful way - as long as I disclosed their name and credited them (Gerard Reyes) for their efforts during my presentation.

In another example, my first participant was instrumental in prompting an important language change for my recruitment poster and consent forms. During my ethics protocol I made the decision to use the more institutionally recognizable signifier 'vogue' rather than 'Ballroom' or 'Kiki' for all of my research documents and recruitment posters. I knew that vogue was merely one category of Ballroom culture, but I also understood the term 'vogue' coupled with performance (thanks to the fashion industry and Madonna) was likely more recognizable to practiced academics working on an ethics board. It was a way to make my project more understandable to 'in-groups' in the hopes to gain ethics clearance and move on towards my research. According to P1, it was imperative that I draw from the lexicon of Ballroom and Kiki culture "to be taken seriously" by Montréal 's Kiki scene during my recruitment phase. This required ethics 
protocol revisions and re-postering in Montréal; an administrative process which required a time-delay and additional trips to Montréal that were out of my budget.

\subsection{Participant demographics \& affective considerations}

The demographics of my participants were as follows: Participant P1 selfidentified as Latina, Chica, and dyke/lesbian aged 25-34. Participant P2 self-identified as a cis-gender Black woman whose sexuality is "complicated - not straight" aged 18-24. Participant P3 self-identified as cis-gender Black gay male aged 25-34. Participant P4 self-identified as a gender-queer gay-identified Latinx aged 35-44. Participant P5 selfidentified as a Filipina cis-gender female straight ally aged 25-34 (see Table A1).

Table A1. Participant demographics

\begin{tabular}{|c|c|c|c|c|c|c|}
\hline \multicolumn{7}{|c|}{ Participant demographics } \\
\hline Pseudonym & Age & $\begin{array}{l}\text { Race \&/or } \\
\text { ethnicity }\end{array}$ & Gender & $\begin{array}{l}\text { Walking } \\
\text { categor(ies) }\end{array}$ & Sexuality & House Role \\
\hline P1 & $25-34$ & $\begin{array}{l}\text { Latina; } \\
\text { Chicana }\end{array}$ & Woman & $\begin{array}{l}\text { Face, Sex } \\
\text { Sirens }\end{array}$ & "dyke/lesbian" & $\begin{array}{l}\text { House } \\
\text { 'aunt'/founder }\end{array}$ \\
\hline $\mathrm{P} 2$ & $18-24$ & Black & $\begin{array}{l}\text { Cis- } \\
\text { woman }\end{array}$ & $\begin{array}{l}\text { Face, Body, } \\
\text { Sex Sirens, and } \\
\text { sometimes } \\
\text { runway }\end{array}$ & $\begin{array}{l}\text { "complicated... } \\
\text { not straight!" }\end{array}$ & $\begin{array}{l}\text { Relatively new } \\
\text { to the scene - } \\
\text { free agent } \\
\text { '007' }\end{array}$ \\
\hline P3 & $25-34$ & Black & $\begin{array}{l}\text { Cis- } \\
\text { man }\end{array}$ & Vogue, runway & gay & $\begin{array}{l}\text { House father \& } \\
\text { informal vogue } \\
\text { teacher }\end{array}$ \\
\hline $\mathrm{P} 4$ & $35-44$ & Latinx & $\begin{array}{l}\text { Gender } \\
\text { queer }\end{array}$ & $\begin{array}{l}\text { Classically } \\
\text { trained in } \\
\text { Ballet/pointe, } \\
\text { jazz, } \\
\text { contemporary; } \\
\text { Vogue, runway, } \\
\text { heels, and } \\
\text { contortion. }\end{array}$ & gay & $\begin{array}{l}\text { Kiki Pioneer } \\
\text { and Mother of } \\
\text { Montréal's } \\
\text { Kiki scene \& } \\
\text { professional } \\
\text { vogue teacher }\end{array}$ \\
\hline P5 & $25-34$ & Filipina & $\begin{array}{l}\text { Cis- } \\
\text { woman }\end{array}$ & $\begin{array}{l}\text { Classically } \\
\text { trained in } \\
\text { ballet; } \\
\text { Waacking, } \\
\text { breakin', dance } \\
\text { hall, House, } \\
\text { Heels }\end{array}$ & "Straight ally" & $\begin{array}{l}\text { B-girl; } \\
\text { Waacking } \\
\text { teacher \& } \\
\text { scene founder } \\
\text { in Ottawa }\end{array}$ \\
\hline
\end{tabular}


Two of five participants were college educated; four of five were employed (in varying fields such as customer service and dance teaching); and all participants lived with roommates or romantic/sexual partners outside of their birth-of-origin home. While not specifically asked during interviews, class struggle/poverty came up in four of five conversations and it was made clear that these four participants were from working-class backgrounds (with one explicitly stating their immediate need for social services and a foodbank). Whereas two of five participants had some form of classical and/or contemporary dance training, most Kikiers and Whackers in the scene(s) are informally governed by the well-known mantra: 'each one, teach one'.38 This expression was commonly used between victims of the cross Atlantic slave trade, which indicated the unregulated, peer-to-peer pedagogical style employed when formal systems of education are denied (Cascio \& Luthans, 2014).39 Most recently, prisoners at Robben Island would teach each other covert communication tactics during solitary confinement (Cascio \& Luthans, 2014). With the continued legacy of slavery manifesting itself in nefarious ways in Canada, such as racially targeted police violence and the over-incarceration of people of colour (Maynard, 2017), Montréal's current socio-political climate is an appropriate backdrop for this meaningful advice (each one, teach one) to take hold. This expression, heard first during my recruitment phase, became a significant signifier hinting towards the anti-capitalist, post-consumption sharing ethos of Kiki House culture.

38 For more on 'each one, teach one' in performance studies see Fogarty, M. (2012). "'Each One Teach One': B-Boying and Ageing." In Ageing and Youth Cultures: Music, Style and Identity, edited by Paul Hodkinson and Andy Bennett, 53-65. London and New York: Berg. 39 For more on the historical importance of education for working-class racialized people see: Du Bois, W.E.B. (2002) Du Bois on education (E.F. Provenzo, Jr., Ed.) Walnut Creek, CA: Altamira. 


\subsection{Inductive coding \& thematic analysis}

After transcribing my qualitative interviews verbatim, which included noting the unspoken, affective responses of each participant throughout the interview, the first step in data analysis was to familiarize myself with each transcript by reading and re-reading each participants response. I decided to use a bottom-up, or inductive approach, which Braun \& Clarke (2006) describe as being more data-driven rather than driven by my research questions and pre-conceived theoretical frameworks. This is not to say I ignored the answers to my research questions, because these responses did include themes that formed some of my arguments, but it bears noting that many of the themes that emerged from the data were found in parts of the conversation that were unstructured and not in response to any one question in particular. Having a less structured interview, therefore, was beneficial. Next, I generated initial codes in my transcripts using 'open-coding' which involves "develop[ing] and modif[ying] the codes as [I] worked through the coding progress" (Maguire \& Delahunt, 2017, p. 3355). Although I initially planned on using NVivo, I preferred to print out my interviews and manually develop the initial codes using colour coding and transferring these initial codes into an excel document. In accordance with Bree and Gallager (2016), this proved to be a user-friendly, time efficient and cost-effective method for keeping my data organized. Some of the codes I identified included non-biological familial support, confidence, house family 'love', joy in performance, families of origin, acceptance/rejection, expression of sexuality, race, ethnicity, gender, sharing, resilience, etc.

Next, I conducted a thematic analysis by cross-comparatively analyzing the codes for patterns and relationships (Maguire \& Delahunt). For example, all of my participants 
spoke about the unique forms of (non-biological) familial support they received from their respective performance scenes. These included affective responses, such as 'my house family gives me confidence, love, joy, emotional support', which led to the theme of stressing the importance of having a non-biological queer alternative kinship network to Kiki house culture, for example. After identifying the themes, I used a simply 'copy and paste' technique to group together all of the participant responses to each theme. Next, I reviewed each theme to ensure it properly articulated what the data seemed to be telling me. I ended up absorbing one theme into another, and some of my themes overlapped. For example, immaterial and material sharing proved to be pointing to the same theme - sharing economies - so I grouped those responses into one theme to keep the data organized and ensure each theme was well-supported by participants' responses. The end-point of this inductive data analysis method was beginning to structure my arguments based on each theme. With these arguments and themes in mind, I could then assess what theoretical frameworks would be best suited to make sense of my findings.

\section{5 'Hybridized' theoretical frameworks}

This research mobilizes queer of colour critique, queer Latinx performance studies with an affective engagement, Chicano Feminism, and (to a lesser extent) critical whiteness studies as theoretical frameworks to best interpret my qualitative data. Tracing the linkages between these theories puts them in dialogue and explains how each is vital to understanding the findings of this research project.

\subsubsection{Queer of colour critique}

A Black drag-queen prostitute sashays along a waterfront. She has decked herself in a faux leather bomber and a white tiger-stripped dress that stops just below her knees. Her face is heavy with foundation as she ponders into the distance. She holds a cigarette between fingers studded with cheap press-on nails, dragging on it with lips painted red... 
It is difficult to discern whether she is melancholic about her life or simply satisfied. This uncertainty, this hint of pleasure and alrightness, flies in the face of those who say her life is nothing more than a tangle of pathologies and misfortunes" -Roderick A. Ferguson (2003, p. 1)

\section{Roderick Ferguson's Aberrations in Black: Towards a queer of colour critique} (2003) opens with the hopeful description above of a scene from Marlon Riggs's 1989 film, Tongues Untied: Giving a Voice to Black Gay Men. According to Ferguson, the figure of the Black drag-queen sex worker "represents the socially disorganizing effects of capital and plays a powerful part in past and contemporary interpretations of political economy" (p. 1). Plainly, her very existence is not only a threat to gender and sexual normativity, but to the normative social formations produced by heteropatriarchy. 40 Her existence is no doubt precarious, but she (and those like her) are over pathologized, criminalized, and assumed to be living hopeless, joyless lives destined for early death. 41 She is "disciplined by those within and outside African American communities, reviled by leftist-radicals, conservatives, heterosexuals, mainstream queers. . . [and] erased by those who wish to make African American culture the embodiment of all that she is not respectability, domesticity, heterosexuality, normativity, nationality, universality, and process" (p. 1-2). This figure of the working class, racialized, sex worker is what Ferguson deems "a fixture of urban capitalism. . . represents the social heterogeneity that characterizes African American culture" (p. 1). She cannot be understood fully without considering her class, ethnicity, gender, race, sexuality, and citizenship status within the

\footnotetext{
40 An example of a normative social formation is the archetype of the white, Christian heterosexual nuclear family.

41 In saying 'those like her' I refer to early trans sex worker activists like Street Transvestite Action Revolutionaries (STAR) founders Sylvia Rivera and Marsha P. Johnson (see Blacktino Queer Performance (2016) for this history). In a Canadian context, 'those like her' would indeed include Indigenous trans political organizer and sex work activist Jamie Lee Hamilton (see Ross, B. L., \& Hamilton, J. L. (2018). "Loss must be marked and it cannot be represented": Memorializing sex workers in Vancouver's west end).
} 
context of dominant national ideals and "liberal capitalist economic and social formations" (p. 2). In Riggs's own words, the film featuring this scene "unabashedly celebrates the struggles, lives, and loves of Black gay men. . . [and] was motivated by a singular imperative: to shatter this nation's brutalizing silence on matters of sexual and racial difference" (Riggs, 1996, p. 185). Breaking the silence on matters of sexual and racial difference and creating space for life in North America is a central goal of queer of colour critique.

I use this figure as described by Ferguson from Riggs's 1989 scene as an entry point to explain the necessity of queer of colour critique in the context of my research. Like the figure of the working-class, racialized sex worker, members of the Kiki community share similar intersecting identities that have become celebrated because of Kiki house culture rather than remain sources of shame and misfortune. In his introduction to No Tea, No Shade, Patrick E. Johnson (2016) notes that the "Black Queer Studies in the Millennium Conference held at the University of North Carolina at Chapel Hill in 2000 was a watershed moment" for its insistence on discussion of race within queer studies and discussions of sexuality in critical race studies (p. 2). Since 2000, Black Queer Studies has "come of age" (p. 1) as evidenced in the proliferation of anthologies devoted to the field and by the (slowly) increasing number of departments teaching the discipline in the social sciences. Within the field of Black Queer Studies is queer of colour critique, which arose from a need to expose the limitations of queer theory; namely, queer theory's reluctance and/or ambivalence towards addressing the interconnections between queer liberalism (Eng, 2010), sexuality, and other modes of 
difference such as race, ethnicity, citizenship, and gender.42 For example, David Eng (2010) notes that "queer liberalism marks an unsettling. . . attempt to reconcile radical political aspirations of queer theory's subjectless critique with the liberal demands for gay and lesbian US citizen-subjects petitioning for rights and recognition before the law" (p. 26). As a result, according to Eng (2010), with the "historical rise of queer liberalism" came the "forgetting of race" (p. 12).

Ferguson (2003) notes that queer of colour analysis "is a heterogeneous enterprise made up of women of colour feminism, materialist analysis, poststructuralist theory, and queer critique" (p. 149). Ferguson's queer of colour critique draws inspiration from women of colour praxis that links to the Combahee River Collective, which demonstrates the importance of considering interconnected, interlocking oppressions and mobilizing more multidimensional analysis of identity politics and social justice activism than previous feminist movements.43 Importantly, queer of colour analysis expands upon women of colour feminism by probing " racial, gender, and sexual practices [that] antagonize and/or conspire with the normative investments of nation-states and capital" (Ferguson, 2004, p.3). This alignment to femme-empowerment particularly for queers of colour is a fitting framework as Kiki culture, similarly, unabashedly celebrates the bodies of cis and trans women of colour.

\footnotetext{
42 Scholarship addressing the limitations of queer theory's subjectless critique include (but are in no way limited to): By José Esteban Muñoz’s Disidentifications (1999), David Eng's Racial Castration (2001), Martin Manalansan's Global Divas (2003), Patrick Johnson \& Mae Henderson's Black Queer Studies (2005), Gayatri Gopinath's Impossible Desires (2005), Jose Quiroga's Tropics of Desite (2000), Ann Stoler's Carnal Knowledge (2002).

43 Originally published in 1977 as "A Black Feminist Statement," The Combahee River Collective premised their mission statement on the realization "that the liberation of all oppressed peoples necessitates the destruction of the political-economic systems of capitalism and imperialism as well as patriarchy" (“Combahee River Collective," 1986, n.p).
} 
Queer of colour critique is also highly useful to this study as it attends to the ways in which the promotion of the heteronormative nuclear family of neoliberal Canada works against the laboriously assembling queer of colour kinship formation. Put in David Eng's words (2010), heteronormative family values "collaborates with a neoliberalism willfully blind to unequal structures of globalization and its increasingly international gendered division of labour" (p. 31). This collaboration of normative family structures and gendered labour practices makes for intense pressures against families of colour to produce productive (capital earning), gender-normative, heterosexual citizens. Through the critical lens of queer of colour critique, when these racialized off-spring fail to conform to these values, their lives depreciate in value. Illuminating this in relation to the study of Ballroom house culture within Jennie Livingston's 1991 Paris is Burning, Chandan Reddy (1998) contends that the ejection of queers of colour from birth homes is compounded by the exclusion of queers of colour from the 'home of the nation'. As Ferguson sums up, Reddy posits that "national culture constitutes itself against subjects of colour" (2004, p. 3). Since House culture anchors and enables sharing economies within Kiki culture, the study of kinship and queer alternative families in the nation-state of Canada is beholden to queer of colour theory.

\subsubsection{Critical whiteness studies}

As a guiding framework, critical whiteness studies are useful to this study in a number of ways. A crucial tenant of Critical whiteness studies (CWS) is the 'naming' of the power of whiteness and white racial privilege despite its universality and ability to operate invisibly (Dyer, 1998; Ferguson 1990). Eng's (2010) definition of whiteness is 
useful in the context of this research as it encompasses ways of thinking about urban place-making. Eng notes:

whiteness at various times signifies and is deployed as identity, status, and property, sometimes singularly, sometimes in tandem. Whiteness was, and continues to be, a valuable and exclusive property essential to the self-possession of the liberal individual, to the value of his or her reputation, and to the normative definitions of the enfrancished US citizen subject (2010, p. 46).

As Thomas Nakayama and Robert Krizek (1995) suggest, white racial construction as a social location has largely "assumed the position of an uninterrogated space" in American history (p. 293). The same can be said for Canadian history as seen in the exploration of whiteness as innocence (Razack, 2002), the 'problem' of Black people in Canada (Walcott, 2003), and the dangerous myth of the Great White [Canadian] North (Baldwin, Cameron, \& Kobayashi, 2010)44. In subtle and overt ways, my qualitative data has revealed the importance of naming whiteness and calling out white supremacy within Montréal 's Kiki scene. For example, my data collection has shown social media to be an effective tool through which white supremacy is policed and its actors are pushed out of this protective community.

\subsubsection{Whiteness as property: The project of queer of colour place-making}

Cheryl Harris (1993) tells readers about her grandmother's painful experience denying her Blackness and exploiting her 'white' features to obtain an office job in Chicago during the 1930s. As a “[B]lack person with white features," Harris's grandmother was not only passing as white in order to feed her family, but she was "trespassing" into the "white world" only because she "accepted the risk of self- 
annihilation" and self-denial as a means of survival (p. 1711). There is much to be learned from this personal retelling of her grandmother's crossing of what Frederick Douglass (1881) and W.E.B Du Bois (1903) called "the colour line," or the crossing of either formally or informally racially segregated spaces in the urban landscape. Crossing into the white world, even if temporarily, meant "gaining access to a whole set of public and private privileges that materially and permanently guaranteed basic subsistence needs" (p. 1713). White people have historically come to expect these public and private privileges. Over time, "American law has recognized a property interest in whiteness," which has been replicated across the border (p. 1713).

Understanding the predicaments of passing in the white world illuminates the precariousness of life for those automatically denied access to such privileged public space because of their visible minority status. As Roediger (2007) suggests, the material (economic) and social benefits of whiteness are often enjoyed at the expense of people of colour. Turning to my project, the economically viable urban centre of Montréal 's downtown can be read as 'inside the proverbial color line' - where property ownership is both directly and indirectly contingent on whiteness. Examining the premature closure of the immigrant owned community urban dance space 'Espace Sans Luxe' through the lens of critical race and whiteness theory reveals the compulsory obstacles facing queer communities of colour when it comes to finding safe space to assemble. 45 The participants in my study, all visible minorities, are subject to constant social and police surveillance when attempting to congregate for Kiki balls and performance practices.

45 Martin Manalansan's (2003) Global Divas is particularly useful in understanding the disparities between queer of colour spaces within white-dominated public queer space. 
Thus, analyzing the difficulty of obtaining rentable space in the city merits an investigation into how whiteness and white supremacy works to disempower and, quite literally, disenfranchise, queer and trans communities of colour.

\subsubsection{Hybridized theory: Queer Latinx performance studies \& queer worlds with an affective twist}

The use of participant observation merits a flexible analytical framework through which to understand the unspoken, often ritualistic dance performances viewed at a Kiki ball. Furthermore, turning to the literature on queer performance helps to explain the ways Kiki culture continually challenges Western understandings of gender and sexuality. In many ways, Kiki balls imitate what film and performance studies scholar Peggy Phelan (1993) calls the "theatricality of everyday life - a life which includes show girls, bangee boys, and business executives... this theatricality is soaked through with racial sexual, and class bias" (p. 99). Building upon performance studies with a focus on racialized subjectivities, Patrick E. Johnson (2003) notes that interdisciplinary performance studies takes up a number of "aesthetic, cultural, and social communicative events, interpretive practices, and critical methodologies" (p. 6).

Combining tenants of performance studies and queer of colour critique, Queer Latinx performance theory conceived of by José Esteban Muñoz $(1999,2003)$ provides a hopeful framework through which to view Kiki subculture. For Muñoz (2009), queer performance in all of its complexity is a "kernel of a potentiality that is transmitted to audiences ... [it] facilitates modes of belonging, especially minoritarian belonging" ( $p$. 98-99). In analyzing the performances of Carmelita Tropicana, Vaginal Davis, and the political camp of Jack Smith, Muñoz (1999) describes "the worldmaking power of 
disidentifactory performances," or the unique ability for "glitter transformed hackneyed orientalisms and tropical fantasies" to be re-conceived as "rich anti-normative treasure troves of queer possibility" in opposition to forced forms of performance by minoritarian subjects (p. ix.-x). To Muñoz, alternative Latina/o drag performers have the creative power to create imagined 'queer worlds', or the power of performance to establish "alternative views of the world" through ritualized theatricality or impromptu dance (p. 195). That being said, these same performers and other entertainers of colour are often subject to the "burden of liveness," or the hegemonic relegation of the minoritarian subject to a "forced performance of [live] Otherness" for the entertainment of the privileged (p. 187). Similar to Muñoz, Prosser (1998) and Halberstam (1998) argue that drag has the potential to simultaneously reproduce and reject cis(and)heteronormativity. Drawing on Muñoz's insightful frameworks, I will explore the queer (of colour) world-making potential of Kiki and Waacking house culture. Berlant and Warner (1998) suggest a queer world-making project occurs when non-heteronormative social groups structure and cultivate their own spaces of existence. A queer world is one that makes queerness, and/or gender non-conformity, desirable in its "unsystematised lines of acquaintance, projected horizons, typifying examples, alternative routes, blockages, [and] incommensurate geographies" (Berlant \& Warner, 1998, p. 558). Building upon this, Tara Atluri (2018) re-imagines a Black queer world-making discourse, which centres the experiences of Black people rather than white subjects. Like the outlandish Latinx drag performers, Kiki competitors have the power to create queer worlds whenever and wherever they assemble - whether they are wearing sweatpants and having a Kiki in a 
crowded apartment on a rainy Tuesday or are carefully costumed at the annual winter Kiki ball.

\subsubsection{Chicana feminism}

Since the late 1980s, Chicana feminist scholars, Chandra Talpade Mohanty (1987; 2003), Chela Sandoval (1991), and Inderpal Grewal (1994) have critiqued Western feminism for its Othering of 'Third world women' - those said to exist in the margins as uneducated, powerless victims at the mercy of their 'backwards' nation-states and the opposite gender. Gloria Anzaldúa’s (1987) foundational Chicana feminist text Borderlands/La Frontera is a semi-autobiographical collection of prose that mobilizes the concept of 'borders' (both physical and psychological) to explain the difficulties of cultural hybridity, traditional gender roles, the machismo of Chicano nationalism, and the impacts of racialized violence in bordered spaces. In similar fashion, the first participant interviewed for this study explains the difficulty in embodying two cultural identities simultaneously that seem to work in opposition to one another: self-identified dyke/lesbian and second-generation Latina. Chicana feminism will be a vital theoretical tool for unpacking this participant's relationship to her everyday gender expression and her gendered Ballroom parental role which subverts traditional notions of 'motherhood' and female categories related to Latina identity.

\subsection{Contributions to sexuality studies \& Key arguments}

This thesis contributes to critical sexuality studies research addressing performance-based activist forms of queer world-making for queer and gender nonconforming communities of colour. Moreover, Canadian Kiki and Waacking/Punking subculture makes important activist and scholarly contributions concerning sharing 
economies, queer of colour pedagogies and methodologies, and everyday anti-oppressive activism in the epoch of increasing pressures for fiscal austerity and queer necro-politics, which seeks to 'disappear' queer and trans people of colour.

Using participant observation and qualitative interviews with pioneering members of Montréal's Kiki scene and the pioneer of Waacking in Ottawa, and interpreting my findings through the theoretical lens of queer of colour theory, critical whiteness studies, and queer Latinx performance studies and Chicana feminism, I suggest that Kiki House subculture facilitates and encourages i) life-affirming, confidence building queer kinship bonds, (ii) alternative ways to simultaneously embody and celebrate non-normative gender expression with Blackness and Latinx identity, iii) non-capitalist economies of sharing (both material and affective) between members of this unique underground counterculture, and iv) hopeful strategies of everyday community activism and resilience to appropriative processes during economic insecurity and necropolitical turmoil.

My key findings reveal that Kiki House subculture facilitates and encourages lifeaffirming, confidence building queer kinship bonds by making both physical space and proverbial queer worlds in the urban landscape for queer and trans performers of colour. As learned by pioneers of both subcultures, the embodied intergenerational praxis of 'each one, teach one' are essential in passing on the traditions of these art-forms and dance styles. In contrast to traditional dance instruction, which takes place in a professional studio for the exchange of money, 'each one, teach one' connotes more experienced dancers in the scene informally training and mentoring less experienced ones free of monetary exchange. I argue that this non-capitalist investment (or unpaid 
mentorship) in the present strength and future of Kiki House culture coincides with its overall ethos of Kiki House culture.

As the data suggests, urban spaces are becoming increasingly gentrified and unwelcoming for working-class queer and trans people of colour. Geographically, four of five of my participants live and perform in Montréal, a complex and, at times, culturally contradictory urban site.46 Despite the odds, House parents within Kiki culture are working to carve out space for their children to collectively come together 'in the social'. The alternative queer worlds of Kiki subculture not only facilitate queer kinship, but they offer an investment in the sexual health and general well-being of its members as evidenced by my observations at a Kiki prevention ball in Montréal. My findings go on to reveal that the unique gender and familial systems within Kiki and Waacking House culture in Montréal and Ottawa facilitate the simultaneous embodiment of Blackness and Latinx identity with ones' preferred gender identity $-\mathrm{a}$ feat that was reported as being impossible or extremely difficult with respondents' biological families.

Furthermore, by examining sharing economies within Montréal's Kiki subculture and, to a lesser extent, Ottawa's Waacking mini-scene, I argue that material and affective forms of sharing work against the current culture of queer exceptionalism in Canada, which places importance on individual autonomy and 'respectable' forms of capitalbased thriving. Immaterial forms of sharing include trade-based skills and volunteerism, while material sharing includes clothing swaps, ride-sharing, upcycling, and thrifting between working-class members of these unique subcultures.

46 By culturally contradictory I refer to the discrepancies between Quebec's diverse racial and ethnic population base and its current ruling party Coalition Avenir Quebec (CAQ) led by Quebec Premier François Legault, who recently instituted the inherently racist CAQ's 'secular' (authoritarian) law, Bill 21. 
Lastly, the data reveals strategies of everyday community activism, resilience, and the shared culture of hope within these subcultures. As Robyn Maynard (2013) attests, "in addition to the everyday bravery of Black survival and care, there has been new life breathed into the Black radical imagination, spurring new forms of activism, art, and intellectual work" (p.15). I argue that Kiki and Waacking subcultures are vital parts of the current uprising in activist forms of the Black radical imagination in Canada. 


\section{Chapter 3: Kiki kinship, Gender, \& Embodied intergenerational praxis}

In his review of Marlon Bailey's essential ethnography Rinaldo Walcott (2016) sums up one of Bailey's central arguments: "queer family is real" (p. 321). The 'realness' or practical function of queer family in the Kiki scene varies person to person. This chapter articulates the significance of the queer alternative kinship structure to Kiki culture in the wider context of Ballroom house culture and specific to each of my participants based in Montréal. I argue the gender and familial systems within Kiki and Waacking House culture provide its members alternative ways to simultaneously embody Blackness, Latinx, and Asian identity in harmony with ones' preferred gender expression. Secondly, this chapter will explain how these performance subcultures have used the intervention of 'each one-teach' to pass down their subcultural artform from generation to generation.

\subsection{Queer kinship in Ballroom and Kiki subculture}

According to Bailey (2013), "family has been an important cauldron of resistance" historically for Black communities. In order to survive, Black families have drawn from a variety of kinship traditions, such as surrogacy and extended families" (p. 88). Kath Weston (1991) challenges the notion that queer kinship is somehow a fictious version of the dominant hetero/homonormative nuclear model. In fact, as Bailey echoes, queer kin often "expos[e] the fallacy of dominant family ideologies by doing the kin labor that many biological families fail to do" (Weston, 1991, p. 93-95). In this way, ball house culture undermines the heteronormative model of the nuclear family. Houses facilitate a sense of family, kinship, and support, especially for LGBTQ youth who typically "experience higher rates of victimization and discrimination" than their straight 
peers (Kubicek et. al., 2013, p. 3). For Bailey's interlocutors, house mothers and fathers provide guidance to those "who have been devalued and rejected by their blood families, religious institutions of their childhood, and society at large" (p. 93). Those in the Ballroom community often face an impossible dilemma within what Bailey (2013) calls their 'biohome': to hide their sexuality and gender conform in order to find belonging, or embrace their queer and gender-non-normativity, become estranged from their biofamily, and live without the resources a 'home' often (although not always) provides.

It is important to note that individuals face different circumstances ranging from complete estrangement from their biofamily to partial acceptance. In both cases, most approach both the Ballroom and the Kiki scene in search of belonging. In Montréal's Kiki scene not all participants were estranged or ejected from their birth family homes, but all of them felt they lacked familial support. For example, when asked about his House affiliation participant P3 prefaced his answer by explaining that he "didn't get kicked out" of his house when he was younger "even though it was hard" living with his birth parents. Reports P3:

They [my family] love me... but they will never support me, never understand me $100 \%$, and that's what you get in the ball scene: Unconditional acceptance and unconditional love... no judgement. I felt like I was belonging to something bigger than me. It's so important. For any human being. And that's what comes out in this era right now. That is what a house brings you.

In both the Ballroom and Kiki scenes, Houses are not based on biology or marriage. Rather, house mothers and fathers have platonic relationships, and with their children they "undertake a labour of kin to create an alternative social and community sphere through a reformation of kinship" (Bailey, p. 89). Bailey calls the efforts of kin labour 'house work', or the labour that "Ballroom members undertake to develop and maintain 
these family like units" (p. 80). House family life is not always utopic, much like biological families. With a tenor of humour, participant P3 states:

Don't be telling me that you're not shady with your sisters and brothers.. that's a lie! Like people are fucking evil with their siblings [laughs]. If someone from your community is shady to you.. like.. it's love! It's part of what a family is! This dynamic and complex familial love will be explored through the notion of 'housework' and affective labour.

\subsubsection{Kiki house-work}

According to my observations and interviews, 'house-work' is also vital to the sustainability of Kiki house families. This house-work comes in many forms and is often shouldered by Kiki house parents. Participant P2 mentioned one unique form of housework in the Kiki scene: "People help each other out. . like I know one of the mentors here, [name redacted], he is a hairdresser and sometimes before the ball he might help people do their hair and brings his own products and stuff to the kids." Unlike their paid jobs outside of the Kiki scene, this volunteer work is non-normatively gendered and involves affective and/or emotional labour. Some of this work includes preparing for Kiki balls, arranging practices, and offering support and encouragement to house children. Participant P4 describes the mechanics of preparing for a Montréal Pride Kiki ball:

I produced the whole ball - [sigh] so I had to be in conversations with all of them [visiting judges]. I figured out the budget and hotels and taxis and flights, in addition to performing in the ball and choosing the judging and teaching the 
classes and running sessions [pause]. God I mean most of that - like $95 \%$ of that is volunteer work.

Producing a large-scale Kiki ball requires planning, scheduling, and sacrificing one's time at the end of an exhausting work week to bring one's best to the ball. House parents often shoulder the majority of this work, which can be exhausting. When I asked about how organizing a large-scale ball felt, $\mathrm{P} 4$ enthusiastically answered the question almost before I was finished asking it:

It has been a real challenge! I think in part the work that I do voluntarily for the scene has definitely exhausted me and I do feel like I hit a few walls. I think I burnt out maybe more than once. And so now I'm treading slowly. It's exposing myself; it's a lot of emotional work.

When thinking about the comment of 'emotional work', it is useful to attend to the notion of emotional labour. According to Arlie Russell Hochschild (1983), emotional labour involves the "management of feeling to create a publicly observable facial and bodily display" of affect in accordance with ones' job requirements (p. 7). Although the participant described above is performing volunteerism, they are in fact describing emotional labour.

Despite the emotional toil, this participant also seemed encouraged and became animated when they spoke about noticing some house children taking on more roles and responsibilities in the scene:

While I was away there were a few balls and I saw that a group of kids did a rideshare down to Toronto to walk in the ball - that makes me very happy that that sort of stuff is starting to happen. Takes the pressure off one person, one parent, ya know what I'm saying? Part of the... the mothering is letting the children grow.

In this case, regardless of their status as 'children', they were encouraged to work together with one another, pool their resources, and make plans for themselves. This 
alternative familial support and queer of colour empowerment positions Kiki children to survive in a culture of intensifying neoliberal austerity - which places increased pressure on individuals to thrive economically with decreased need for natural social supports. Often thought of as a "kind of non-politics," 1980s Reagan-era neoliberalism is a "way of being reasonable and of promoting universally desirable forms of economic expansion and democratic government" (Duggan, 2003, p. 10). Promoting free market capitalism and hands-off style of governance, neoliberalism promotes a compulsive culture of "personal responsibility" (p. 12). As learned from my key interlocutors, unguided selfsufficiency is surely not a core value of Kiki culture in Montréal and there is no shame in relying on others.

In addition to this organizational and administrative house-work is affective labour. All 5 participants spoke about varying forms of affective and emotional labour associated with being a part of their Kiki House or Whacking community. I asked participant P4, pioneer and self-described Mother of the Kiki scene in Montréal, about their general responsibilities within the scene. Participant P4 notes the work they do:

There is a whole bunch of responsibility that I carry on my shoulders. I'm the person people turn to for support. The big thing about the Kiki scene is that. . . it was created in relation to community health and sexual health.. youth programs and bringing the community together. THAT [said with emphasis] in fact is why I'm interested in creating a scene here in Montréal.

Without a doubt there are incredible amounts of hands-on house-work, or affective labour (Hardt, 1999) involved in the building of such a scene. Even though they do not belong to a specific House family, also called being '007' or a free agent, this key interlocutor provides emotional and logistical support to the community they have worked so hard to cultivate. 


\subsubsection{Kiki mothering: "More like a cool gay aunt"}

Mothering is vital to Kiki House culture; so much so that the Kiki community in Montréal dedicated a whole ball to motherhood called 'A Mother's Kiki Ball' around Mother's Day in order to "pay homage to the nurturing efforts of female figures" in the lives of Kiki house members (“A Mother's Kiki Ball” 2019). At this Kiki ball, categories called for fake baby bumps, Mother Earth inspired looks, and a 'realness' category that celebrated working moms and dads. Similar to Ballroom culture, much of Kiki mothering is performed by biological males and gestures towards a "fetishistic femininity" which 'queers' the archetypal heteronormative notion of motherhood (p. 106). That being said, (typically queer) cis-women have been known to take on the role of 'mother' at the head of Kiki Houses. As learned from a video-recorded community town-hall called the "Beyond the Kiki panel” with leaders of Montréal's Ballroom and Kiki scene(s)47, Peru born Cuarta Baby is the Mother of the Kiki House of Benetton and founder of the Montréal Kiki Ballroom Alliance. She speaks to her roles as a house parent: "[My role is] taking care or sharing the knowledge that I have with other people and promoting Ballroom events. . . I can't just walk a ball I have to represent ("Beyond the Kiki Panel," 2019). Rather than just walk in a ball, she stands as a representative for her whole House in competition spaces. Cuarta Baby continues by describing her work as a form of emotional support for her children. In speaking about this affective labour, Cuarta Baby adds "women have to do this type of labour all the time without being thanked [another panelist shouts out "or acknowledged" and Cuarta Baby continues] yeah, or even acknowledged!" (“Beyond the Kiki Panel,” 2019). This Kiki House mother is speaking to

\footnotetext{
${ }_{47}$ Organized by Fierte Montréal and Mark Andrew Hamilton.
} 
the gendered nature of affective labour. Coining the term, Arlie R. Hochschild (1983)

describes emotional labour as the "induction or suppression" of affect in order to set others at ease.

In conversation with Ebony Magazine, the founding house mother of American Kiki, Aisha Diori (2012), described the essence of motherhood: "at their core, house mothers establish community, instill knowledge, shed tears, evoke laughter and at times go into their own pockets to help out those who are less fortunate" (Brock, para. 3). Unlike Ballroom culture, however, parental structures in Kiki culture do not necessarily mirror those of Ballroom House mothers (butch queens, femme queens, or women) and fathers (Butch queens, butches, or men) (Bailey, p. 92). The parental categories seem to be more fluid and everchanging. When I asked my first participant P1 about her role as a house parent, she sighed and took a pause to think. Participant P1 notes:

People keep asking me that! [chuckles]. So, me and this other person [name redacted], we co-founded it [our house], so they automatically assume that he is the father and I am the mother.. which in practice, or as a technicality, it would be true. But I look, or I guess we look at it as an alternative family structure. Which is like, not necessarily something that will be looked in. . . [pause]. . like, it doesn't really look well to all people, especially Toronto families. But it is just how families here are. Like if anything I'm more of a cool aunt and he is a gay uncle, you know what I mean?

With hesitation, P1 admits that her title of 'mother' just does not seem to fit. When she notes that it 'doesn't really look well' to people in Toronto's Ballroom scene, she means that the Kiki scene is forging its own configurations of parenting and co-parenting that do not necessarily conform to the gendered labour binaries of house mother/house father. In much of Ballroom culture, "mothering is socially configured domestic labour" performed by butch queens, femme queens, and sometimes cis-women (p. 106). 
In this example, self-described "cool gay aunt" participant P1 describes the scenes importance for her simultaneous expression of cultural heritage, gender nonconformity, and queer sexuality. When asked about what the scene means to her, P1 poses the rhetorical question: "how do I reconcile the fact that I have a specific racial and cultural background that at the same time is its own microcosm that has problems with... like.. non-heterosexuality?" Addressing their own quandary, the participant explains that "it's kinda like when you go to like a queer party... you can relate to it socially but then you go to a thing that is relevant to your culture but you cannot necessarily feel like you can be queer in that space." Before joining Kiki ball culture, the participant describes the pressures of expressing culturally contingent Latina gender norms:

I only knew what it felt like to perform gender within Latin American, like heteropatriarchal contexts.. so, like, I always felt like femininity was a prison imposed on me. And I didn't want to have things imposed on me just because of the gender that I was supposed to be.

As understood through a Chicana feminist lens, Kiki culture allows her to celebrate both identities simultaneously in an uninhibited, unregulated way. This participant's feelings about rigid gender norms and heterosexism calls to mind Gloria Anzaldúa's (1999) foundational text Borderlands/La Frontera. To "find herself," despite the fear of being abandoned by la raza (the culture), Anzaldúa had to "disengage from [her] family... to find [her] own intrinsic nature buried under the personality that had been imposed on [her]" (p. 20; p. 16). More recently, according to Nathália Araújo (2018), the Chicana lesbian "as a matter of survival and motivated by sexual impulses, struggles to surpass the passive role repression assigned to her and refuses to accept the heteronormative rule" (p.1). This participant expressed feelings of estrangement from both the larger queer community and her own Latin-Canadian culture as she never felt as 
though she fully fit in to either group. By the participant's own admission, it is Kiki House family culture that facilitates her subversion of the restrictive gender and sexuality roles assigned to her:

When I started going into umm.. most specifically vogue, I learned how to express femininity in a way that felt subversive and on my terms rather than gender expectations from my [birth] family and culture. It felt really liberating to feel like I could be feminine the way that I wanted it to be without the heteronormative pressures. It [Kiki] comes from a community of diasporic people that have to deal with culture in their households and also being queer. I feel that it's a legacy... I'm involved in it in a way that continues it...

In the example above, participant P1 spoke about being a part of something bigger - a

continued legacy. In writing about a new radical black politics, Cathy Cohen (2004)

explains that “. .. the reification of the nuclear family, the conformity to... informally

regulated gender roles and intimate sexual relations are but the tip of the normative moral super structure they [predominantly working-class queers of colour] confront daily" ( $\mathrm{p}$. 29). One example of many, this participant demonstrates that Kiki Houses are instrumental in upending the normative, culturally contingent 'super structures' in their lives that make it hard for them to feel like they belong.

\subsubsection{Intergenerational [grand]fathering across scenes}

As opposed to mothers in both the Ballroom and Kiki scene, the role of (grand)father is often hyper masculinized and undertaken by cis-men and gender-nonconforming gay women. During my participant observation session, the Legendary Grandfather Archie Burnett Ninja advised young Kikiers and audience members alike to put 'each one, teach one' into practice.48 As previously mentioned, 'each one, teach one'

48 This Kiki ball was held at Montréal LGBTQ+ Community Centre and organized by 3 key Kiki house parents and pioneers of the scene in conjunction with Aids Community Care Montréal (ACCM), REZO, and Jeunes Queer Youth (JQY). 
describes the way more experienced (often older) Kiki performers invest time training their younger Kiki counterparts without an exchange of money and often outside of traditional dance studio spaces. At this particular Kiki ball, and as witnessed in numerous Montréal-based Kiki ball live stream videos, judges ironically seem to take on an informal teaching role. This differs from the typical function of judges in the larger Ballroom scene, which is to score, chop, and only sometimes offer critique. It would be rare in the more competitive Ballroom scene for a judge to intervene in a category, pause to give advice, and give the walkers a second chance to 'bring it to the runway', or "to put forth the best presentation or performance" (Bailey, 2013, p. 253). In the Kiki scene, however, in addition to scoring each competitor and deciding whether they 'pass' by getting their tens, or, if they fail as indicated by getting 'chopped' 49, judges may pause during a runway category and offer advice or give instruction to performers - temporarily embodying a 'fatherly' or 'motherly' role. For example, in the middle of the 'Virgin Vogue' battle, Grandfather Ninja in his booming voice suddenly ordered the DJ to cut the music and took over the mic to speak to the two young competitors on stage. As the two rose from their ground poses with concerned looks on their faces, Ninja pointed at them and sternly said: "when you're on this floor, you live all of your life. [pause] You get it? [Loudly] We gunna do that shit again!" [crowd cheers] "Here is the deal. You're invested in this. When you show your life, show all of it. LET'S GO! [crowd cheers even louder] Give em' a hand!" Taking Ninja's instruction, which seemed to intuitively mean that the voguers needed to dance with more conviction and confidence, the voguers turned on 
their heels, heads held high, towards the end of the runway with renewed senses of conviction. They know they invested in this - they planned, they practiced, they created costumes and personas for the category they are competed in, and most of all they were willing to invest in the vulnerability of subjecting your artform to critique. The music began again and the voguers eagerly battled their category once more; this time, Ninja was finger snapping and shouting out "yes!" to the competitors as they subtly stole glances up at him, seeming to search for approval. This finger snapping was a physical signal to the young Kiki kids that their efforts to improve were courageous and worthy of praise.

The [grand] fathering here involved a modicum of 'tough love' and critical (if not jarring) intervention. While housemothers often 'nurture' through emotional labour, according to Bailey, "housefathers are guides" (p.106-107). To an extent, these familial roles follow "dominant [or heteronormative] family scripts," but they do so by 'flipping' or 'queering' the traditional gender roles ascribed to mother and father. Just like in the Ballroom community, the Kiki scene is "shaped by notions of fatherhood and masculinity in the outside world" (p. 110). In this case, critical yet kind encouragement in moments of failure translated to a new-found spark of energy in the Kikiers and it was clear they gained the confidence to 'try again' rather than admit to being defeated. Unlike mainstream Ballroom competitions where voguers rarely (if ever) get a chance to re-do their category on the runway, in this instance Montréal Kiki blurs the line between competition and instructive, coached dance performance. For a moment the voguers become house children listening to the advice of their grandfather, rather than simply competitors in a strict category being judged by a legendary grandfather from another 
city. After the winner was chosen for the virgin vogue battle and the music for the next category began to play, Grandfather Ninja signaled the two voguers to come close for more advice away from the microphones and eyes of the crowd. It was apparent to me that Ninja took his role as mentor, grandfather, and judge very seriously and he purposefully invested time and energy into each competitor who walked the three-and-ahalf-hour ball that evening.

\subsection{Situating Gender in Ballroom \& Kiki House culture}

My first participant (P1) was instrumental in outlining basic tenants of Kiki House culture and its nuanced gender roles in Montréal. In her words, "you cannot talk about Canadian Ballroom without talking about Toronto.” This participant reiterates this when speaking in a panel on the relationship between Toronto Ballroom and the emergence of the Kiki scene in Montréal, P1 notes:

Toronto is a big sis. Sometimes you need your big sis to beat you up [laughs]. I see Toronto as the gatekeepers. . . maintaining the essence of what Ballroom is. The walkers [in Toronto] give a lot of Black excellence. We need the people from Toronto's guidance. You cannot come with an entitled attitude into it. I like the tough love but I'm also from the third world, so yeah ("Beyond the Kiki Panel," 2019).

Twysted Miyake-Mugler (Father of the Kiki house of Siriano) echoes this and states that leaders in the larger Toronto Ballroom scene see the importance of mentorship scene-toscene because they once looked to New York for such mentorship and support. Twysted states "Speaking to 'being the big sis', that is something that we deliberately try to do... because we wanted that support when we were starting in Canada from New York, right" ("Beyond the Kiki Panel," 2019).

Returning to my interview with participant $\mathrm{P} 1$, in her experience the mainstream Ballroom scene in Toronto is "more... traditional and they have the gate keepers of the 
tradition. . . whatever happens in New York - like the rules and the same categories that they use there - they [those in the Toronto mainstream ball scene] are very respectful towards that." When this participant says 'tradition', she is referring to the traditions of Ballroom gender categories as they emerged from the 1970s and 1980s in New York. According to Bailey (2013), the gender system is linked to Ballroom members' "quotidian experiences in the larger society," and include six central categories that also describe elements of their sexuality: Butch Queens (gay men), Butches (female to male transgender), Femme Queens (male to female transgender), Butch Queens Up in Drag (gay men who perform in drag), men/trade (biological males who live as men and are non-gay identified), and women (biological females who live as women of any sexuality).

In these descriptions, Bailey notes the gender categories often "reflect the pervasive conflation of sex, gender, and sexuality in the broader society" (p. 31). The sex categories of male, female, and intersex within Ballroom culture are a result of "ongoing processes or activities as opposed to biological fact" and members of the scene often use drag or body modification to either transition genders in every aspect of their lives or temporarily assume a different gender for the purpose of the ball (p. 33). These identity categories are "malleable and mutable. . . and when it comes to sex, gender, and sexuality, most things are open, negotiable, and alterable" (p.34). Although Bailey reports privileging of cis-gender men and masculinity in the Ballroom tradition, "femme queens, women, and butches continue to challenge exclusionary practices and push against the boundaries and hierarchies that subvert them” (p. 48). Bailey's interlocuters' reported that their Ballroom gender expression does not always align with the gender identity they live in the outside world. Throughout this research, it was unclear whether or not 
cisgender men and forms of masculinity were held in higher regard than femme leaning gender roles within Montréal's Kiki scene. That being said, Kikiers' live in a heteropatriarchal society that indeed stigmatizes trans-femininity and gender nonconforming people of colour.

The carefully constructed gender categories in Ballroom subculture serve to illustrate how working class or poor ball members "contend with and navigate through the high risk of being victims of homophobic, femmephobic, and transphobic violence" (p.51). Furthermore, any examination of these 'traditional' Ballroom categories requires an interrogation into class and racial oppression. For example, passing as a biological female for a Femme Queen (or transgender woman) may be the difference between anything from obtaining employment (or not) to getting home safe at the end of the night (or not). In this way, the performance of gender and self-fashioning becomes a means of survival. Citing Jane Ward's notion of gender labour, Bailey calls this gender performance labour - "whereby the community creates, recognizes, and confers legitimacy on particular performances of gender and sexual identity" (p. 45). In opposition to Judith Butler's (1993) notion that drag "reinscribes the same norms that it purports to subvert," Bailey contends that the Ballroom gender systems:

offer far more cultural import because they reflect possibilities of reconstituting gender and sexual subjectivities, of reconfiguring gender and sexual roles and relations, and of creating ways to survive an often dangerously homophobic, transphobic, and femmephobic public sphere (p. 75).

Asserting that performing gender in Ballroom culture is more in line with Susan Stryker's contention that gender is what we do, not who we are.50 An example of 'doing gender' in 
the Ballroom scene is the criterion of 'realness'. The fundamental criteria of 'realness' is perhaps the most stable across Kiki and Ballroom culture across borders and has been over the last five-six decades (Bailey, 2013, p. 55). For Bailey, "to be real is to minimize or eliminate any sign of deviation from gender and sexual norms that are dominant in heteronormative society... [They] must embody the so-called markings of masculinity or femininity" (p. 58). Realness categories break down further to mimic heteronormative modes of being. For example, the executive realness category would require one to "to perform heteronormasculinity for 'Wall Street,' to be seen as a gender normative businessman" (p. 59).

The realness category as described by Bailey above closely mirrors that of the category within Kiki culture and serves similar functions with regards to gender expression. In speaking about the realness category within Ballroom culture, however, participant P1 notes that "Ballroom [as opposed to Kiki] is very rigid in terms of gender." P1 likened the gender categories in Toronto to actors auditioning for a role:

...you have to play that role, which has certain requirements. Like if you're doing realness as a male figure you have to pass as a male. . if you're a guy that's queer and you're walking straightness than you have to look like a straight guy. And if you're a trans man that is trying to look like a cis guy walking realness than you need to look like a cis guy.

Addressing the nature of these narrowly defined gender categories, P1 notes "it's not that it [Ballroom] is less accepting of those identities that are more fluid, it is just that you are supposed to sell a role... it's just like the thing they have to deliver, its limited in the category." Participant P1 goes on to note that:

I wouldn't say that mainstream ball is like necessarily a gender queer space or something, I would say it is a space that is full of queer people. . . So it's not like it's an unaccepting place for that [gender fluidity], it's just like, in practice, in the 
competition aspect of it, it is definitely more conventional. But in the Kiki scene there is definitely more of a range.

In Montréal's Kiki culture, members have a 'Ballroom gender' which may in fact differ from their everyday gender identity. Additionally, the city's Kiki balls often have many 'open to all' categories in which competitors can perform gender according to two general, subjective categories: Male figures (MF) which refers to butch queens, 'butches', and trans men and Female figures (FF), or drag queens and femme queens (or trans women). At the 'Gasolina Kiki Ball', the realness category effect required male and female figures to dress like a "Latin urban artist." Examples included JLo and Cardi B for FFs and Bad bunny or Daddy Yankee for the MFs. According to P1, compared to the Toronto scene, "Montréal tries to push the envelope a little bit. They [Toronto and Montréal] balance each other out in a way." Participant P1 states that "the Kiki scene is a little bit more open to gender fluidity" as noted in their inclusion of gender non-binary categories. Participant P3 confirms this notion of gender flux throughout the Kiki scene when stating: "I see Kiki scene more as a local scene. . . it is more about the youth and the new generation, what they can bring, how they can bring gender" whereas in the mainstream ball scene:

... formal rules are unbreakable in the mainstream scene. Even though it is 'LGBT of colour', there is still quite a lot of like umm.. how do you say hesitations about gender. In the mainstream scene if you want to walk as a woman - let's say best dressed - you have to wear a purse and stuff like that. The rules are unbreakable. But in the Kiki scene - yeah it's really not traditional. You get to create new rules and new categories and make more space for other people. And it is less stressful too.

One of these categories P3 is referring to is the category of 'Best Dressed - Non-Binary', which was described on a Facebook event and came with a clarifying note to address recent controversies with the category: 
Ballroom categories are structured in the pursuit of passability and are binary by design. As a result a non-binary aesthetic has to be androgynous to distinguish itself. Once again this is not to say that being non-binary hinges on androgynous expression but it is necessary within the context of Ballroom at this stage.

Therefore one walking this category must pass as neither-male-nor-female-born, much like femme queens must pass for cisgender women and butch queens must pass off as straight men in their respective categories ("Party Monster: A Halloween Mini Kiki Vogue Ball,” 2019).

Participant P3 noted some issues judging the new category as few in the scene raised the question "does that mean that... [unintelligible] a cis-woman or a cis-man are not allowed to walk..? It's hard to judge.. uhhh! It's so very blurry.” According to participant P3, a gender non-binary identified competitor walked in the Sex Sirens category under the 'gender non-binary' gender label. As P3 describes it, "basically the non-binary person got mad because they lost against a cis-man. Yeah so it was a little dramatic because the person was like 'and I lost. . it was about gender.” Although participant P3 notes that "we still have work to do with these types of categories," everyone at the ball was said to respect the judges' ruling as "the most important thing is about the performance. Like, personally, the non-binary person wasn't selling it enough and that is why they lost. It wasn't like, 'oh you're non-binary.. nah nah" it's like, 'no, you didn’t sell it enough!' you have to kill it."

\subsection{1 'Waacking' through gender norms}

Although contemporary Waacking subculture is also influenced by dominant gender norms, my Waacking participant P5 successfully 'queers' the traditional female gender norms taken up by cis-women in the scene. The original Punking scene was dominated by cis-gay-men, but since the 1990s, with the disappearance of most [male] progenitors during the early AIDS crisis," (Bragin, 2014, p. 64) "contemporary Waacking is most widely practiced by non-Black, cisgender females in transnational hip-hop/street- 
dance communities" (p. 63). This is the case for my Waacking participant as she identifies as a straight Filipina cis-woman. In our interview, however, P5 noted that her gender expression does not align with the majority of female Waackers in the scene who typically wear femininely coded clothing like crop-tops or dresses that are meant to mimic Disney characters like Cinderella. P5 describes a situation where a fellow competitor is shocked to learn she is about to compete in a Waacking category. Participant P5 states,

I don't dress up like Cinderella in a big dress and things like that - a lot of people do and that's what 'the look' [makes air quotations] is. But for me, [tugs on own over-sized tee-shirt] I wear basketball jersey's and people are like - 'oh are you performing?!' and I'm like 'yeah' and they are like "oh you are wearing this and that" And I'm like - "yeah I wear baggy clothes all the time!" I'm not trying to cover up I'm trying to just be comfortable in who I am.

In this case, the dominant scripts of femininity that are reproduced in Waacking subculture do not facilitate the fluid expression of P5's gender. In fact, she diverts from the hyper-feminine to 'be comfortable in who [she is]' whilst performing. P5 goes on to note what the showcasing of her atypical gender expression in Waacking subculture does for her affectively:

Growing up I wasn't that confident. I wasn't 'out there' and over-the-top so it's really created a confidence in my dancing and style - and being authentic. Like, being able to be confident in my own skin and wear these things... and if people are going to judge you, so what! I feel like I have become the best version of myself [said with intensity]. Through the waacking and street dancing club scene - knowing you can dance in front of people as who you are just gives me confidence! [smiles fondly]

The 'feeling' of performing in public as the 'best version' of herself gives participant P5 confidence and autonomy. The notion of expressing the self through clothing and fashion style runs parallel to the Ballroom scene. As Bailey (2013) writes, "expressing performative identities through fashion is an integral part of this culture" also known as a 
form of fashioning the self (p. 32). In a way, then, the public affirmation and process of performing the 'spectacle' of Waacking does in fact facilitate this participant's (P5) sense of gender comfortability and gender transgression.

\subsection{Embodied intergenerational praxis}

Understanding the mechanisms with which new generations are taught their performance form by more experienced and knowledgeable dancers and/or mentors helps elucidate my finding on the value of embodied intergenerational praxis in Kiki culture. In this spirit of 'each one, teach one", these two mentors and instructors emphasized their passion for teaching their performance form outside of their existing (paid) dance teaching relationships and in a more familial 'Kiki' context. Although participant P3 and P4 teach vogue classes to both Kiki ball members and members of the public and monetary transactions occur, which is not a praxis based on 'each one - teach one', histories of ball culture are not forgotten as both participants report incorporating Ballroom history or "Ballroom 101" into each class. For example, in classes with dancers new to the scene, participant P4 describes the origins of Ballroom in New York and speaks to the importance of balls as "created in relation to community health and sexual health youth programs and bringing the community together." 51 For P4, teaching this "sacred history" to members of the public interested in the form is a task they take "very seriously" to avoid cultural consumption of Ballroom culture. P4 notes that having these conversations:

... is why I am interested in creating a scene here in Montréal. It's not just the social aspect - I'm very much not focused on the competition - it's much more about the focus on the community and sexual health and education and kinship and family. That [said with emphasis] is my purpose as a pioneer... to create a

51 This argument is fully realized in the section on the traditions of radical Black activism in Chapter 3. 
space for LGBTQ youth and in particular for queer youth of colour and other immigrants, other ethnicities.

When speaking about what drew them into their role as teacher and pioneer of Kiki in Montréal, participant P4 notes:

The way that I think of leading is that I am there to lead and take responsibility and to do work for the community but I'm also there to teach them how to do it themselves, so the mentoring actually happens there - so I will see people that have incredible potential and I will foster, you know, cultivate their interest. And I see their talent and I try to encourage that.

Despite being paid for teaching vogue sessions throughout the year, the overwhelming majority of the teaching is volunteer work. P4 states, "I have been doing a ton of work for free voluntarily for over a year and a half - not to mention all of the years teaching. This [Kiki sub-culture] doesn't live and die by me, you know? I definitely encourage people to take the reins and schedule their own events." For this participant, part of the teaching is encouraging students to embrace the culture and share it with others. This teaching strategy is community oriented and challenges the individualism that can occur when activists fancy themselves 'the movement' or certainly indispensable to it.

Similarly, when I asked self-identified Black cis-gender gay man P3 about his role as a Kiki House parent in Montréal, he stated: 'I don't consider myself a 'teacher' [said with emphasis] cause I'm learning when I'm explaining the moves.. I think of it more like, I'm a friend, I'm a supporter." Here it becomes clear that the informal teaching process is a mutually beneficial, interactive transaction in the Kiki scene. For P3, the act of 'teaching one' effectively also allows him to simultaneously refine his own movements.

As Bailey (2013) indicates, there are myriad teaching and learning transactions between house parents and their children within American Ballroom culture: from "how 
to don fashionable garments" in various gender categories to how to engage in safer sex strategies through HIV/AIDS Prevention balls (p. 48). While this remains true in Kiki subculture, as indicated by P3, house parents may also simultaneously consider themselves students (or children) of their artform. As P3 continued to speak about his role as teacher within the scene, he noted that: “sometimes I think I'm still a kid myself! I'm a friend first, I'm not your parent. That's too hard of a job [laughs]. I'm still a good listener, I can still give you advice. . . just listen to your problems like I'm really open to that." Rather than take up the task of being a full parent, P3 offers the support that is most realistic for him as a young person. In this way, parental teaching roles are more flexible in Kiki house culture. In this way, queer kinship teaching roles are somewhat nonhierarchical (in comparison to the larger commercial Ballroom scene) and certainly mutually beneficial.

\subsubsection{Pedagogical tactics: Whacking subculture in Ottawa}

Viktor Manoel is known as the last remaining survivor of the original 'legendary' punkers (Bragin, 2014). According to Bragin, many of the teachers and creators of this subculture died during the height of the AIDS epidemic, leaving few to pass on the tradition to younger generations of would-be punkers. Manoel understands the impact of this pedagogical imperative and passes on his radical dance tradition by continuing to teach and guest lecture about Waacking history across the United States and internationally. Marking his first teaching session in Canada, Manoel and fellow vogue Legend New York's Grandfather Archie Burnett taught a weekend dance workshop and informational panel discussion at a Waacking conference in Montréal in March, 2019. Host of the event and fellow contemporary dancer Axelle Munezero describes it as a 
"weekend of knowledge. . . with the only [whacking] pioneer still alive" (Asymmetry, 2019). The Facebook images of the intimate panel discussion depict eager young dancers scribbling down notes and listening intently as Manoel and Burnett share insight on the origins of their craft. Manoel is quoted on the event page stating, "As an OG of punking/whacking, it is my responsibility to unleash the expressing of beauty from ugly and creating ART from your pain, and guiding you with the trust you give me" [sic] (Asymmetry). In a sense, this community organized Waacking dance workshop and panel discussion harkens to pedagogical processes of 'each one, teach one'.

While acknowledging that only one of my participants engaged in Whacking performance culture, she did so in a way that immeasurably demonstrates the values of 'each one, teach one'. Participant P5, Filipina cis-gender woman and straight LGBTQ ally began dancing competitive jazz, tap, and ballet around age seven. As a secondgeneration Asian girl, P5 often felt out of place in a dance class full of middle-class white girls. Born to immigrant parents "trying to start a life in Canada," dance was always a large expense; coupled with the isolation and feelings of "not belonging in dance studios", P5 quit ballet altogether in search of something else. Around age fourteen, along with playing basketball P5 reports "getting interested in street dance culture" - watching music videos and mimicking hip hop artists' style of dance. In 2010 or 2011, P5 found waacking culture by taking classes in Montréal with "people who have learned from the originators - so third generation waackers." Learning the history from these Waackers inspired P5 to do her own research on the performance form, and during our interview she provided me with a very helpful history of the subculture. Around 2012-2013 P5 felt comfortable identifying as a Waacker, but she was frustrated with having to travel to 
different cities to hone her performance form. So, in 2014, P5 starting teaching Waacking classes and formed an Ottawa based online Waacking social networking "hub" in order to communicate and organize with other dancers. Currently P5 runs under her own dance label and organizes informal Waacking battles around the city in public spaces (which will be explored in the place-making section to follow).

When I asked about her teaching style, and what teaching brings to her life, P5 noted that a lot of her first classes were free and held at a University campus in Ottawa. Reports P5, "some [classes] you had to pay - because I have to eat," but mostly "there is no financial benefit to it." For P5, teaching was more about "the positive impact that goes towards kids of colour - women - LGBTQ folks, immigrants - like we are part of that." The demographic of her classes are mixed race youth and young adults - mostly females - all who have the history of Waacking culture imparted on them alongside learning the moves. States P5, "I may not be LGBTQ, but I'm an ally and immigrant and I want to empower young women in dance.” In the past, P5 has been hired by dance studios to teach classes to younger dancers aged 11-13. In these cases, she reports "it's kind of hard to impart this history on them - but you also tell them the negative social context and reword it for kids and speak to the generation and try to educate them without scaring them. The context has to be appropriate." P5 was adamant about not stealing from the culture and feels it is important to give credit where it is due.

As evidenced in this chapter, Kiki house parents and their children are performing labour to carve out space collectively by coming together 'in the social' (to borrow House Father Ninja's turn of phrase). Additionally, queer kinship is vital to Kiki and Waacking subcultures for a myriad of reasons. Furthermore, 'each one, teach one' is a unifying 
ethos of care within both performance subcultures. Queer alternative kinship and the unique embodied intergenerational praxis of 'each one, teach one' within both scenes enable processes of alternative affective and sharing economies, which make lifeaffirming, queer worlds possible. 


\section{Chapter 4: Space \& Place-making, Sharing Economies \& Affective labour, \& Performance activism}

The strength of queer alternative familial relations and kinship within Kiki and Waacking subcultures enables other life-affirming processes to be explored in this chapter. As members of Montréal's Kiki subculture and Ottawa's Waacking scene fight to eke out physical space to create queer worlds in cities that have become increasingly hostile to working-class queer and trans people of colour, they create sharing economies that constitute the queer worldmaking practices that make life possible. By exploring strategies of everyday community activism and the shared cultures of hope within these subcultures, it becomes evident that their affective labours 'clap-back' to necropolitical forces that would have their members 'disappeared' in the nation state of Canada.

\subsection{Queer of colour place-making \& world-making}

Understanding social dynamics in any Canadian city invites a 'remembering' of local histories of policing and criminalizing racialized, classed, queer and gender nonconforming subjects (Tedesco \& Bagelman, 2017). In this section I explore the processes and impact of gentrification and white supremacy on working-class QTBIPOC populations. With this context in mind, I argue that Kiki and Waacking performance subcultures perform the (near) impossible task of cultivating 'space' (local place-making) for themselves in the city, which results in life-affirming queer world-making practices.

Gentrification and the privileging of white citizen-subjects negatively impacts working class QTBIPOC people living in Canadian cities. According to Catherine Nash (2013), younger generations of primarily white, cis-gender, middle-class, gays "are experiencing themselves as sexual and gendered beings in historical and geographical 
circumstances that are completely different from the LGBT generations that went before" (p. 250). Echoing this, Amin Ghaziani (2014) cites numerous causes for gentrification in gaybourhoods such as "a dramatic increase in societal acceptance of homosexuality, ramped-up urban revitalization efforts, an influx of straight people, and casual disclosures by gays and lesbians that they feel safe living pretty much anywhere in the city" (p. 4). Working-class trans people of colour, however, may not share these sentiments. As gaybourhoods gentrify, they have been considered "space[s] of whiteness" (Brown, 2013) and are often "critiqued as commodified spaces that serve mostly upper- and middle-class patrons" (Lewis, 2013). For example, Becki Ross and Jamie-Lee Hamilton (2018) note that "under the guise of 'revitalization', settler capitalist profiteering across Vancouver's core has intensified," which has resulted in impossibly high apartment rental rates and "only a handful of queer clubs, community spaces, and cafes bravely hang on against the levelling march of gentrification" in Vancouver's West End (p. 10).52

Similarly, the gentrification of the Church-Wellesley gay village in Toronto has significant impacts on the community who once collectively gathered there. Simon Rosser, West, and Weinmeyer (2008) argue that structural changes in gay Villages, including a decline in concentration and social cohesiveness, has serious implications for planning HIV prevention, intervention and treatment services. The 2005 demolition of the infamous steps53 leading up to Second-Cup on Church and Wellesley further demonstrates how affluent, white citizen-subjects are welcomed into the public fold while

52 Jamie Lee Hamilton worked in Vancouver's club scene as a 'gender illusionist', one of the only legal jobs for Two-Spirit transsexual women at the time.

53 The Second Cup Steps were "a [public] haunt for various subcultures," especially for "Toronto-area gays of the 1980s and 1990s" (Micallef, 2017). 
others are seen as threats to it. QTBIPOC youth gathered at The Steps "when there was nowhere else to go, because planners, politicians, and business owners were openly reserving the [gay] village for neoliberal white gay consumer citizens" (Haritaworn, Moussa, \& Ware, 2018, p. 7). Self-identified poor, working-class writer and community organizer, Asam Ahmad (2018) marks the removal of the steps as "the final sign that gentrification was full-blown and in effect" in their gay village (p. 126). Ironically, Micallef (2017) points out that "cities try so hard for this kind of organic community, but then when it exists, there's a contradictory urge to move it along down the sidewalk" (n.p). This contradiction is by design and a long-standing method of controlling undesirable citizens, such as young people of colour with no fixed address in urban spaces meant for the comfort and safety of middle-upper class 'productive' citizens. These capitalist investments in punitive surveillance, what Sarah Lamble (2013) would call "queer investments in punishment," threaten the existence of queers socially constructed as 'racialized' and economically marred by poverty - the very community that gay neighborhoods once served (Spade, 2011).

Anti-black racism and racial profiling are not just rampant in the police forces, but white civilians continue to police black life (Maynard, 2017) in nefarious ways in spite of Canada's deceiving reputation as a multicultural and inclusive country.54 According to journalist P.R Lockhart (2018), 'living while Black' is a catch phrase to describe “the myriad ways black people are viewed with suspicion, profiled, and threatened" in public spaces (para. 7). Whether it is a Black child trying to sell bottled water in her own

54 See Himani Bannerji's (2000) The dark side of the nation: Essays on multiculturalism, nationalism and gender for a critique of the development of Canada's official multiculturalism policy. 
neighborhood on a hot day, or a group of friends trying to bar-b-que in a public park, frantic calls to police from 'concerned' (white) residents illustrates the ways people of colour have been continually forced to justify their existence in public life (Lockhart, 2017, para. 6). Pioneer of the Kiki scene in Montréal, non-binary Latinx participant P4 pushes back against 'living while Black' when stating this of their teaching method: "I teach this in my classes: you are not helping anybody by remaining meek and hidden." Participant P4 deters Kiki members from remaining "meek and hidden" despite racebased violence and hostility, transphobia, homophobia, and societal pressures to 'disappear' themselves rather than assert their racialized bodies. bell hooks's (1992) commentary on the complexities of Black visibility and race representation becomes particularly salient here - especially her insistence on loving ones' Blackness in a cultural that cannibalizes African American culture. hooks (1992) notes that loving ones' Blackness is an act of political resistance within a (white) pop culture that has exoticized, commodified, and appropriated Blackness. In this context, by teaching their students to refuse remaining meek and hidden, Kiki pioneer P4 is teaching members of the subculture to publicly affirm that Black and Latinx life matters. Within Canada's sordid, ongoing history of anti-Black racism and exclusionary politics of homonationalism, P4's insistence on life-affirming practices is vital as it encourages the celebration of Blackness and Latinx identity and encourages bodies of colour in the Kiki scene to claim spaces in valorizing ways.

\subsection{Creating 'queer of colour worlds' despite the odds}

Although gentrification has impacted the Kiki community in Montréal significantly, they have managed to create 'queer life-worlds' to facilitate belonging. The 
'by design' nature of white gentrification described above has led to the premature closure of an important community-owned and operated safe space for Kikiers' of colour in Montréal. Epitomizing what constitutes service to her community, Axelle "Ebony" Munezero came to Canada as a refugee and claims that street dance helped her "find a space" in her landed city of Montréal (Indongo, 2017). With community support and funding from the Conseil des arts et des lettres du Quebec's (CALQ) Concertation and Innovation program, Munezero turned the metaphorical idea of found space and belonging into a physical location - a converted apartment above Amherst Street Bar in Montréal's gay village for hip hop dancers, break dancers, whackers, and voguers to meet and uninhibitedly express themselves creatively (Indongo, para. 1). Appropriately named for its cozy, casual, and 'second-home' appeal, for a minimal yearly fee Espace Sans Luxe (Space without Luxury) offered members the chance to take year-round informal dance sessions "where some dancers play host — not dance teacher — and you don't go to class: you come to train. .., share your skills, to exchange ideas, and to be in a place where you know you belong." (Indongo, para. 4).

During the recruitment phase, the moment I entered the space I felt as though I was entering into someone's home. I had interrupted a dance battle, and the handful of people in the space all paused to note my presence. Although I was not the only white person in the space, I could sense my white body was in a space not made for 'my comfort' - like all other public spaces I had navigated that day in the city. As I was welcomed into the space, I noticed the walls were lined with framed photos of dancers and community information boards instead of the standard floor-to-ceiling mirrors used in traditional dance studios. I walked into the kitchen and was offered a place at the table 
while a group of folks laughed and smoked cigarettes on the fire escape. Speaking to this familial feel, Munezero notes that Espace "is a new kind of cipher, where the battle element of street dance is left outside [, while] inside it's about community learning" (Indongo, para. 4-5).55 The 'feeling' of the space reflected this, as the anonymity and speed of city life seemed to dissolve into a humble place of familiarity.

Unfortunately, the rented Espace closed prematurely in November 2018 due to the need for "major [building] renovations for an indefinite period because of damage to its structure and foundation" and the cancelation of the CALQ Concertation and Innovation program funding (Munezero, 2018, para. 2). Without the financial support of the CALQ, Munezero writes that moving costs and rent for another space is too exorbitant (2018, para. 3). But the loss of this space did not deter regularly scheduled vogue sessions made evident from their Facebook group 'Vogue Montréal and Ballroom Community'. This resilient subculture found rentable space in a nearby LGBTQ community centre where they now charge a $\$ 1.00$ donation per vogue practice session. The church-turnedcommunity space also hosted the HIV/AIDS prevention ball 'Let's talk about sex' in March 2019 and has plans for 'HIV 101 workshops' combined with Kiki vogue sessions (also at the affordable cost of $\$ 1.00 /$ session).

Being pushed out of the gay village in Montréal for the reasons described above illustrates how queer and trans people of colour involved in Kiki culture are subject to acts that contribute to what Syrus Marcus Ware (2019) calls a sense of "un-belonging." Ware asserts that "as marginalized people, we feel this sense of un-belonging, aware of 
our unintelligibility to the masses when we leave our homes and encounter the state in all its forms. This state, and its people. . s seem hell-bent on the eradication of our people through a slow and persistent genocide" (p. 23). Even the temporary use of safe rented space is invaluable to the Kiki community as places for queer people of colour to congregate are few and far between (Tanovich, 2006). As evidenced, despite this 'unbelonging' the Kiki community continues to come together and create pockets of space for themselves to express alternative styles of familial belonging.

These pockets of space, temporary though they may be, can be thought of as 'queer life-worlds'. Far from permanent or even longstanding, like some of the more commercial gay bars filled with tourists lining Montréal's gay village, these humble spaces are made special because of those who inhabit them. They centre 'queerness' and promote the pleasure-making of the 'racialized' Other. As Fiona Buckland (2002) notes, these spaces are "determined by the moving participant. The participant actively creat $[\mathrm{es}] .$. the experience, rather than being its passive consumer" (p. 61). The queer life-worlds they create enable members to "fashion themselves and realize their imaginative possibilities through dress, bearing, social interactions, and dance" (Buckland, 2002, p. 36). These descriptions are fitting for the dancers of Espace and those I witnessed in the Kiki community who actively create their own experiences by working hard to carve out space in the gentrified city.

\subsection{1 'Queering' city hall through improvisational Waacking}

Waacking leader participant P5 confronted these same difficulties in acquiring safe and affordable space to congregate for dance practices and battles in Ottawa. As discussed in the previous chapter, self-identified as the "only active female Filipino Street 
Dancer in the Ottawa dance community" participant P5 started Ottawa's first ever Waacking group. When she first began organizing dance battles and practices, she used a common area at the University she attended. After graduating from University, which meant the space was no longer accessible, she described "finding space" and raising funds as two of her biggest challenges in growing the Waacking scene in Ottawa. With creativity and hard work applying for micro-grant(s) offered by the city of Ottawa, this participant expanded Waacking by adding other forms of related improvised social dance such as breakin', house, hip-hop, and locking.

By the summer of 2019, P5 and her dance crew were hosting monthly dance battles with small cash prizes in various public spaces around Ottawa. Known as 'Th3rdFridays' (because the competitions were held on the evening of the third Friday in each month), these battles drew all-ages crowds with mixed demographics. One such battle was held in a community room within Ottawa City Hall. The impressively tall ceilings, large windows, and amplified sound system made for an unlikely and decadent location for an impromptu social dance battle. The space was typically used for various city council related meetings and smaller government-funded events. The impact of this contrast was a proverbial 'queering' of the space.

In a similar way, my outdoor Waacking participant observation session was held on a summer evening on the lawn of Ottawa City Hall (known as Lisgar field). The wellmanicured public park in front of the impressive City hall building was adorned with large City of Ottawa and Canada flags. The normally formal government-funded space was 'interrupted' with outdoor dancing on a portable dance floor and disco-esque music complete with battle commentary. As the crowd slowly grew the first row of spectators 
sat down on the grass surrounding the temporary dance floor. I stood in order to move freely and ensure my view was unobstructed. Similar to Kiki subculture, the commentator read the competitors' names and indicated there were dancers from surrounding cities such as Montréal. As the battle continued, I noticed the crowd was slightly more subdued than the Kiki crowds I had previously witnessed. That being said, spectators dressed in various sports jerseys and street wear mildly cheered dancers on by clapping and whistling. Perhaps due to the location, the battle also drew crowds of what I perceived to be tourists visiting parliament and surrounding areas. These curious spectators stood out in contrast to the seasoned dancers who moved and swayed with the music and became animated at impressive poses and fast movements. As the sun went down below the hill and each category concluded, the winners gathered for a group picture to be posted on the group's Instagram page. Winners brimmed with pride as they held up their 'loot' bags and struck dynamic poses with Ottawa City Hall looming large in the background.

What stood out in this participant observation session was the existence of what I will call opposite or contrary forces. Quiet tourists and white families with strollers stood next to animated dancers of colour who shouted out to those battling in the middle of the cypher. The humble temporary dance floor made of particle board marked with tape and sneaker scuffs sat atop the perfectly manicured lawn of City hall. Because of this lively community-organized battle, the typically 'formal' white-dominated space became temporarily 'queered'. Because power works in subtle ways, it bears noting that this mixed-street dance battle scene stands in stark contrast to the organized Kiki' balls I witnessed in Montréal, which were held in urban sites far removed from dominant white culture (such as rented apartments turned into community dance spaces). Although this 
participant's dance crew was 'endorsed' by the city because they were granted use of their spaces for free, they mobilized this endorsement to build community visibility for their performance scenes and temporarily solved their challenge in finding space to gather for battles. According to Edward Said (2000), geography is socially constructed and "invented histories" can be thrust upon historical sites to re-orient their meaning in accordance to dominant culture (p. 180). Said (2000) explains that "geography can be manipulated, invented, [and] characterized quite apart from a site's merely physical reality" (p. 180). In relation to this participant observation session, the government building adorned with Canadian flags and meticulously manicured green space connotes Canadian nationalism despite the geographical sites' historical reality of being built on stolen, unceded Algonquin territory. Furthering this, when the motley crew of Waackers and break-dancers temporarily occupied Ottawa city hall its geographical 'memory' is masked in a way that reorients the spectator's thinking. The result of which is a fleeting moment of queer world-making for the dancers of colour that purposefully take up space there.

\subsubsection{Contending with 'white habits' in Kiki Culture}

Based upon my limited interactions and observations, whiteness does not 'hide' in Kiki culture as it does in larger Canadian society. To explain this, I find Sara Ahmed's (2007) framing of whiteness as a form of habit useful. According to Ahmed (2007), white bodies “. . . do not get 'stressed' in their encounters with objects or others, as their whiteness 'goes unnoticed'... white bodies do not have to face their whiteness"' as a rule - or, “... as a habit” (p. 156). As observed from participant observation sessions and Kiki ball videos, in Montréal's Kiki subculture people of colour, Latinx, Black, and/or 
Asian people 'outnumber' white-passing people - albeit not by exorbitant amounts. Regardless of whether or not white Kiki ball performers and spectators 'outnumber' any other races, white bodies are not the central focus in Kiki culture as they are in the rest of Canadian society. This may be disorienting to white people used to being comfortable in majority white public spaces coming into the Kiki scene as both spectators and as performers. Ahmed explains this: "they [white bodies] are not orientated 'towards' it [their own whiteness], and this 'not' is what allows whiteness to cohere, as that which bodies are orientated around" (p. 156). Participant P1 offers commentary that speaks to the orientation and habits of white bodies in the Kiki scene. I had to pause my interview with P1 midway through as the Patisserie we were located in was closing. As we packed up our things we continued to speak about why I was doing the research. I confessed that I had grappled with my role as a white outsider researcher, and as I began recording again P1 passionately stated:

I wish, like, more white people in the scene would ask themselves that question about their presence in Ballroom. A lot of people that are there do not question their presence [said with frustration]. But that is just my opinion. And sometimes they weed themselves out because what the judges are looking for in the categories are very... in sync with [pauses] the cultural realities, like, racial features of Black and Latino people. So like, if you're walking 'body' it's very rare to see or find a white girl who walks body well. At the end of the day the categories were made by Brown people and they were meant to showcase Black and Brown talent... That make sense?

This participant confirms that there are inevitably white performers who 'do not question' their presence in Kiki culture. Ahmed notes this spatial entitlement, or 'white habit' as being indeed unnoticed to white people, which would account for this participant's frustrations. However, in Kiki subculture, white entitlement does not always go unnoticed 
and 'unchecked', and therefore cannot hide as it does in daily interactions that occur within the city.

White bodies are welcomed in Kiki culture, but they are also held accountable for their actions should they misalign with the overarching 'ethos of care' for people of colour in the scene. The swift reaction to the Kiki ball spitting occurrence of white supremacy mentioned in chapter one demonstrates this. One prominent Torontonian Ballroom house father states: "to spit on ANYONE at a function, and of all people a black woman of trans experience, not to mention a judge, a pioneer, and a wonderful person who welcomed you in their space." According to one of my participants, although the larger Kiki community in Montréal expressed wanting to seek-out the spitter for redress, the trans woman who was spat at was satisfied with having the person kicked out of the event and "just wanted to move on" (as phrased by participant P4 second-hand). In both cases, the white spitter was 'called out' online and the Kiki community engaged in thoughtful conversations on how to handle the situation in a way that centered the wishes of the trans woman of colour who was the target of this violence. If incidences like this can happen within the relatively trans-empowered space of a Kiki ball, it demonstrates just how engrained white supremacy is in Canadian culture. That being said, it also illustrates how queer of color counter-culture is 'clapping back' to this offensive and abusive display of power. By creating their own rules, those in the Kiki scene are framing space as places of mutual respect and enacting a celebration of people of colour that in fact becomes life-affirming. 
When talking about Montréal's Kiki scene in general, Black, non-heterosexual56 cis-woman participant $\mathrm{P} 2$ comments:

There are lots and lots and lots of white spaces. But, if you see someone white that is in the Kiki scene, you have to tell yourself that there was something that was missing in their white spaces that makes them be part of this scene. You know? There is something that they were lacking, something that brought them here.

The welcoming nature of the participant above seemed to be returned in the space of the few Kiki balls I have attended, and there are indeed many active white Kikier's/House children in the scene. Speculatively, there are a number of factors that could deter white people from predominantly white queer spaces and entice them to the Kiki scene. According to Robin DiAngelo, "white poverty brings white people into proximity with people of colour in a way that surburban and middle-class life does not" (p. 66).

As argued, there is a discourse of good (white, heterosexual, gender normative, able-bodied body) versus the bad (Black, Brown, Indigenous, homosexual, disabled, gender non-conforming) body in Canada. Furthermore, there is an underlying discourse of the "good homosexual" (Smith, 1994; Duggan, 2002) versus the unacceptable 'dangerous queer' or “monster-terrorist-fag” (Puar, 2007; Puar \& Rai, 2002). These narratives construct whiteness, citizenship, and homonormativity as the only acceptable vehicles for producing the productive and thriving homosexual citizen-subject. When theorizing on how the ideal white body is constructed in relation to the black body, Radhika Mohanram (1999) states: "[t]his ideal body can be achieved only by placing 'the body' outside of history, by ignoring historical events such as colonialism and slavery,

56 When asked if she wanted to volunteer her sexuality, this participant reported her sexuality as 'complicated' and 'not-straight' but did not wish to further identify. 
and facts such as racism and sexism; in short, by ignoring the cultural and historical constructions of the body" (p. 32).

\subsubsection{De-centering whiteness: "Thick Black girls to the front!"}

According to participant P1, the very nature and design of Kiki and Ballroom categories 'weed out' those whose [white] bodies are not meant to be celebrated or centered. Bailey (2013) provides context for the sentiment of this participant's argument. In mainstream Ballroom culture, "body categories abound. . . there are 'Big Women's Body', 'Thick Butch Queens’ Body', 'Big Boy Body', [and] 'Full Figure Girl’’' (p. 171). If Body Kiki ball categories had an underlying theme, they would be best described by an audience member at the HIV/AIDS Kiki prevention ball I attended as: "thick Black girls to the front!" According to Kamille Gentles-Peart (2016), the image of the 'thick black woman' is often misunderstood as a "monolith across African diasporic cultures" (p. 77). I proceed here with caution so as to not make sweeping generalizations. That being said, Gentles-Peart notes that many Caribbean cultures celebrate full-figured women and men in a way North American society does not. Writes Gentles-Peart (2016), "thinness as well as whiteness are the central components and prerequisites of beauty, so black women (even thin ones) can never fully claim beauty in this [Euro-American beauty regime] system” (p. 80). Ballroom 'body' categories dismiss Western notions of what a beautiful body ought to look like and instead of celebrating thinness, Body categories reward fullfigured bodies - both artificially padded ones (as in the case with contestants 'up in drags') and those with natural curves. Participant P1 points out that this body category was created for the celebration of "Black and Brown talent" and it is rare to see white Kikiers' collect trophies in these categories. Whereas those with larger body types are 
often stigmatized in North American culture due to a general "fear of fat" regardless of race or ethnicity (see Bell and McNaughton, 2007; Monaghan, 2008), larger Black bodies face different realities of exclusion than white larger bodies do. The point participant P1 makes is that not just anyone can flaunt their curves and be rewarded with tens across the board in Kiki culture. While white Western beauty standards (i.e. thinness and ablebodiedness) are held in high esteem in North America and elsewhere, the Kiki scene in Montréal facilitates the celebration of full-figure Black and Brown female bodies in dynamic ways that de-center white beauty standards.

\subsection{Serving each other: Sharing economies \& Affective labour}

In addition to serving up fierce runway looks and skillful choreography during practice sessions and competition, members of Montréal's Kiki scene masterfully serve one another, house affiliation aside, through the sharing, lending, and trading of material goods such as clothing and accoutrement (such as shoes and hair pieces) often without money changing hands. 57 This section argues that material and immaterial (or affective) forms of non-capitalist sharing disrupt the current culture of queer exceptionalism and neoliberalism in Canada, which favours 'respectable' majority white and monogamous queers, insists upon fiscal autonomy, and encourages capital-based spending.

\subsubsection{Defining 'sharing economies' in the context of this research}

Far from a modern concept, bartering and sharing goods and services has occurred across many cultures throughout history (Richardson 2013). In the context of this research, my understanding of 'sharing economy' follows a more sociological

${ }_{57}$ Part of my title 'Serving each Other' is inspired by Marlon Bailey's (2013) note that a feature of ballroom community labour is that "members express love for one another and serve each other when needed. .." emphasis added (p. 210). 
approach in that "it focuses on the changing role of individuals, the more conscious and responsible consumer behaviour and the growing altruistic mentality" of members of communities (Codagnone \& Martens, 2016). Chris Martin (2016) notes that for-profit sharing economies could range "from a potential pathway to sustainability to a nightmarish form of neoliberalism' (p. 149). While beyond the scope of this thesis, some debates in political economy concerning sharing economies focus on the ways that neoliberal logics cause the foreclosure of 'affect' and 'sharing' for marginalized community members in favor of more democratic and socially just trajectories. The loose definition of sharing economy I seek to enact tends towards the more hopeful 'potential pathway to sustainability' model à la the creation of queer utopias/queer worlds. A further clarification is warranted in that the Kiki and Waacking communities studied here have demonstrated elaborate 'second-hand economies' which refer to people giving away or selling their used material goods to others (Frenken et al. 2015). More prevalently in this research, however, is 'unconsumption' or 'postconsumption,' which refers to material upcycling and reuse without buying new or used materials (Albinsson \& Yasanthi Perera, 2012). Postconsumption grew out of "anarchist movement[s] as a form of resistance to the capitalist economic model" (Albinsson \& Yasanthi Perera, 2012, p. 303). To expand this definition, I wish to add immaterial sharing here because of the affective labour involved in sharing ones' time and skill set within these specific performance countercultures.

Citing a lack of funds to buy clothes and costume pieces, all four Kiki participants spoke of the necessity of second-hand clothing shopping, do-it-yourself garment altering, and the sharing of clothing in preparation for (and even during) Kiki-ball competitions. 
Participant P4 mentions this culture of sharing and describes it as such: "if you see somebody that has something that may work for a ball you just ask them to borrow it. I just lent a pair of boots to [name redacted] in Toronto from a competing House." Being competitors on the runway does not interfere with this culture of sharing. Similarly, participant P1 confirmed this in our conversation about a staged moment she created at one of her first ball performances in Toronto, Ontario. Traveling to Toronto from Montréal on the greyhound bus, P1 created a veritable tableaux vivant (or living picture) in her recreation of a particular popular magazine cover of a celebrity taking a bath. 58 She states:

Obviously I couldn't use a real tub. It would be so expensive. What I did was I bought a bin that kinda looked like a tub and then I spray painted it, and I was like, literally naked with a robe, and then I had two 'male figures' [a Ballroom walking category] help me. They were not even in my house - I had no house at the moment and it was Toronto, so I didn't know anyone... and these two people helped me?! [with surprise] So, I can't really say that Toronto is shady cause they could've just been like... oh no nobody is gunna help you. No - they were super [said with emphasis] willing to do it.

Although this participant does buy the bin used to recreate the bathtub in the magazine cover shot, thus indicating a capital exchange, the sentiment behind the purchase was to circumvent the unfeasible and costly act of using an actual tub on stage, which the participant notes was actually done by a New York Ballroom competitor in years previous. More importantly, participant P1 was struck by the compassion shown by her competitors as they lifted her in her creatively crafted tub across the length of the raised runway. Despite being her competitors, the more experienced Ballroom house members

58 To protect the anonymity of this participant I have limited the description of the celebrity on the magazine cover as the participant's costume may be available online via photograph on various social media websites. 
saw a more junior 007 'free agent' (or someone not specifically affiliated with a house) from a different Canadian city and "did not hesitate to jump into action" in the words of P1.

\subsubsection{Kikiers' - neoliberalism's party poopers!}

As P1 experienced above, compassion and competition go hand-in-hand in Kiki culture. In larger Canadian society, however, forces of neoliberalism put compassion and competition in dialectical opposition. According to Stephen Dillon (2011) neoliberalism attempts to 'free' the market by dismantling unions, investing in privatization, and defunding social services. Dillon notes that "neoliberalism is not just a project of capital; it is also a project of white supremacy and heteropatriarchy" (p. 173). Indeed, competitiveness, individualism, and the increasing necessity of fiscal austerity due to cuts to social services conjures up what Ann Cvetkovich (2012) refers to as "public feelings" and other affect theorists have labeled 'hostile' economies or cultures of fear (Ahmed, 2004; Massumi, 2002; McManus, 2011). The example given by P1 above is doubly effective as it demonstrates the usefulness of the altruistic sharing of ones' physical and emotional labour in the ball scene, as well as offers insight into various ways the community takes inspiration from larger ball scenes and makes it accessible to workingclass young people of colour. States P1 on the scene in Toronto: "the scene [in Toronto] might be shady but it all comes from love. Let's not forget that these people were marginalized by society and balls brought them together." This gesturing towards tough love fits with Bailey's (2013) insight that Ballroom members “express love for one another. . . ultimately adding overall value to each other's lives, especially when facing desperate situations" (p. 210). Additionally, it creates counter-publics that resist 
neoliberal individualist discourses, emphasis on privatization and individual consumption, as well as produces, or creates, other ways of living together.

The interaction between the more junior ball walker - self-identified Latina dyke and her more experienced Butch Queen brothers in the space of the ball is an unexpected moment of collective caring - a rare moment in these neoliberal times. It is useful here to return to the figure of the Marlon Riggs' black prostitute drag queen smoking a cigarette in beautiful confidence on the pier of a dock within a city that wants her dead and forgotten. The fierce Toronto ball competitors embody unapologetic confidence in a way that gestures towards love - love for their Latina sister who lives in another city and is a free-agent "nobody" (in the words of the participant) in another scene. As pointedly (and humorously) noted by Aimee Carrillo Rowe and Francesca T. Royster (2017), “queers and women of colour are neoliberalism's party poopers," also known by Sarah Ahmed $(2010 ; 2017)$ as 'feminist killjoys' (p. 243). My argument for the significance of these majority non-capitalist sharing economies is that they challenge neoliberal notions of fierce individuality and fiscal austerity. And, as this section has suggested, the Kiki community in Montréal does this paradoxically in that Kiki ball competitions ironically brings its members together in a shared ethos of care and, in fact, love.

In addition to the sharing of clothes, participants report purchasing used-clothing and upcycling found household items to create a look. The purchasing of second-hand items and the use of everyday items around the house is economically more viable for young Kikiers than acquiring new, often brand name items for a ball. Participant P2 recalls preparing for a Sex Sirens category and dressing as an 80 s themed exercise model: "I went to a thrift-store and got a bodysuit and fanny pack. Then I found a broom stick 
and tin plates and made fake dumbbells to carry! A lot of stuff I borrow. I borrowed a friend's lab coat last ball." 59 This creativity and is typical of both the mainstream Ballroom scene and the smaller, less competitive Kiki scene. Although mainstream Ballroom does have very distinctive rules for gendered categories, Bailey (2013) confirms that innovation is key to the subculture. One of his interlocutors notes "I feel like if you can't be creative than you can't be innovative and you can't grow. You can't bring new things to yourself. . o or to your house or to anywhere, really. You have to be creative" (p. 48). For Bailey's Ballroom participants in Detroit, the "creative potential that this sphere enables" happens both individually and collectively. Similarly, Montréal's creative potential starts with the individual and is intended to spread to the collective. P4 notes they encourage Kiki participants to realize their full potential both as individuals and as part of the collective. P4 states:

If you can't bring all of your energy and presence to the table, then essentially you're missing out on realizing your own potential. . . the Kiki ball scene is there to support people in their individual evolution that'll hopefully create a stronger community of individuals.

Towards the end of our interview, P1 notes "the people that are organizing in Montréal... there is a lot of interest in trying to innovate and not necessary try to stick to very rigid gender rules of mainstream ball."

The Kiki scene seems more forgiving in terms of participants using found objects and affordable means with which to create a look. An examination of the New York Ballroom scene will provide context. Bailey notes that "expressing performative identities through fashion is an integral part of this [New York Ballroom] culture” (p. 32).

${ }_{59}$ Ballroom vernacular that indicates craft (or crafting) is a "secret economy" denoting "fraudulent activities or the acquisition of items or services through illegal means" (Bailey, 2013, p. 253). 
Often named after haute-couture brand names, houses in both the Kiki and Ballroom scenes often prepare for walking categories by acquiring brand name designer fashion pieces for a competition. In fact, some of the categories specify the prerequisite of designer labels, as evidenced in a Ballroom flyer for a 2004 'Black Ball'(which is a double entendre as performers are often Black and are required to actually wear black at this particular ball) hosted by the Legendary House of Prestige. One such category is 'labels,' characterized as such:

Labels (American fashion exhibit) American designers are often criticized for following their European counterparts, but tonight's the night to end this madness. Come done head to toe in 5 or more American designer pieces 2004/2005 to upset the Europeans \$ (p. 62).

Its opposite was described as "high fashion European labels" which calls for exactly what it describes. Another label category for Butch Queens Up in Drags called for "head to toe pandemonium. winter 2004/2005 totally done causing HAVOC. Letting the children know you are the true label villain, and your not having it \$\$" [sic] (p. 63). A superficial analysis of this would stereotype Ballroom children as materialistic and driven by vanity and celebrity. But for Bailey, consumption can. . . be understood as an act of resistance to or survival within the exclusionary practices on which consumption in our market-driven capitalist system is based. Simply, it "cannot be understood as purely criminal on one hand or wholly resistant on the other" (p. 33).

\subsection{Sharing economies in the Black Radical Tradition}

As outlined in my introduction, Black collective activism is essential in dismantling queer essentialism and challenging white supremacy in the nation-state of Canada. According to Johnson and Lubin (2017), although “. . . diverse individuals and communities - from students and cultural workers to activists and intellectuals - have 
redefined the concept of Black radicalism for Afro-diasphoric scholarship" over the decades, Black radical activism remains "an enduring weapon against successive racial regimes" (p. 1-2). Pioneer scholar of the Black Radical Tradition, Cedric J. Robinson (2000) contends that black radicalism is the result of "collective intelligence" assembled over generations of struggle against white supremacy (p. xxx). The Black Radical tradition was born (in part) out of a response to the trans-Atlantic slave trade. Because of genocidal, intergenerational enslavement, "slaves had acquired a sense of the calculus of oppression as well as its overt organization and instrumentation," for which these collective knowledges were built (p. xxx). From slavery revolts, to the Black Power movement of the 1960s, and to the Black Lives Matter movement of today, intergenerational 'collective knowledges' have been instrumental in driving the Black Radical tradition. Although the socio-political climates are vastly different, this thesis argues that Kiki ball gatherings (especially HIV/AIDS prevention balls) harken to activism in the Black Radical Tradition.

At the August 2019 Gasolina! An Urban Kiki Ball held at La Sala Rossa in Montréal, the mission of the hosting house was to one of "honouring the black, Latinx and Afrolatinx legacy of Ballroom in Montréal” "“Gasolina! An Urban Kiki Ball, 2019, n.p). One particular category demonstrated the traditions of Black radical activism and social justice within Kiki subculture. The Open to all (OTA) runway category was described as

“iviva la raza! the brown berets were community-based social justice group that organized against police brutality modelled in part on the African American Black Panther Party. Bring it in a fashionable outfit featuring a beret and show us a revolutionary strut. Just, do not wear blue cause: NO COPS AT PRIDE! 
This walking category references the Brown Berets, who took their lead from the Black Panthers, a foundational radical civil rights movement in the style of Black radical activism. In the video for the Kiki ball, one Black ball walker (who appeared female) approached the judges table for the category carrying a fake machine gun, dressed in black 1970s attire, all the while holding a picket sign (whose words could not be read from the video). Reminding one of a Black Panther as the category called for, this ball walker turned their back towards the judges, and their long, black leather jacket had a sign pined to it reading: "Black Trans Lives Matter!" Although this competitor was chopped, in just a few categories later the same black leather jacket with the activist message on the back was seen worn by another competitor. It was clear that this jacket had been shared between the two ball walkers. A central tenet of Black radicalism is that Black liberation and freedom is inexplicably linked to a "break with the totality of racial capitalism" (Johnson \& Lubin, 2017, p. 4). In a demonstrable way, the sharing of this activist accoutrement symbolized a sibling-hood of Black ball walkers keeping the early traditions of Black Radical activism alive on the runway. Just as the history of Black radical activism was passed down to these ball walkers, so were their material goods passed along in a way that circumvented more participation in racial capitalism per Johnson \& Lubin (2017).

\subsection{Serving up hope amidst queer necropolitics}

Kiki and Waacking subcultures celebrate the bodies of people of colour in a way that provides a hopeful framework for surviving necropolitical forces. Achille Mbembé (2003) notes that the Foucauldian notion of biopower does not " account for contemporary forms of subjugation of life to the power of death" (p. 40 ) Necropower, 
according to Mbembé, "accounts for the various ways in which. . . weapons are deployed in the interest of maximum destruction of persons and the creation of death-worlds," where (neoliberal) living and working conditions are such that whole populations turn into "the status of the living dead" (p. 40). Building upon this theory, Puar (2007) explains how "liberal gay politics" have expanded and been complicit in the racism inherent in discourses of terrorism and anti-immigration (p. 36). Queer necropolitics, then, acts as a proverbial sorting machine - assimilating the respectable, white, cisgender, upper-middle class 'queer' and marking the deviant, racialized, trans, queer subject as deserving of slow death.60

Organizer against anti-Black police violence in Montréal and author of Policing Black Lives, Robyn Maynard (2017) contends that racialized queer and trans youth in Montréal live (and have lived) in historically violent, precarious times. As learned from the important activist work of groups like Black Lives Matter (BLM) and various modes of press (such as citizen journalism), writes Shatema Threadcraft (2017), the state is intent on "assur[ing] its citizens that it has produced the 'right kind' of dead [i.e. racialized bodies]" (p. 553). Because Black, Latinx, and Indigenous youth are often "imbued with the quality of danger," they are subject to targeted state surveillance and life-threatening punitive policing tactics (Maynard, 2017, p. 211). Often denied the assumption of childhood/youthful innocence and indeed thought to be 'un-grievable' (Butler, 2006), Black and Latinx young people navigate state sanctioned violence in a way that is unfamiliar to their white peers. Charest (2009) indicates that between 2001 -

60 See Posocco, S., Kuntsman, A., \& Haritaworn, J. (2014). Queer necropolitics. Abingdon, Oxon: Routledge. 
2007 the Service de Police de la Ville de Montréal (SPVM) deployed 'anti-street gang squads' to justify reportedly random street checks which in fact singled out Black boys and youth (40\%) "with just over 5\% of whites (total)" (Maynard, 2017, p. 90-91). Furthermore, "incivilities laws" in Montréal against public spitting, disturbing the peace, noise, and prostitution are said to impact Black, Latinx, and South Asian youth over any other demographic (Tanovich, 2006).

Compounding this, when these racialized populations experience HIV/AIDS, Arnold, Rebchook, \& Kegeles (2014) explain that they become "triply cursed" as they may experience the shame and stigma of an HIV positive diagnosis alongside homophobia and racism. Moreover, Bailey (2019) contends that HIV is not just a contractible retrovirus, but it "functions as a vector of power, a social category, which acutely shapes the quality and possibilities of life and the conditions of death, sometimes prematurely, for Black gay men" (p. 164). Although the HIV/AIDS epidemic continues to impact both cis-gender and trans men and women of all races, African American men who have sex with men "are disproportionately burdened by new and existing HIV infections" (Dickson-Gomez et. al., 2014, p. 2156). Within a Black queer cultural context, "social isolation, low self-worth, violence, and poverty. . . are social risk factors that make people more vulnerable to the [HIV/AIDS] epidemic" (Bailey, 2009, p. 633). This is significant as Bailey informs that the historical "social conditions of HIV/AIDS weigh heavily on the self-worth of individual members and the community" at large (Bailey, 2013, p. 203). 
Facing this bleak reality is no doubt depressing.61 Despite this, Threadcraft claims that "blacks have more than the bodies of the slain around which to organize, even within a strictly necropolitical sense" (p. 554). The population groups described above constitute the key demographic of my participant base and of Kiki and Ballroom culture in North America at large. Returning to my participant observation session of Montréal's 'Let's talk about sex' mini Kiki ball, a particular impromptu dance duet known as the 'Grand March' demonstrates the scene's nuanced and radical approach to activism for queer and trans people of colour - primarily those often deemed 'at risk' to HIV/AIDS transmission. The DJ began by playing Salt n' Pepper's 1994 hit "Whatta man” as Toronto's legendary ball Pioneer Father Sevyn Magnifique and Montréal's Pioneer Gerard X Reyes (AKA Bronzé 007) started fondling one another in the middle of the cipher. Their opening dance was a spectacle of male Black on gender-queer Latinx love: they dry-humped, mimicked oral sex, and creatively 'danced out' scenes of gay sex on the dance floor. As the two continued to embrace one another in a series of undulating hips and even a sensual lap dance that nearly sent a table flying, it became clear this underground scene was enacting a radical form of HIV/AIDS prevention labour that centered the sexual pleasure and desire of its Kiki members.

Bailey argues against surveillance of black queer sex and instead advocates for a "reconceptualization of prevention methods. . that would take into account the multiple factors that account for the sexual behavior of black gay men, including the need and desire for intimacy" (p. 20). The argument here is that Black gay men are always already

61 José Esteban Muñoz (2006) writes about the gendered nature of depression and considers it (unfairly) the "dominant affective position addressed within the cultural field of contemporary global capitalism" (p. 675). See Muñoz (2006). 
seen as 'at risk' and unprotected sex provides them "with a form of intimacy and affection that they do not otherwise receive" (Johnson, 2017, p. 20). The grand march demonstrates that HIV/AIDS prevention efforts need not be 'unsexy' as the leaders performing this affective labour challenge the clinical, sterile, and ultimately failing prevailing health discourses that attempt to conduct HIV/AIDS prevention in Canada. Queer necropolitics are at work when these health services fail men who have sex with men - predominately men of colour. Therefore, queer necropolitical forces are challenged by staging this provocative and effective HIV/AIDS house-work. This spectacle of unplanned, loving, impromptu semi-public gay sex play between two men of colour (one Latinx and one Black) is in opposition to the more traditional HIV/AIDS public health prevention messages.

Having a strong queer alternative family (or House) and holding onto the knowledge that the future holds "moments of joy" (in the words of participant P2) can be life-affirming for queer people of colour. Another Kiki ball moment of "performance labour" (Bailey, 2013) illustrates how the scene works in practical ways to offer hope to its members amidst a backdrop of everyday institutionalized necropolitical turmoil. The grand prize category of the 'Let's talk about sex' HIV/AIDS prevention ball was listed as a 'House production' requiring at least 3 walkers from different categories. The category description required each competing House to pay homage to the tradition of HIV/AIDS advocacy in some way and the winning House staged a 'choreographed moment' of receiving an HIV positive diagnosis. Setting the scene with a table and chair in front of the judges table, a vogue femme walker (complete with heels, doctor's lab coat, and clip board) acts out delivering the bad news to the patient - a Body category walker dressed 
with a pos $(+)$ sign on her top (see Image 1 below).

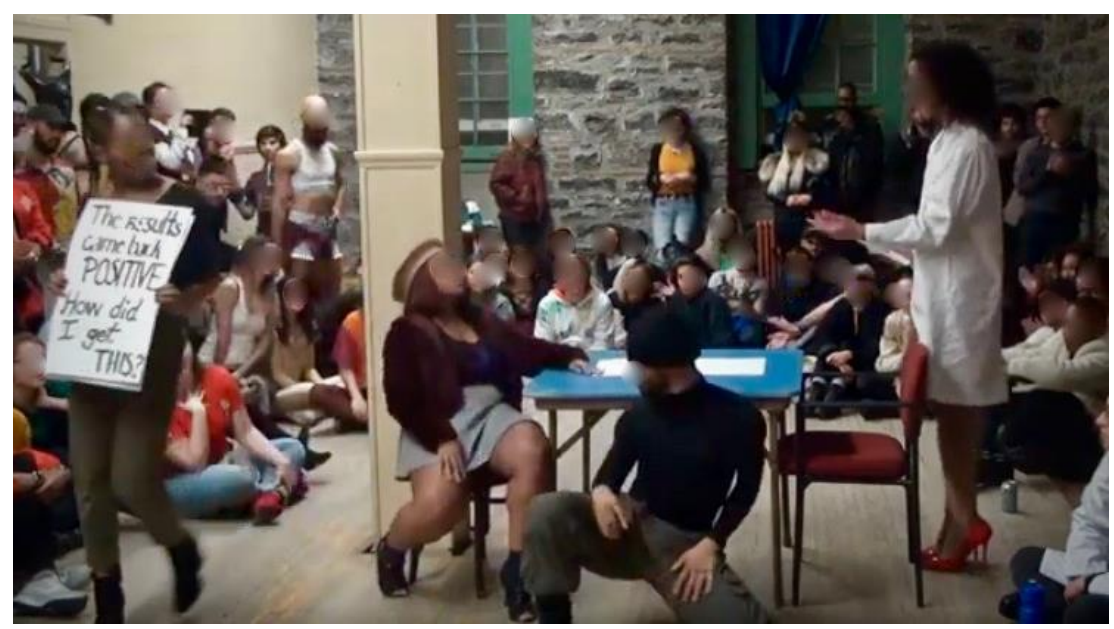

Image 1. A video screen shot of the winning 'House Production' category for grand prize at the March 2019 HIV/AIDS prevention Kiki ball. Sign (left) reads: "The results came back POSITIVE. How did I get THIS?" Taken from: Let's Talk About Sex! Mini Kiki Ball: Grand Prize as a House. (2019, April 13). [Video file] Vogue Montréal and Ballroom. Retrieved from: https://www.youtube.com/watch?v=Gs7LgDa5fjA

As the 'pos patient' moves in distorted, distressed movements, a House child dressed in plain clothes circles them with a sign reading "I feel scared and alone." Another House member dressed in black jumps on the table and vogues/duck-walks in place where the 'pos patient' was seated (soon thereafter the MC announced this voguer-in-black symbolized 'HIV stigma'). Circling the staged 'moment', another House child reveals a sign that reads "[d]estigmatization, protection, getting tested frequently, and awareness are essential and crucial!" as others comforted the 'pos patient' in the middle (see Image 2 on next page). 


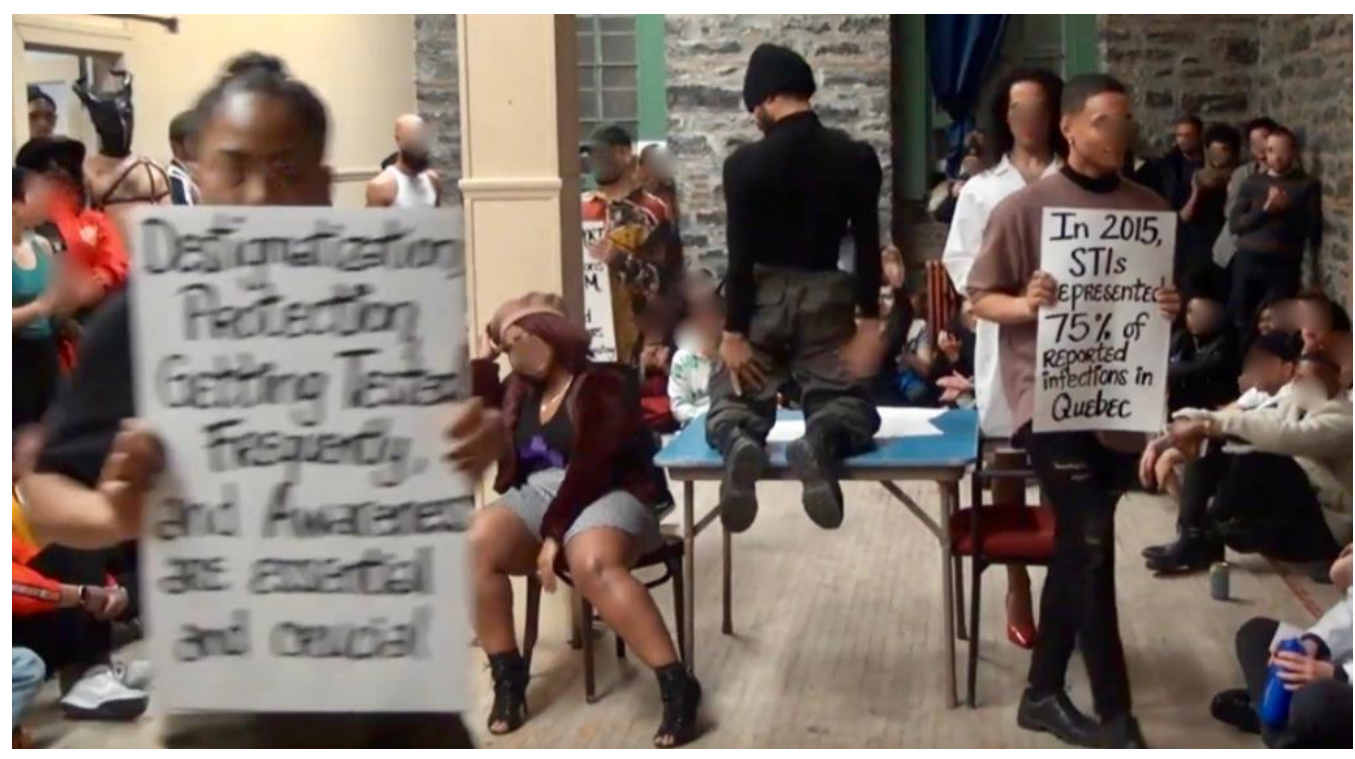

Image 2. A video screen shot of the embodiment of 'HIV stigma' dressed in black dances on the table as the 'HIV pos walker' sits, defeated. Sign (left) reads: "Destigmatization, protection, getting tested frequently, and awareness are crucial" Sign (right) reads: "In 2015, STI's represented 75\% of reported infections in Quebec."

Taken from: Let's Talk About Sex! Mini Kiki Ball: Grand Prize as a House. (2019, April 13). [Video file] Vogue Montréal and Ballroom. Retrieved from:

https://www.youtube.com/watch?v=Gs7LgDa5fjA

Growing increasingly more confident with the help of House friends, the 'pos patient' eventually springs up, pushing 'HIV stigma' into a 'dip', and dances provocatively in the effort to take back her sexuality as the 'doctor' lifts up a sign that reads: "YOU are NOT your illness and/or disease!" (see Image 3 below).

After the winning performance Grandfather Ninja and the pioneer of Kiki in Montréal gave an approving standing ovation, the crowd erupted in cheering, and it was clear who would take home the trophy. In this example, these moments of choreographed activism and the ensuing cipher of joy they elicit act as a sort of temporary respite from necropolitical forces and structural oppressions (i.e. racism, transphobia, homophobia, HIV/AIDS stigma) which seek to silence and subdue the minoritarian subject. Part of producing counter-hegemonic "affective economies" (Ahmed, 2004) is that Black bodies, 
queerness, and pleasure are celebrated. Such performances are vital in that they decenter death, illness, and the breakdown of Black bodies and communities.

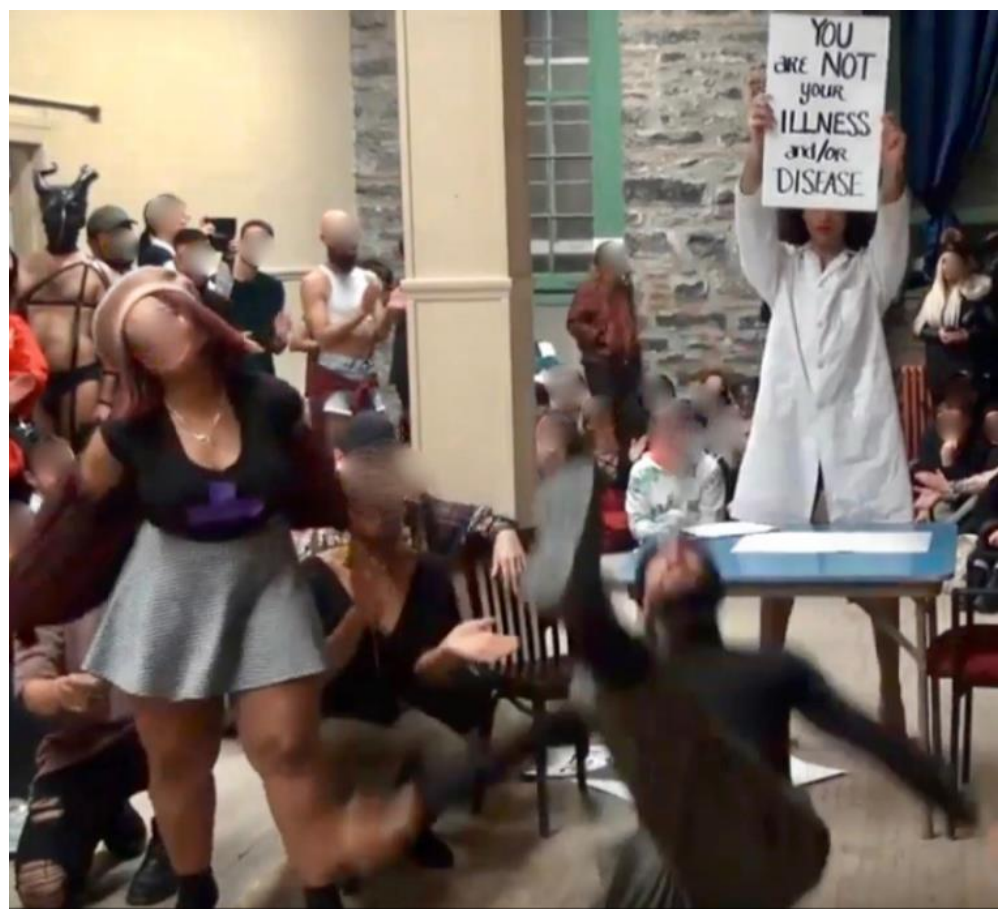

Image 3. A video screen shot of the 'HIV pos walker' springing up and pushing 'HIV stigma' into a dip. Doctor holds up sign reading: "YOU are NOT your ILLNESS and/or DISEASE."

Taken from: Let's Talk About Sex! Mini Kiki Ball: Grand Prize as a House. (2019, April 13). [Video file] Vogue Montréal and Ballroom. Retrieved from: https://www.youtube.com/watch?v=Gs7LgDa5fj 


\section{Conclusion}

\subsection{A note on affect: The maddening impossibility of ignoring 'feelings'}

A sudden lurch forward, a burst of soft yellow light, and the sound of luggage being pulled with the help of gravity from its overhead plastic container woke me from my surprisingly comfortable 3-hour long greyhound bus sleep. I was exhausted after conducting my first participant observation session but finally 'home'. It was only out of obligation that I sleepily turned my cell phone on to order an Uber as it was 3:20 AM and no Ottawa city buses were operational. After I could see that my uber driver was on his way I adjusted my backpack straps, headed outside, and checked my texts. I received a message from my chosen brother - a fellow graduate student - requesting I text him back when I got home safe. Thankful for the text, I checked in and told him my bus arrived safely, to which he responded 'so... how did it go!?' He knew how nervous and excited I was to attend my first Kiki ball. After drafting numerous responses trying to describe my experience I finally replied with the honest truth: it was completely indescribable! He then answered in a way I did not appreciate at the time: 'but wait... isn't that your job now?!"

Throughout the data collection process I greatly resisted and resented my own affective responses to the uniquely personal forms of dance and familial closeness I was lucky enough to witness. As a person often described as emotional or sensitive, which many of us grow-up being taught are unwanted traits coded 'feminine' and therefore somehow 'weak', I endeavored to make a miraculous 180 degree turn and become the objective researcher paying attention to themes and patterns in their data. I would let the data speak for itself and contextualize it with the theories and methodological approaches 
I had worked so hard to understand. But in the process of participant observation and transcribing the non-verbal cues in my interviews I became frustrated to find that unspoken affect was often the loudest language of my participants. Interviews that were scheduled for 45-60 minutes ended up being two hour long conversations that I had to reluctantly bring to a close. This performance subculture literally saves lives - how naïve was I to think that the work would require an unfeeling approach? I came to realize that when corporeal performance is the sole vehicle of expression - affect is the fuel.

Despite living in a city that relentlessly tries its best to silence and displace them, the participants in this research embody what it means to be hopeful. For all of the stressors that were spoken I could hear the pain of the unspoken in their pauses. I could sense their frustrations when talking about the unfairness of their everyday lives outside of Kiki ball culture. But mostly, I could not help but feel their joy when talking about anything related to Kiki or Waacking subculture - even the family drama. Upon reflection, the second biggest hurdle I experienced was coming to terms with the maddening impossibility of ignoring 'feelings' and my own affective responses throughout the research process. Without a doubt, the greatest challenge of this research remains the impossibility of connecting a subjective 'felt' experience to the largely reductive signifiers of the English language - words are inadequate when articulating the primarily primal display of emotion. There is an impossibility to researching danceespecially that of the marginalized, 'racialized' diasporic queers who have built an entire complex, living, and everchanging community that cannot be reduced to words on paper. Fortunately, I had a rich body of literature to draw from after recognizing the importance of affect to this project. As the themes began to emerge from my qualitative 
data I sat with a list of key phrases related to my participants' affective responses. I learned about the joy attached to their Kiki family, the pain connected to feelings of unbelonging in other areas of their life, and the unbridled passion they felt for their mode of queer performance. Looking at the words on the page I felt as though I had somehow collected a tiny immaterial "archive of feelings" in the words of Ann Cvetkovich (2003). I posted this list on the wall above my workspace at home and referenced it often. In reference to Tammy Rae Carland's art exhibit (titled 'Archive of feelings'), Cvetkovich (2013) speaks about the importance of acknowledging the affect attached to everyday objects. Even though my list of affective responses referenced the immaterial, Cvetkovich's words rang true to me: "these personal feelings are important enough to be made public" (2013, p. 76). One of my indirect objectives became purposefully documenting this humble archive of personal feelings. These feelings are invaluable resources for building sharing economies through which QTBIPOC 'serve each other'.

\subsection{Research Summary}

This research asks how do Kiki and Waacking/Punking subcultures resist and transform hegemonic productions of racialized gender and sexuality, and what radical activist tactics are being deployed in these nuanced scenes? Employing qualitative interviews and participant observation methods, I argue that Kiki and Waacking subcultures (maintained by embodied intergenerational praxis and pedagogical processes) are instrumental in facilitating life-affirming queer kinship bonds, alternative ways to simultaneously embody and celebrate non-normative gender expression with Black, Asian, and Latinx identity, non-capitalist economies of sharing, and hopeful strategies of everyday community activism and resilience to appropriative processes during economic 
insecurity and necropolitical turmoil. This research contributes to broader debates in sexuality and gender studies surrounding creative modes of queer of colour empowerment, place-making/queer world-making, and the hopeful effects generated by having queer alternative kinship networks for those marginalized by ethnicity, race, class, gender, and sexuality.

After describing my personal connection to the project, reflecting upon my social location, and introducing key terminology, chapter one reviewed the literature on the history of Ballroom, Kiki, and Waacking/Punking subcultures. To provide sociopolitical context I describe a runway incident involving an uninvited guest to a Kiki ball who spat at a panel of judges, primarily targeting a trans woman of colour seated at the judges table. This overt act of aggression is easy to identify. And yet, microaggressions related to white supremacy, homophobia, and transphobia likely occur in the lives of Kiki members on a near daily basis. Often the "unexamined centre" of North American society, the normalization of whiteness and "white racial unconsciousness" reinforces a culture of complacency with white supremacy (Doane, 2003, p. 7). This case demonstrates just how engrained white supremacy is in Canadian culture. But it also highlights how queer of color counter-culture is addressing these abusive displays of (white) power in life-affirming ways. My second chapter articulates my data collection and recruitment methods, queer of colour methodologies, and 'hybridized' theoretical frameworks. This chapter concludes by relaying how this research contributes to sexuality studies and reveals all of my essential arguments.

The third chapter of my thesis expands upon the unique gender and familial systems within Kiki and Waacking House culture in Montréal and Ottawa. 'House' 
culture provides its members with nuanced ways to simultaneously embody Blackness, Latinx, and Asian identity in harmony with their preferred gender expressions. Next, I describe how these performance subcultures have evolved throughout the decades through the radical pedagogical intervention of 'each one-teach', or their 'embodied intergenerational praxis'. Such shared knowledge and pointed efforts to raise up the next generation of Kiki and Waacking performers enables a shift towards a deeper understanding of the affective labour and alternative sharing economies based on reciprocity created out of these dynamic spaces.

The last chapter of this thesis articulates the significance of queer of colour placemaking and world-making for working-class queer and trans people of colour living in increasingly gentrified cities. Specifically, it points out the Kikiers' and Waackers' ability to claim both physical space and create queer worlds in a city that privileges capital generators, or upper-class white Canadian citizens whose racial privilege and class status affords them the freedom to acquire property. From what I witnessed, it is extremely difficult to find and maintain safe space for queer and trans people of colour to gather together 'in the social'. I could sense a feeling of loss when participants spoke about Espace Sans Luxe. That being said, the community has fought hard to acquire alternative spaces to come together for a Kiki. In a similar way, through my Waacking participant observation session I became witness to a visible 'queering' of City hall in Canada's capital city. Next, chapter three outlines the material and immaterial economies of sharing between members of these underground subcultures. I conclude this last chapter by exploring strategies of everyday community activism and the shared culture of hope 
within these subcultures in the midst of necropolitical forces such as the aftermath of gentrification and inadequate HIV/AIDS public health services.

\subsection{Research limitations}

Although I do not wish to overly reinforce the binary of outsider/insider research,62 it must be stated that my outsider status as an Anglophone white settler who does not practice Kiki or Waacking limits my research in various ways. By opening my thesis with a reflexive introspection in relation to these performance forms, I hoped that my story would create a type of "epistemological entrance" into this research (Berry \& Clair, 2011, p. 202). Despite efforts towards continual reflexivity and an awareness of my social position throughout the research process, these risks and limitations deserve keen attention. As mentioned in my recruitment section, I am grateful for the respondents who were willing to share their knowledge with me. I do, however, understand that a researcher of colour who practiced Kiki and Waacking (or at least regularly attended balls) would have likely established a more authentic sense of trust and rapport with participants. This may have enriched the participant responses' and made data interpretation more accurate to the lived experiences of the respondents. Furthermore, all of my participants were second generation immigrants to Canada. Being a Canada-born settler may have foreclosed conversations regarding national belonging and racism, and researchers from immigrant families would likely be able to 'bridge the gap' in having these conversations. Additionally, although only two of five participants spoke French as a first language, my ability to speak their first language could have enhanced the quality

62 I agree with Dwyer and Buckle (2009) that presenting oneself as either strictly 'insider' or 'outsider' is "overly simplistic" (p. 60). 
of our interviews. With these limitations and risks in mind, I hold the simultaneous belief that there is a dire need for research that confronts the consequences of white-dominant queer exceptionalism in a Canadian content. I contend that white researchers need not shy away from these projects and instead mobilize their privilege in thoughtful, antioppressive ways that serve communities 'outside' of their own.

\subsection{Knowledge gap regarding Waacking subculture}

Even though research concerning Ballroom and Kiki performing arts subculture for queer and trans people of colour is scarce, 63 there is an even more pronounced deficit in traditionally documented knowledges surrounding Punkin' and Whacking/Waackin’ subculture.64 Moreover, there are very few remaining Punkin' and Whacking elders currently teaching the tradition. Because of this, my knowledge production concerning punkin' and subsequent whacking scenes have been limited to a one in-person interview with a second-generation whacker and video footage of the last remaining pioneer of the scene - Viktor Manoel and his contemporaries.65 Therefore, this thesis acknowledges that a fuller and more complete exploration of Punkin/Whacking history is warranted. That being said, it would be imprudent to ignore this subculture as Ottawa is home to a growing subculture of young waackers led by an instructor who experiences racism and the very real pressures of the gender norms placed on women.

63 Exceptions include but are not limited to Marlon Bailey (2013), Fiona Buckland (2002), Cathy Cohen (1996), Brian Currid (1995), Jonathan David Jackson (2002), and Patrick E. Johnson (2003).

64 Exceptions include but are not limited to Naomi Bragin (2014), Nyong'o, Tavia (2008), and Imani Kai Johnson (2015).

65 In addition to using informational videos from Viktor Manoel, I have also consulted videos on the topic of punking and waacking history from Tyrone Proctor and Kumari Suraj - two second generation dancers with demonstrable knowledge on the subject. 


\subsection{Considerations: Racial stereotypes regarding affect}

As previously demonstrated, LGBTQ2S people of colour living in Canada are often stereotyped as 'criminal' and "dangerous" (Maynard, 2017) for simply 'living while Black' in instances of being present in public life daily. The onus on the researcher is to develop a keen awareness to the ways in which our work either has the potential for good or the risk for furthering negative stereotypes about the marginalized populations we study. Upon considering this, I realized that when gendered experiences are incorporated into racist processes, affect becomes an important consideration. As Carrillo Rowe and Royster (2017) point out, "women of color are often associated with excessive affect" (p. 243). Similarly, Muñoz (2002) challenges the idea that Latino/a affect is excessive with the notion of "feeling brown." Rather than turn away from affect because of the risk in crossing-over into 'white affect studies' territory, I turned to the literature and gained some awareness of these slippages. I align my thinking to Claudia Garcia-Rojas (2017) who proposes an empowering alternative to studying affect in relation to queer women of colour. In understanding their "affective economies," researchers can uncover "systems of power and oppression, hegemonic knowledge structures, and dominant economies of affect" which can aid in building multiple empowering and practical strategies, or "ethics of survival," for those studied (p. 255). I am still thinking of ways to proceed with caution when it comes to describing affect in conjunction with social oppressions such as race, ethnicity, gender, and sexuality.

\subsection{Areas for future research}

There is expansive potential to conduct larger-scale, nation-wide qualitative research on Kiki, Waacking, and Ballroom House subcultures and the forms of activism 
they take up. This research is limited in scope because of its focus on the geographic locations of Montreal and Ottawa. Future community-based and activist-led research could work towards addressing Robyn Maynard's (2017) question: "what would it look like to imagine a future of Black freedom, of lives unencumbered by the everyday and spectacular moments of suffering caused by the racially structured institutions that govern society?" (p. 230). Larger-scale research of this kind could reveal the nuanced activist methods of each performance subculture, thereby providing a wider context on the state of these scenes nation-wide. Research of this scale could then be further expanded, or lead to similar studies, that compare the hopeful potential and familial structures of Kiki, Waacking, and Ballroom subcultures across the border into the United States. The expansion and careful dissemination of this knowledge could work towards archiving and documenting the lived realities of the most-marginal members of these performance subcultures for future generations.

Additionally, with the rising trend of for-profit online sharing economies in Canada (such as Uber and Varagesale), there is future research potential for a political economy focused analysis of non-capital based postconsumption sharing economies within House subcultures from province to province. This research could not only increase the understanding of the importance of 'sharing' and 'upcycling' for queer and trans communities of colour in these underground scenes, but it could help to explain the environmental benefits of postconsumption sharing in a culture that values hyperconsumption (specifically, 'fast-fashion').

Although outside the scope of Kiki, Waacking, and Ballroom related subcultural research, I would be remiss to not acknowledge the growing communities of Two-Spirit 
drag activism that takes up the vital task of decolonizing gender in the settler colonial nation of Canada. Ottawa hosted its first "2-Spirit Ball" in the summer of 2019, and the language of gathering together for a 'ball' gestures towards ballroom culture albeit in nuanced ways. Indigenous Two-Spirit drag, also called 'Indigi-drag' is addressing processes of cultural appropriation and land dispossession in ways that drag adjacent communities have not. Just as Kiki is a subculture within a subculture, the Indi-drag community is what Two-Spirit drag queen Levi Foy (AKA Prairie Sky) calls "a minority within a minority" (“a minority within. . .,"2019, para. 5). This is a further area for insider-research conducted by and for Indigenous Two-Spirit communities.

\subsection{Concluding reflections}

The American Kiki scene, and as this research demonstrates - the eastern 'Canadian' Kiki scene in Montréal, offers young people the chance to develop and master category specific skills (like vogueing) in a more intimate, less judgmental environment with their peers and house parents (Rogell, Cheatle, \& Jordenö, 2016). I am in agreement with Prosser (1998), Halberstam (1998), and Munoz (1999) that drag has the potential to simultaneously reproduce and reject cis(and)heteronormativity. In a Kiki context, however, queer of colour performance subverts gender norms and creatively 'mocks' the heteronormativity of the nuclear family. These Kiki experts make calculated investments in their craft and their queer chosen families. Guided by love and driven by the thrill of competition, these subcultures challenge queer exceptionalism and engage in grassroots activism reminiscent of early Black radical activism. By showing up to weekly practices, gathering together 'in the social', and making it home safely after the Ball in cities that makes life precarious for them, all of the participants in the study refuse to remain meek 
and hidden. And by refusing to remain meek and hidden like their Ballroom and punking predecessors, Kiki and Waacking house family members echo the Majorian claim, we are still fucking here! 


\section{References}

“'A minority within a minority': A peek inside Ottawa's 2-spirit ball” (2019, Aug 17). $C B C$ news online. Retrieved from https://www.cbc.ca/news/canada/ottawa/2-spirit-ball-ottawa-video1.5246619

Aguirre-Livingston, P. (2011, June 9). Dawn of a new gay. The Grid TO (9 June). Retrieved September 20, 2018.

Ahmad, A. (2018). “Queer circuits of belonging,” In S. M. Ware, J. Haritaworn, and G. Moussa (Eds.), Marvellous grounds: Queer of colour histories of Toronto (119128). Toronto, ON: Between the Lines.

Ahmed, S. (2010). The Promise of Happiness. Durham, NC: Duke University Press. . (2007). A phenomenology of whiteness. Feminist Theory, 8(2), 149-168. . (2004). Affective economies. Social Text, 22(2), 117-139. . (2004). The cultural politics of emotion. Edinburgh: Edinburgh University Press.

Albinsson, P. A., and Yasanthi Perera, B. (2012). Alternative marketplaces in the 21st century: Building community through sharing events. Journal of Consumer Behaviour, 11(4), 303-315.

Altman, D. (2001). Rapture or continuity? The internalization of gay identities. In J. Hawley (Ed.), Postcolonial, queer: Theoretical intersections (19-42). Albany, NY: State University of New York Press. 
AlyssaChloeNYC [Username]. (2012, January 7). Grace Jones do or die feat. Viktor (Manoel) and Danny Lugo [Video File]. Retrieved from https://www.youtube.com/watch?v=v2-1uUbYFL4

Anzaldúa, G. (1987). Borderlands/la frontera: The new mestiza, 2nd ed. San Francisco: Aunt Lute Books.

Araújo, N. (2018). A detour in longing: Gender, sexuality and lesbian desire in Carla Trujillo's what night brings and Emma Pérez's gulf dreams. Estudos Feministas, 26(3), 1-9.

Arnold, E. A., and Bailey, M. (2009). Constructing home and family: How the ballroom community supports African American GLBTQ youth in the face of HIV/AIDS. Journal of gay \& lesbian social services, 21(2-3), 171-188.

Arnold, E. A., Rebchook, G. M., and Kegeles, S. M. (2014). 'Triply cursed': Racism, homophobia, and HIV-related stigma are barriers to testing, treatment adherence, and disclosure among young Black gay men. Culture, Health and Sexuality, 16(6), 710-22.

Aylward, C. (1999). Canadian critical race theory: Racism and the law. Halifax: Fernwood Publishing.

Awwad, J. (2015). Queer regulation and the homonational rhetoric of Canadian exceptionalism. In S. Lenon, O. H. Dryden, and J. Awwad (Eds.), Disrupting queer inclusion: Canadian homonationalisms and the politics of belonging (1934). Vancouver, BC: UBC Press. 
Bailey, M. M. (2019). Black gay sex, homosex-normativity, and Cathy Cohen's queer of color theory of cultural politics. GLQ:A Journal of Lesbian and Gay Studies, 25(1), 162-168.

. (2013). Butch queens up in pumps: Gender, performance, and ballroom culture in Detroit. The University of Michigan Press. . (2009). Performance as intravention: Ballroom culture and the politics of HIV/AIDS in Detroit. Souls, 11(3), 253-274.

Baldwin, A., Cameron, L., and Kobayashi, A. (2010). Rethinking the great white north: Race, nature, and the historical geographies of whiteness in Canada. Vancouver BC: UBC Press.

Balzer, D. (2015, June 10). Interview: Rashaad Newsome on voguing, heraldry, and FKA twigs. Momus: A Return to Art Criticism. Retrieved from http://momus.ca/interview-rashaad-newsome-on-voguing-heraldry-and-fkatwigs/

Banks, C. (2018). Disciplining Black activism: Post-racial rhetoric, public memory and decorum in news media framing of the Black Lives Matter movement. Continuum, 32(6), 709-720.

Bannerji, H. (2000). The dark side of the nation: Essays on multiculturalism, nationalism and gender. Toronto: Canadian Scholars' Press.

Barbara, E. (31 Oct 2019). Party monster: A halloween mini kiki vogue ball [Facebook Event]. The Sala Rossa. Retrieved from https://www.facebook.com/events/3084550914893471/ 
Bassichis, M., Lee, A., and Spade, D., (2011). Building an abolitionist trans and queer movement with everything we've got. In N. Smith and E. A. Stanley (Eds.), Captive genders: Trans embodiment and the prison industrial complex (15-40). Oakland, CA: AK Press.

Becquer, M. and Gatti, J. (2005). Elements of vogue. In K. Gelder (Ed.), The subcultures reader. London and New York: Routledge.

Belk, R. (2014). Sharing versus Pseudo-Sharing in web 2.0. Anthropologist, 18, 7-23.

Berlant, L. and Warner, M. (1998) Sex in public. Critical Inquiry, 24(2), 547-566.

Berry, K. and Clair, P. (2011). Reflecting on the call to ethnographic reflexivity: a collage of responses to questions of contestation. Cultural studies critical methodologies, 11 (2), 199-209.

Beyond The Kiki Panel. (Aug, 2019). Neverapart.com. Retrieved from https://www.neverapart.com/features/beyond-the-kiki-panel

Bragin, N. (2014). Techniques of Black male re/dress: Corporeal drag and kinesthetic politics in the rebirth of waacking/punkin. Women \& Performance - A Journal of Feminist Theory, 24(1), 61-78.

Braun, V. \& Clarke, V. (2006). Using thematic analysis in psychology. Qualitative Research in Psychology, 3, 77-101.

Bree, R. \& Gallagher, G. (2016). Using Microsoft Excel to code and thematically analyse qualitative data: a simple, cost-effective approach. All Ireland Journal of Teaching and Learning in Higher Education (AISHE-J), 8(2), 2811-28114.

Bridges, D. (2001). The ethics of outsider research. Journal of Philosophy of Education, 35(3), 371- 386. 
Brock, M. (2012). "House Mothers": Motherhood Redefined for LGBT Youth.

Ebony.com. Retrieved from https://www.ebony.com/news/house-mothersmotherhood-redefined-for-lgbt-youth/.

Brockenbrough, E. (2016). Becoming queerly responsive: Culturally responsive pedagogy for Black and Latino urban queer youth. Urban Education, 51(2), 170196.

Brown, M. (2014). Gender and sexuality II: There goes the gayborhood? Progress in Human Geography, 38(3), 457-465.

Browning, B. (1998). Infectious rhythm: metaphors of contagion and the spread of African culture. New York: Routledge.

Buckland, F. (2002). Impossible dance: Club culture and queer world-making. Middletown, CT: Wesleyan University Press.

Burgess, A. (2017). Steps to gentrification. In J. Lorinc, T. McCaskell, M. Fitzgerald, J. Farrow, and S. Chambers (Eds..), Any other way: How Toronto got queer. ON: Coach House Books.

Burton, J., Gossett, R., and Stanley, E. A. (2018). Editors' note, March 2017. Trap door: Trans cultural production and the politics of visibility (xxiv-xxv). Cambridge, MA: The MIT Press.

Butler, J. (1993). Bodies that matter: On the discursive limits of 'sex'. New York: Routledge

Butler, J. (2006). Precarious life: The power of mourning and violence. London: Verso. 
Canadian Human Rights Commission (2019, June 17). Banning religious symbols puts everyone's rights at risk. Retrieved from https://www.chrcccdp.gc.ca/eng/content/banning-religious-symbols-puts-everyones-rights-risk

Carland, T. R., \& Cvetkovich, A. (2013). Sharing an archive of feelings: A conversation. Art Journal, 72(2), 70-77.

Carrillo Rowe, A., \& Royster, F. T. (2017). Loving transgressions: Queer of color bodies, affective ties, transformative community. Journal of Lesbian Studies, 21(3), 243253.

Cascio, W. F., and Luthans, F. (2014). Reflections on the metamorphosis at Robben Island: The role of institutional work and positive psychological capital. Journal of Management Inquiry, 23(1), 51-67.

Charest, M. (2009). Mécontentement populaire et pratiques d'interpellations du SPVM depuis 2005: Doit-on garder le cap après la tempête? Montréal: SPVM.

Chatzipapatheodoridis, C. (2017). Strike a pose, forever: The legacy of vogue and its recontextualization in contemporary camp performances. European Journal of American Studies, 11(3), 25.

Chauncey, G. (1994). Gay New York: Gender, urban culture, and the makings of the gay male world, 1890-1940. New York: Basic Books.

Codagnone, C. and Martens, B. (2016). Scoping the sharing economy: Origins, definitions, impact and regulatory issues. Institute for prospective technological studies digital economy working paper 2016/01. Joint Research Centre of the European Commission. 
Cohen, C. J. (2004). Deviance as resistance: A new research agenda for the study of Black politics. Du Bois Review: Social Science Research on Race, 1(1), 27-45.

Collins, P. H. (1990). Black feminist thought: Knowledge, consciousness, and the politics of empowerment. New York: Routledge. . (1997). Comment on Hekman's “Truth and method: Feminist standpoint theory revisited:" Where's the power? Signs, 22(2), 375-81.

Collins Spanish-English Dictionary (n.d.) 'Puto'. Retrieved from https://www.collinsdictionary.com/dictionary/spanish-english/puto Combahee River Collective. (1986). The Combahee river collective statement: Black feminist organizing in the seventies and eighties (1st ed.). New York, NY: Kitchen Table, Women of Color Press.

Conquergood, D. (2002). Performance studies: Interventions and radical research. TDR: The Drama Review, 46(2), 145-53.

Crenshaw, K. W. (1991). Mapping the margins: Intersectionality, identity politics, and violence against women of color. Stanford Law Review, 43(61), 1241-99.

Currid, B. (1995). We are family: House music and queer performativity. In P. Brett, S. E. Case, and S. Foster (Eds.), Cruising the performative: Interventions into the representations of ethnicity, nationality, and sexuality (165-196). Bloomington: Indiana University Press.

Cvetkovich, A. (2012). Depression: A public feeling. Durham, NC: Duke University Press. 
DanceMogulMagazine [Username]. (2012, August 22). Viktor Manoel original punker punking - waacking pt.1 [Video file]. Retrieved from

https://www.youtube.com/watch?v=hdUJ1NoFhsk

Dickson-Gomez, J., Owczarzak, J., St.Lawrence, J., Sitzler, C., Quinn, K., Pearson, B., and Amirkhanian, Y. A. (2014). Beyond the ball: Implications for HIV risk and prevention among the constructed families of african american men who have sex with men. AIDS and Behavior, 18(11), 2156-2168.

Dillon, S. (2011). The only freedom I can see: Imprisoned queer writing and the politics of the unimaginable. In E. A. Stanley and N. Smith (Eds.), Captive genders: Trans embodiment and the prison industrial complex (169-184). Oakland, CA: AK Press.

Doane, W. (2003). "Rethinking whiteness studies," In A. W. Doane and E. Bonilla-Silva (Eds.), White out: The continuing significance of racism (3-18). New York: Taylor and Francis Books, Inc.

Douglass, F. (1995). The color line. Boulder, Colorado. Charlottesville, Va;: University of Virginia Library.

Dryden, O. H. (2010). Canadians denied: A queer diasporic analysis of the Canadian blood donor. Atlantis, 34(2), 77-84.

Dryden, O. H. (2015). A queer too far: Blackness, gay blood and transgressive possibilities. In O. H. Dryden and S. Lenon (Eds.), Disrupting queer inclusion: Canadian homonationalisms and the politics of belonging (116-132). Vancouver: UBC Press.

Du Bois, W. E. B. (2007). The souls of Black folk. Oxford: Oxford University Press. 
Duggan, L. (2003). The twilight of equality?: Neoliberalism, cultural politics, and the attack on democracy. Boston: Beacon Press.

Dwyer, S., Buckle, J. (2009). The space between: On being an insider-outsider in qualitative research. International Journal of Qualitative Methods, 8(1), 54-63.

Eff, B. (2017, March 12). The revival of ballroom cultural in Montréal. Vice Canada. Retrieved from https://www.vice.com/fr_ca/article/78qegb/la-renaissance-de-laculture-ballroom-a-Montréal

Eng, D. L. (2010). The feeling of kinship: Queer liberalism and the racialization of intimacy. Durham, NC: Duke University Press.

Eng, D. L. and Han, S. (2018). Racial melancholia, racial dissociation: On the social and psychic lives of Asian Americans. Durham, NC: Duke University Press.

Ferguson, R. A. (2003). Race-ing homonormativity: Citizen, sociology, and gay identity. In M. G. Henderson and E. P. Johnson (Eds.), Black queer studies: A critical anthology (52-67). Durham, NC: Duke University Press.

Fink, M. (2015). Don't be a stranger now: Queer exclusions, decarceration, and HIV/AIDS. In O. H. Dryden, S. Lenon, and J. Awwad (Eds.), Disrupting queer inclusion: Canadian homonationalisms and the politics of belonging (150-168). Vancouver, BC: UBC Press.

FitzGerald, M. and Rayter, S. (2012). Queerly Canadian: An introductory reader in sexuality studies. Toronto, ON: Canadian Scholars' Press.

Foster, R. (2016). Therapeutic culture, authenticity and neo-liberalism. History of the Human Sciences, 29(1), 99-116.

Freire, P. (1993). Pedagogy of the oppressed. New York, NY: Continuum. 
Frenken, K., T. Meelen, M. Arets, and P. van de Glind (2015). Smarter regulation for the sharing economy. The Guardian. Retrieved from https://www.theguardian.com/science/political-science/2015/may/ 20/smarterregulation-for-the-sharing-economy

Garcia-Rojas, C. (2017). (Un)disciplined futures: Women of color feminism as a disruptive to white affect studies. Journal of Lesbian Studies, 21(3), 254-271.

“Gasolina! An Urban Kiki Ball” (31 Aug 2019). Facebook event. Retrieved from https://www.facebook.com/events/527633317776391/

Ghaziani, A. (2014). There goes the gayborhood? Princeton, NJ: Princeton University Press.

Glesne, C. (1999). Being there: developing understanding through participant observation. In C. Glesne (Ed.), Becoming qualitative researchers: An Introduction (43-66). New York, NY: Longman.

Goldmark, M. (2015). National drag: The language of inclusion in "RuPaul's drag race.". GLQ: A Journal of Lesbian and Gay Studies, 21(4), 501-520.

Görög, G. (2018). The definitions of sharing economy: A systematic literature review. Management, 13(2), 175-189.

Greey, A. (2018). Queer inclusion precludes (Black) queer disruption: Media analysis of the Black Lives Matter Toronto sit-in during Toronto Pride 2016. Leisure Studies, $37(6), 662-676$.

Hahn, R. (2019, April 19). Inside Paris's burgeoning ball scene. Vogueworld. Retrieved from https://www.vogue.com/vogueworld/article/paris-ball-ballroom-sceneculture-kiddy-smile-cleopatra-ball-steffi-mizrahi-lasseindra-ninja-voguing 
Haider, A. (2018, August 20). How drag balls went mainstream. BBC Culture Online. Retrieved from http://www.bbc.com/culture/story/20180810-drag-balls-theglamorous-performances-that-mean-resistance

Halberstam, J. (2005). In a queer time and place: Transgender bodies, subcultural lives. New York University Press.

Hall-Araujo, L. (2016). Ambivalence and the 'American dream' on RuPaul's drag race. Film, Fashion \& Consumption, 5(2), 233-241.

Hancock, A. (2011). Solidarity politics for millennials. New York: Palgave MacMillan. Hardt, M. (1999). Affective labor. Boundary 2, 26(2), 89-100.

Haritaworn, J. (2008). Shifting positionalities: Empirical reflections on a queer/trans of colour methodology. Sociological Research Online, 13(1), 1-12.

Haritaworn, J. (2018). Queering urban justice: Queer of colour formations in Toronto. Toronto, ON: University of Toronto Press.

Harris, C. I. (1993). Whiteness as property. Harvard Law Review, 106(8), 1707-1791. Hart, B. (2015). Vogue is not for you: Deciding whom we give our art to. Radical Faggot. Retrieved from: https://radfag.com/2015/05/31/vogue-is-not-for-youdeciding-whom-we-give-our-art-to/

Hochschild, A. R. (1983). The managed heart: Commercialization of human feeling. Berkeley, CA: University of California Press.

Holmes, A. and McGuinty, L. (2015). Harnessing the power of the sharing economy: Next steps for Ontario. Toronto, ON: Ontario Chamber of Commerce. hooks, b. (1992). Black looks: Race and representation. Boston, MA: South End Press. 
Indongo, N. (2017, March 31). Espace Sans Luxe gives Montréal street dancers home of their own. CBC News. Retrieved from: https://www.cbc.ca/news/canada/Montréal /espace-sans-luxe-1.4050501

Internet Movie Database (IMDB) (n.d). Viktor Manoel biography. Retrieved from https://www.imdb.com/name/nm0543527/bio?ref_=nm_ov_bio_sm

Irving, D. (2015). Performance anxieties: Trans women's un(der)-employment experiences in post-Fordist society. Australian Feminist Studies, 30(83), 50-64.

Johnson, E. P. (2017). No Tea, No Shade: New Writings in Black Queer Studies. Durham: Duke UP, 2017. 422. . (2003). Appropriating Blackness: Performance and the politics of authenticity. Durham, NC: Duke University Press.

Johnston-Gerrerro, M. P. (2016). Embracing the messiness: Critical and diverse perspectives on racial and ethnic identity development. New Directions for Student Services, 154, 43-55.

Johnson, I. K. (2015). Hip-hop dance. In J. A. Williams (Ed.), The Cambridge Companion to Hip-Hop (22-31). Cambridge: Cambridge University Press.

Jones, T. J. and Ellis, J. (2017). It's a Kiki. In A. Abramovich and J. Shelton (Eds.), Where am I going to go: Intersectional approaches to ending LGBTQ2S youth homelessness in Canada and the US (41-48). Toronto, ON: Canadian Observatory on Homelessness Press.

Josephson, T. (2016). Trans citizenship: Marriage, immigration, and neoliberal recognition in the united states. Law, Culture and the Humanities, 12(3), 647-668.

Karenga, M. (1999). Odu IFA: The ethical teachings. The University of Sankore Press. 
Keo-Meier, C. and Hicks, L. (2014) Youth. In L. Erickson-Schroth (Ed.), Trans bodies, trans selves: A resource for the transgender community (446-475). Oxford University Press.

Khan, J. (2019). Retrieved from: https://janayakhan.com/Black-lives-matter/

Kiki the Movie. (n.d.) 'Kiki: About the film'. Retrieved from http://www.kikimovie.com/synopsis

Kinsman, G. (1996). The regulation of desire: Homo and hetero sexualities (second edition) Montréal: Black Rose Books.

Kinsman, G. W. and Gentile, P. (2010). The Canadian war on queers: National security as sexual regulation. Vancouver: UBC Press.

Kubicek, K., McNeeley, M., Holloway, I. W., Weiss, G. and Kipke, M. D. (2013). 'It's like our own little world": resilience as a factor in participating in the ballroom community subculture. AIDS and Behavior, 17(4), 1524-1539.

Kumari Suraj [Username] (2016, July 3). What is waacking? Queer history of punking, whacking, waacking 1970-2003 - PT 1 [Video file]. Retrieved from https://youtu.be/162XRkUym2Q.

La Fountain-Stokes, L. (2009). Queer ricans: Cultures and sexualities in the diaspora. Minneapolis: University of Minnesota Press.

Lamble, S. (2013). Queer necropolitics and the expanding carceral state: Interrogating sexual investments in punishment. Law and Critique, 24(3), 229-253.

Lewis, N. M. (2013). Ottawa's le/the village: Creating a gaybourhood amidst the 'death of the village. Geoforum, 49, 233-242. 
Lewis, M. A., Litvinoff, S. and Maxtone-Graham, J. (Producers) and Simon, F. (Director). (1968). The queen [Motion Picture].

Lockhart, P. R. (2018, August 1). Living while Black and the criminalization of blackness. Vox. Retrieved from https://www.vox.com/explainers/2018/8/1/17616528/racial-profiling-police-911living-while-black

Maguire, M., \& Delahunt, B. (2017). Doing a thematic analysis: A practical, step-by-step guide for learning and teaching scholars. AISHE-J: The All Ireland Journal of Teaching and Learning in Higher Education, 9(3).

Manalansan, M. F. (2003). Global divas: Filipino gay men in the diaspora. Durham: Duke University Press.

Manoel, V. and Burnet, A. (2019, March 16). Conférence sur le whacking [Facebook Event]. Montreal, QC: Asymmetry. Retrieved from https://www.facebook.com/events/248173612763819/.

Martin, C. J. (2016). The sharing economy: A pathway to sustainability or a nightmarish form of neoliberal capitalism? Ecological Economics, 121, 149-159.

Massumi, B. (2002). Parables for the virtual: Movement, affect, sensation. Durham, NC: Duke University Press.

Maynard, R. (2016). Fighting wrongs with wrongs? How Canadian anti-trafficking crusades have failed sex workers, migrants, and Indigenous communities. Atlantis: Critical Studies in Gender, Culture \& Social Justice, 37(2), 40-56. Maynard, R. (2017). Policing Black Lives: State violence in Canada from slavery to present. Halifax: Fernwood. 
Mbembe, A. (2003). Necropolitics. Public Culture, 15(1), 11-40.

McKittrick, K. (2006). Demonic grounds: Black women and the cartographies of struggle. Minneapolis, MN: University of Minnesota Press.

McManus, S. (2011). Hope, fear, and the politics of affective agency. Theory \& Event, 14(4).

Mfuko, A. [Username] (2011, March 9). Tyron proctor, master of waacking, and original soul train dancer, breaks it down. [video file]. Retrieved from https://youtu.be/Cb0zQNK-meo

Micallef, S. (2017). Town squares and spiritual hearts. In J. Lorinc, T. McCaskell, M. Fitzgerald, J. Farrow, and S. Chambers (Eds.), Any other way: How Toronto got queer. ON: Coach House Books.

Mohanram, R. (1999). Black body: Women, colonialism, and space. Minneapolis, MN: University of Minnesota Press.

Mohanty, C. (1988). Under western eyes: Feminist scholarship and colonial discourses. Feminist Review, 30, 61-88.

Mohanty, C. (2003). "Under western eyes" revisited: Feminist solidarity through anticapitalist struggles. Signs: Journal of Women in Culture and Society, 28(2), $499-535$.

Monforte, I. (2010). House and ball culture goes wide. The Gay \& Lesbian Review Worldwide, 17(5), 28.

Monzo, L. D. (2016). “They don’t know anything!” Latinx immigrant student appropriating the oppressor's voice. Anthropology \& Education Quarterly, 47(2), $148-166$. 
Moten, F. (2003). In the break: The aesthetics of the Black radical tradition.

Minneapolis: University of Minnesota Press.

Mullings, B. (1999). Insider or outsider, both or neither: some dilemmas of interviewing in a cross-cultural setting. Geoforum, 30(4), 337-350.

Munezero, A. (2018). Interruption des activites a l'espace sans luxe pour une periode indeterminee. 100lux.ca. Retrieved from http://www.100lux.ca/articles/2018/11/8/interruption-des-activits-lespace-sansluxe-pour-une-priode-indtermine.

Muñoz, E. J. (1999). Disidentifications: Queers of color and the performance of politics (volume 2). Minneapolis, MN: University of Minnesota Press.

Muñoz, E. J. (2006). Feeling brown, feeling down: Latina affect, the performativity of race, and the depressive position. Signs, 31(3), 675-688.

Murray, D. A. B. (2015). Real queer?: Sexual orientation and gender identity refugees in the Canadian refugee apparatus. London: Rowman \& Littlefield International.

Nakayama, T. K., and Krizek, R. L. (1995). Whiteness: A strategic rhetoric. Quarterly Journal of Speech, 81(3), 291-309.

Nathália Araújo, D. G. (2018). A detour in longing: Gender, sexuality and lesbian desire in Carla Trujillo's what night brings and Emma Pérez's gulf dreams. Estudos Feministas, 26(3), 1-9.

Nash, C. J. (2013). The age of the "post-mo"? Toronto's gay village and a new generation. Geoforum, 49, 243-252.

Nyong'o, T. (2015). After the ball. Bully Bloggers. Retrieved from https://bullybloggers.wordpress.com/2015/07/08/after-the-ball/ 
Obasogie, O. K. and Newman, Z. (2016). Black lives matter and respectability politics in local news accounts of officer-involved civilian deaths: An early empirical assessment. Wisconsin Law Review, 2016(3), 541-574.

Ophelian, A., Florez, S., Griffin-Gracy, M., and Floating Ophelia Productions (Directors). (2016). Major! [Documentary]. San Francisco: Floating Ophelia Productions, LLC.

“Outrageous Waack,” Ebony Magazine, (August 1978), 64-66.

Phelan, P. (1993). Unmarked: The politics of performance. London and New York: Routledge.

Pituca, P. (2019, May 11). A mother's kiki ball [Facebook Event]. Montreal, QC: Bar Le Ritz PBD. Retrieved from https://www.facebook.com/events/390017528499820/. Podmore, J. A. (2006). Gone 'underground'? lesbian visibility and the consolidation of queer space in Montréal. Social \& Cultural Geography, 7(4), 595-625.

Puar, J. (2007). Terrorist assemblages: Homonationalism in queer times. Durham, NC: Duke University Press.

Puar, J. K., \& Rai, A. S. (2002). Monster, terrorist, fag: The war on terrorism and the production of docile patriots. Social Text, 20(3). 117-148.

Raeanne, Q. (2011). Kiki ballroom: underground drag culture surfaces in Toronto. Daily Xtra. Retrieved from: https://www.dailyxtra.com/kiki-ballroom-5242

Ramirez, A. M. (2018). Speaking our truths, building our futures: Arts-based organizing in 2SQTBIPOC communities in Toronto. In S. M. Ware, J. Haritaworn and G. Moussa (Eds.), Marvellous grounds: Queer of colour histories of Toronto (71-82). Toronto: Between the Lines. 
Rayter, S. (2012). Introduction: Thinking queerly about Canada. In M. FitzGerald and S. Rayter (Eds.), Queerly Canadian: An introductory reader in sexuality studies (xvxxvii). Toronto, Ontario: Canadian Scholars' Press.

Razack, S. (2002). Race, space, and the law: Unmapping a white settler society. Toronto: Between the Lines.

Reddy, C. (1997). Home, houses, nonidentity: 'Paris is burning'. In R. M. George (Ed.), Burning down the house: Recycling domesticity (356-57). Boulder: Westview Press.

Richardson, J. (2013). The real sharing economy is boom-ing (and it's not the one venture capitalists are cashing in on). AlterNet. Retrieved from http://www.alternet.org/environment/real-sharing-economy-booming-and-its-notone-venture-capi-talists-are-cashing.

Riggs, M. T. (Director and Producer) (2014). Tongues untied [Motion Picture]. San Francisco, CA: Kanopy Streaming.

Riggs, M. T. (1996). Tongues re-tied. In M. Renov and E. Suderburg (Eds.), Resolutions: Contemporary video practices (185-88). Minneapolis, MN: University of Minnesota Press.

Robinson, C. J. (2000). Black marxism: The making of the black radical tradition. Chapel Hill, NC: University of North Carolina Press.

Roediger, D. R. (2007). The wages of whiteness: Race and the making of the American working class. London: New York; Verso.

Rogell, A. and Cheatle, L. (Producers) and Jordenö, S. (Director) (2016). Kiki [Documentary]. Sweden and USA: Story AB \& Hard Working Movies. 
Ross, B. L. and Hamilton, J. L. (2018). "Loss must be marked and it cannot be represented": Memorializing sex workers in Vancouver's west end. BC Studies: The British Columbian Quarterly, 197, 9-38.

Said, E. (2000). Invention, memory, and place. Critical Inquiry, 26(2), 175-192.

Sanchez, A. (2011, July 18). Punking+posing=whacking workshop with Ana Lollipop Sanchez. New York, NY: Peri-dance Studios.

Schor, J. (2014). Debating the sharing economy. Great Transition Initiative. Retrieved from http://greattransition.org/publication/debating-the-sharing-economy

Scully, A. (2012). Decolonization, reinhabitation and reconciliation: Aboriginal and place-based education. Canadian Journal of Environmental Education, 17, 148158.

Simon Rosser, B. R, West, W. and Weinmeyer, R. (2008). Are gay communities dying or just in transition?: Results from an international consultation examining possible structural change in gay communities. AIDS Care, 20(5), 588-595.

Simpson, L. B., Walcott, R., and Coulthard, G. (2018). Idle no more and Black lives matter: An exchange. Studies in Social Justice, 12(1), 75-89.

Smith, A. M. (1994). The imaginary inclusion of the assimilable "good homosexual": The British new right's representations of sexuality and race. Diacritics, 24(2-3), 5870.

Smith, M. C. (2018). A civil society?: Collective actors in Canadian political life (second edition). Toronto, ON: University of Toronto Press.

Sommer, S. R. (2001). C'mon to my house: Underground-house dancing. Dance Research Journal, 33(2), 72-86. 
Spade, D. (2011). Normal life: Administrative violence, critical trans politics and the limits of law. New York: South End Press.

Stryker, S. and Whittle, S. (2006). (De)subjugated knowledges: An introduction to transgender studies. In S. Stryker and S. Whittle (Eds.), The transgender studies reader (1-17). New York: Routledge.

Tanovich, D. M. (2006). The colour of justice: Policing race in Canada. Toronto: Irwin Law.

Tedesco, D. and Bagelman, J. (2017). The 'missing' politics of whiteness and rightful presence in the settler colonial city. Millennium - Journal of International Studies, 45(3), 380-402.

Threadcraft, S. (2017). North American necropolitics and gender: On \#BlackLivesMatter and Black femicide. South Atlantic Quarterly, 116(3), 553-579.

Timm Knudsen, B. and Stage, C. (2015). Affective methodologies: Developing cultural research strategies for the study of affect. New York, NY: Palgrave Macmillan.

Trevenen, K. and Degagne, A. (2015). Homonationalism at the border and in the streets. In S. Lenon, O.H. Dryden, and J. Awwad (Eds.), Disrupting queer inclusion: Canadian homonationalisms and the politics of belonging (100-115). Vancouver, BC: UBC Press.

Tuck, E. and Yang, W. (2012). Decolonization is not a metaphor. Decolonization: Indigeneity, Education \& Society, 1(1), 1-40.

Tuhiwai Smith, L. (1999). Decolonizing research methodologies: Research and Indigeneous peoples. New York: Zed Books. 
Twine, F. W. and Gallagher, C. (2008). The future of whiteness: A map of the 'third wave'. Ethnic and Racial Studies, 31(1), 4-24.

Upadhyay, N. (2019). 'Can you get more American than Native American?': Drag and settler colonialism in RuPaul's drag race. Cultural Studies, 33(3), 480-501.

Vogue Montréal and Ballroom [username]. (2019, April 13). Let's talk about sex! mini kiki ball: Grand prize as a house [Video File]. Retrieved from https://www.youtube.com/watch?v=Gs7LgDa5fjA

Walcott, R. (2003). Black like who?: Writing Black Canada. Toronto, ON: Insomniac Press.

Walcott, R. (2006). Black men in frocks: Sexing race in a gay ghetto (Toronto). In C. Teelucksingh (Ed.), Claiming space: Racialization in Canadian cities (121-134). Waterloo, ON: Wilfred Laurier University Press. . (2016). Still here: Gender, ballroom, and HIV/AIDS. TSQ: Transgender Studies Quarterly, 3(1-2), 321-325.

Walker, J. (2016). Has Toronto's ballroom scene gone mainstream? DailyExtra.com, arts and entertainment. Retrieved https://www.dailyxtra.com/has-torontos-ballroomscene-gone-mainstream-70045.

Ware, S. M. (2017). “All power to all people?: Black LGBTTI2QQ activism, remembrance, and archiving in Toronto." TSQ: Transgender Studies Quarterly, 4(2), 170-180.

. (2019). "The most unwelcoming 'outstanding welcome': Marginalized communities and museums and contemporary art spaces." Canadian Theatre Review, 177(1), pp.10-13. 
Ware, S. M., Haritaworn, J., and Moussa, G. (2018). Marvellous grounds: Queer of colour histories of Toronto. Toronto: Between the Lines.

Warner, M. (1999). The trouble with normal: Sex, politics and the ethics of queer life. New York: Free Press.

Warner, T. E. (2002). Never going back: A history of queer activism in Canada. Toronto, ON: University of Toronto Press.

Weston, K. (1991). Families we choose: Lesbians, Gays, Kinship. New York:Columbia University Press.

Wilson, J. (2010). Bulldaggers, pansies, and chocolate babies: Performance, race, and sexuality in the Harlem renaissance. Ann Arbor: University of Michigan Press.

Wright, M. M. (2014). Transnational Black feminisms, womanisms and queer of color critiques. In M. Evans, C. Hemmings, M. Henry, H. Johnstone, S. Madhok, A. Plomien, and S. Wearing (Eds.), The SAGE handbook of feminist theory. SAGE Publications, Inc.

Yates, K. (2016, September 10). Kiki: The wild dance movement formed out of radical resistance. Strike a pose.... Huckmag [online subcultural magazine]. Retrieved from: https://www.huckmag.com/art-and-culture/kiki-vogue-radical-identitysocial-change/ 


\section{Appendix A: Informed consent form}

\section{Consent Form}

Title: Serving each Other: Sharing economies and affective labour in Montreal's Kiki scene

\section{Carleton University Project Clearance}

CUREB clearance \#109065

Date of Clearance: $* * *$

Date of (original) ethics clearance: July $19^{\text {th }} 2018$

\section{Ethics Clearance for the Collection of Data Expires: $* * *$}

I, , choose to participate in a study entitled 'Serving each Other: Sharing economies and affective labour in Montreal's Kiki scene'. This study aims to understand what led me to practice, teach, and/or compete in kiki and/or vogue dance. Additionally, this project seeks to understand if my experience with vogue and/or kiki dance have impacted other areas of my life. The researcher for this study is Jess Lundy of Carleton University's Pauline Jewett Institute of Women's and Gender Studies. They are working under the supervision of Professor Dan Irving with the Institute of Interdisciplinary Studies of Carleton University.

Should you consent, this study involves an audio-recorded 30-60 minute interview to occur in a public place of your choice (like a coffee/tea shop or Ottawa public library). Once the recording has been transcribed, or written out in full, the recording will be destroyed within 3 months after your interview has taken place.

Participation is entirely voluntary, and you have the right to withdrawal from the study within 3 months after your interview. If you withdraw from the study by contacting the lead researcher, all of your information will be destroyed. You also have the right to decline answering questions you feel uncomfortable with. If you feel uncomfortable with any of your responses after the interview, you may ask that certain responses not be included in the project within 3 months after your interview has occurred.

In this consent form, you will be asked to voluntarily sign your name. In the demographic form used before your interview, you will be asked for your name, age category, race, ethnicity, and gender identity. After this, your data will be assigned a code name (or pseudonym) so that your identity will not be directly associated with the information you have provided. If you choose to voluntarily waive your anonymity, please pay special attention to the 'Risks' section below.

I will reimburse your costs of transportation (i.e. bus or fuel) for up to $\$ 5.00$ per way, for a total of $\$ 10.00$ maximum. Light refreshments will be provided during your interview. As a small token of appreciation, you will receive a $\$ 10.00$ gift card to a coffee shop of your choice. This is yours to keep, even if you withdraw from the study.

\section{Risks}

Please be aware that participating in this project could cause emotional stress brought on by talking about identity-related issues (like race or gender). In the unlikely event of an information breach (of your name, gender, race, etc.), if you are employed by or affiliated with a dance studio, community-based dance hall, and/or a kiki/vogue 'house' that you may be critical of during your interview, you may face negative social and/or economic consequences (job loss, for ex.) 
Should you require counseling or mental health services as a result of your participation in this study, please inform the lead researcher. They will provide you with detailed information on free or low-cost service options for you in or around your area.

\section{*DEPENDING ON WHERE THE PARTICIPANT LIVES, I WILL INSERT EITHER OF THE FOLLOWING:}

For support in Ottawa, I can assist you in calling the social services intake line with Centretown Community Health Centre at 613-233-4443 ext. 2109. If you are an Ontario resident, you may also access no appointment, no referral necessary, free, walk-in counseling at a clinic listed near you (under 'locations' in

http://walkincounselling.com/).

OR:

For support in Montreal, you may wish to contact Centre d'Intervention de Crise, located at 8710 Rue de Marseille, for 24/7 free telephone intervention, face-to-face meetings, and consultation and support (\#514-351-6661). Alternatively, I can assist you in contacting Info-Santé at 8-1-1 to access a directory for clinics and walk-in mental health resources around you. CONTINUE WITH: I can help you access these resources, although I have no budget for long-term counseling. That being said, should you require transportation to your initial counseling appointment, I will offer bus fare or fuel transportation costs for up to $\$ 5.00$ per way, for a maximum of $\$ 10.00$.

Should you choose to remain anonymous, the likelihood of these risks occurring are low because identifying information (your name) will not be published and the researcher will leave out specific details that may lead one to guess your identity. All research data will be encrypted and password-protected on a secure computer and any hard copies of data will be kept in a locked cabinet at Carleton University. Professor Dan Irving and myself will be the only people with keys to this cabinet.

Once the project is completed, all de-identified research data will be kept for 5 years and potentially used for other research projects on this topic. At the end of 5 years, all research data will be destroyed. If you would like a copy of the completed project, you will be provided a copy if you contact the researcher within 5 years after your initial interview.

The ethics protocol (\#109065) for this study has been reviewed and cleared by the Carleton University Research Ethics Board. If you have any ethical concerns with the study, please contact Dr. Bernadette Campbell, Chair, Carleton University Research Ethics Board-A (by phone at 613-520-2600 x 4080 or email at ethics@carleton.ca).

\section{Researcher contact information:}

Jess Lundy

The Pauline Jewett Institute of Women's and Gender studies, Carleton University

Tel: (613) 520-6645

Email: jess.lundy@carleton.ca

\section{Supervisor contact information:}

\author{
Dr. Dan Irving \\ Human Rights and Sexuality \\ Institute of Interdisciplinary studies \\ Carleton University \\ Tel: 613-520-2600 x. 1899 \\ Email: dan.irving@carleton.ca
}

Do you agree to participate in this study? ___ Yes __ No

Do you agree to be audio-recorded? __ Yes __ No 
Would you like to remain anonymous, or do you want to waive your right to anonymity and have your data made attributable to you? Check one below

I want to remain anonymous:

I want the researcher to use my name:

(IF you wish to use your name in the study, please type out the name you wish to use):

Signature of participant

Date

Signature of researcher

Date 


\section{Appendix B: Interview guide \& Demographic form}

\section{Carleton}

U N I VER SIT Y

Canada's Capital University

\section{Interview guide \& Demographic form}

After consenting to this study, please answer the questions you are comfortable answering. The following demographic information will be made confidential using pseudonyms (code names) and you may decline to answer questions by indicating 'no response'.

Participant:

1. Current city and province of residence? (ex. Ottawa, Ontario or Montreal, Quebec):

2. Which dance style(s) do you perform, teach, and/or compete in?

3. Are you a member of a 'house' or informal kinship structure related to your dance/performance style? If so, please list (you will be asked about this later on).

4. What is your age? Circle one
a) $18-24$ years old
d) 45-54 years old
b) 25-34 years old
e) 55-64 years old
c) $35-44$ years old
f) $65-80$ years old

5. Describe what gender(s) you most closely identify with in everyday life and in your performance form (ex: cis-gender woman, femme queen, gender non-binary, etc.)

6. Kindly tell me a bit about your race and ethnicity. How do you generally identify?

\section{During our interview I will ask you to discuss:}

- When did you enter into your dance/performance style and why?

- What inspired you to partake in this subcultural tradition at the time?

- Has your dance/performance style influenced or informed your emotional well-being? If so, describe.

- If you are associated or belong to a 'house' system, kindly elaborate on:

- what this familial structure means to you.

- your gendered roles, if any, within this community

- Is there anything else you'd like to share about your experiences with these dance/performance scenes? 


\title{
Appendix C: Recruitment Posters (original \& revised version)
}

\section{Original recruitment poster}

\section{Carleton}

UNIVERSITY

\author{
Recruitment Poster
}

\section{Let's have a *kiki!}

\section{Participate in a study on vogue and/or ballroom performance culture}

To participate in this study, you must be:

$\checkmark$ A 'voguer' or kiki dancer of any skill level

$\checkmark$ At least 18 years old

$\checkmark$ Comfortable reading and speaking English

*In this 30-60-minute, one-on-one interview, you will be asked about what motivates you to partake in kiki and/or vogue dance. Does this specific dance style impact other areas of your life? Your participation in this study will be anonymous.

Participants will be compensated with a $\$ 5$ gift card to either Tim Horton's or Walmart

The ethics protocol for this project has been reviewed and cleared by the Carleton University Research Ethics Board. If you have any ethical concerns with the study, please contact 4 University Research Ethics Board-A (by phone at 613-520-2600 ext. 2517 or via email at ethics@carleton.ca).

Please contact the researcher, Jess Lundy, for more details on this study at jess.Iundy@carleton.ca 
Appendix C: Recruitment Poster (revised)

Revised recruitment poster to include researcher phone number, participant compensation increase, and 'Kiki, ballroom, and/or Waacking/Punking' language.

\section{Why Carleton U N I VER S I TY \\ LET'S HAVE A KIKI! \\ Participate in a study on Kiki, BALLROOM, \&/or Waacking/Punking performance culture! \\ To participate in this study, you must: \\ $\checkmark$ Be at least 18 years old. $\checkmark$ Be involved in Kiki, Ball, House, and/or Waacking/Punking performance subculture. \\ In this 60-minute interview you will be asked what motivates you to partake in these unique performance styles. How do these specific dance/performance forms impact other areas of your life? All of the information you provide will be kept confidential. \\ Participants will be compensated with a $\mathbf{\$ 1 0}$ gift card to a coffee shop of their choice.}

The ethics protocol (\#109065) for this study has been reviewed and cleared by the Carleton University Research Ethics Board. If you have any ethical concerns with the study, please contact Dr. Chair, Carleton University Research Ethics Board-A (by phone at 6 0 or email at ethics@carleton.ca).

Please contact the researcher, Jess, to participate! jess.lundy@carleton.ca or (text or call)
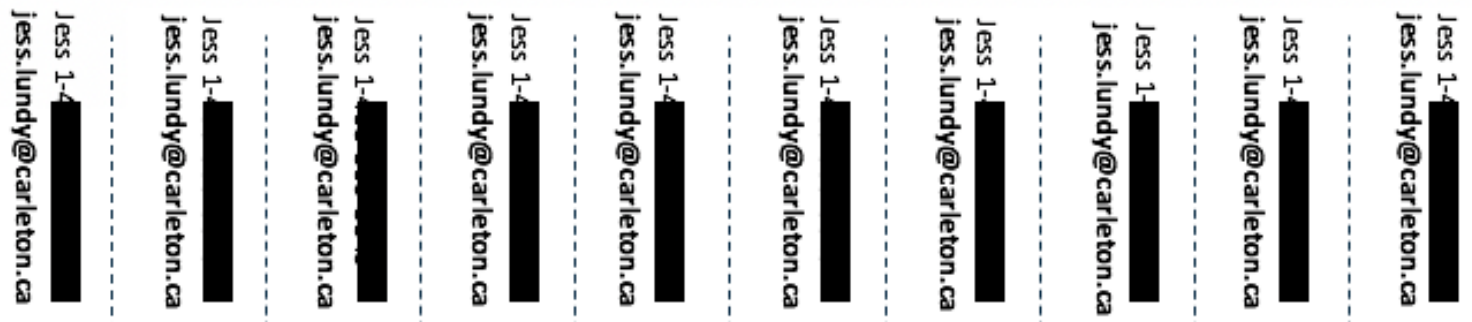